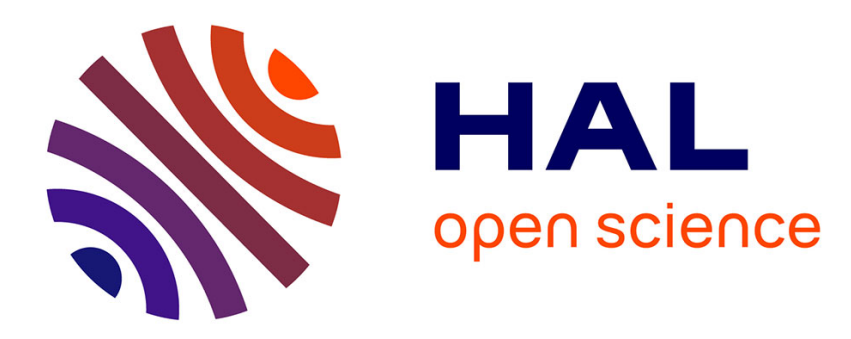

\title{
La Grotte de la Naissance. Recherches sur le bouddhisme khmer. II
}

François Bizot

\section{To cite this version:}

François Bizot. La Grotte de la Naissance. Recherches sur le bouddhisme khmer. II. Bulletin de l'Ecole française d'Extrême-Orient, 1980, 67 (1), pp.221-274. 10.3406/befeo.1980.3346 . hal-03585022

\section{HAL Id: hal-03585022 \\ https://hal.science/hal-03585022}

Submitted on 22 Feb 2022

HAL is a multi-disciplinary open access archive for the deposit and dissemination of scientific research documents, whether they are published or not. The documents may come from teaching and research institutions in France or abroad, or from public or private research centers.
L'archive ouverte pluridisciplinaire HAL, est destinée au dépôt et à la diffusion de documents scientifiques de niveau recherche, publiés ou non, émanant des établissements d'enseignement et de recherche français ou étrangers, des laboratoires publics ou privés. 
La Grotte de la Naissance. Recherches sur le bouddhisme khmer. II François Bizot

\section{Citer ce document / Cite this document :}

Bizot François. La Grotte de la Naissance. Recherches sur le bouddhisme khmer. II. In: Bulletin de l'Ecole française d'ExtrêmeOrient. Tome 67, 1980. pp. 221-274;

doi : https://doi.org/10.3406/befeo.1980.3346

https://www.persee.fr/doc/befeo_0336-1519_1980_num_67_1_3346

Fichier pdf généré le 08/02/2019 


\section{LA GROTTE DE LA NAISSANCE}

\section{RECHERGHES SUR LE BOUDDHISME KHMER, II.}

PAR

F. BIZOT

\section{TABLE DES MATIËRES}

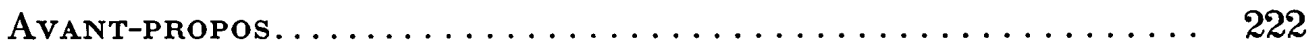

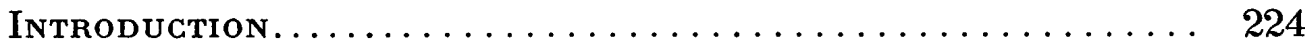

Ghapitre premier. — Les entrailles de l'auguste Mère . . . 230

1. Le mont de la Jonque. - Fondation de l'Ermitage. - Les derniers témoins.................... 230

2. Les apprêts du pèlerinage. - L'excursion annuelle sur les

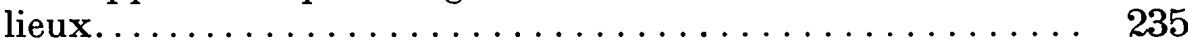

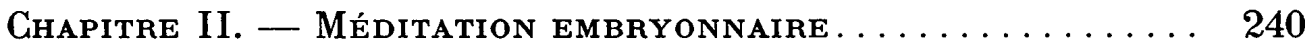

A. Traduction de TL133........................ 241

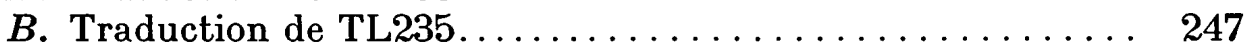

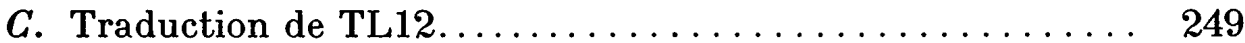

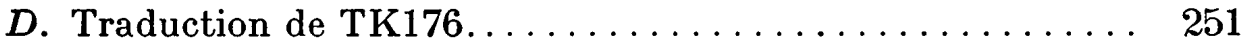

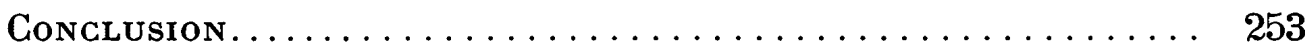

Postface.................................. 258

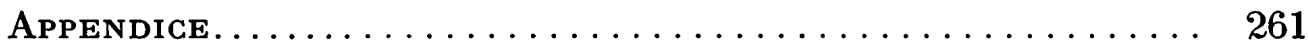

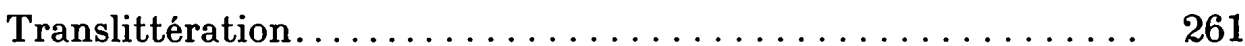

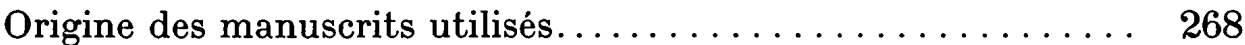

Index. . . . . . . . . . . . . . . . . . . . . . . . 270

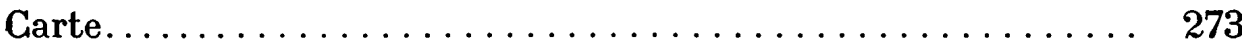

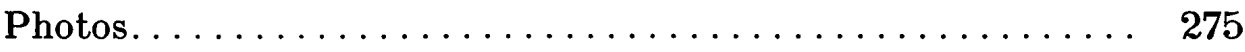




\section{AVANT-PROPOS}

L'étude des rapports de l'homme avec le sacré passe au Cambodge par une herméneutique dont le sens est mû en fonction d'une idée interne spécifique : l'épanouissement de l'être par une succession d'ontogenèses mystiques. La tradition enseigne un certain nombre de rites de passage qui poursuivent la modification du statut religieux de l'homme, de sa naissance jusqu'à sa mort. Ces épreuves impliquent toutes, de façon transparente, sinon une mort rituelle proprement dite, une régression utérine suivie d'une nouvelle naissance. L'intuition fondamentale de ce bouddhisme vécu est donc une initiation en palier conduisant à une renaissance ultime. Mais cette idée de renaissance n'est pas seulement vécue dans l'activité subconsciente et inconsciente du groupe. Elle est directement mise en œuvre dans les structures de la société même qui marque en autant d'étapes qu'il en faut le devenir social et spirituel de l'individu. Elle est donc la clé qui sous-tend, avec un aspect obsédant, l'analyse des comportements fondamentaux de cette école bouddhiste dont l'enseignement est essentiellement une embryogénie sacrée visant à fournir à l'adepte un modèle dans sa quête du Nibbāna qui passe par une régression utérine.

On voit que l'expression de ce sacré-vécu adhère aux structures directrices que les ethnologues et les sociologues ont déjà mises en évidence par des analyses conduites à divers niveaux au sein de différentes cultures. Un rapprochement avec ces archétypes d'une pensée religieuse universelle peut être un support d'investigation précieux, même à l'intérieur d'une approche volontairement restrictive, voulant par exemple traiter uniquement d'une herméneutique et d'un type donné d'expérience religieuse historiquement vécu. Le fait religieux doit être étudié comme un fait réel. Mais en appliquant des classifications et des thèmes solidaires de la pensée religieuse en général, par exemple, à l'épreuve vécue par le Yogãvacar lors de son regressus dans le ventre de l'auguste mère, on ne doit pas perdre de vue que cette façon de procéder est extérieure à l'expérience du candidat. Le danger des études comparatives est de fonder leurs interprétations sur des faits parallèles mais pas toujours assimilables lorsqu'on les observe à l'intérieur de leur tradition respective. Les rites ne portent pas en eux-mêmes leur signification mais revêtent un sens propre au niveau seulement du strict contexte de l'expérience dans laquelle ils entrent. D'autant plus que, dès que les études comparatives dépassent la simple typologie descriptive des faits, on remarque que c'est pour déboucher sur une recherche des structures fondamentales des systèmes religieux. L'expli- 
cation des relations entre l'homme et l'idée qu'il se fait du divin est une chose; celle des origines et de la fonction du phénomène religieux en est une autre. Attentives aux aspects de la description, les " Recherches sur le bouddhisme khmer " ambitionnent plus étroitement de porter un témoignage compréhensif des faits religieux vivants, vécus du dedans, placés dans un temps et une culture donnés. Le but poursuivi n'est donc pas d'insérer les modes de pensée du bouddhisme au Cambodge au sein d'un cadre universaliste qui marque le domaine de l'histoire des religions : il est d'étudier les valeurs particulières de cet univers total dans lequel l'homme vit sans rien y chercher d'autre. L'analyse de cette vision propre des choses s'attachera à porter, non seulement sur un ensemble de rites et d'enseignements oraux, mais également sur un grand nombre de textes dont le témoignage irrécusable fournit des éléments intérieurs de compréhension que la seule étude des faits n'aurait jamais donnés. 


\section{INTRODUGTION}

Il est un point précis que les rites d'initiation les plus variés font parfaitement ressortir et qui est passé inaperçu au Cambodge : l'importance du mythe, du commencement absolu où les choses se sont accomplies pour la première fois. Quelle est l'origine de la boule à cinq excroissances $^{1}$ actualisée par le néophyte à l'intérieur du ventre symbolique? G'est le caillot de sang en cinq parties qui produit, au début des temps, l'Être primordial, l'ancêtre mythique, c'est-à-dire le Dhamma personnifié ${ }^{2}$.

A. Leclère avait eu le souci d'étudier la conception des Khmers sur ce point et ce pionnier des études bouddhiques au Cambodge obtint d'importantes précisions auprès des représentants les plus élevés du clergé. A la suite de son enquête sur "l'origine première des choses", la copie d'un manuscrit lui est remise en 1897 : le «Kampî Préas Thomma chhéan $\|^{3}$. Il s'agit du Dhammajhān $n^{4}$ ou du Dhammavinsuñ ; les deux textes se ressemblent et sont souvent intitulés indifféremment. A. Leclère donne une traduction libre du passage relatif à la création, mais son travail sur cette question est tombé dans l'oubli. Ce texte aurait pourtant dû attirer l'attention des chercheurs, car il porte le trouble dans le tableau qu'on a brossé de l'histoire du bouddhisme au Cambodge où le Theravāda et les livres du canon pāli sont présentés comme l'unique source des croyances... Ce temps mythique est fondamental à l'expérience du Yogāvacar. Les étapes cosmogoniques qui lui sont révélées, de même que les forces mises en œuvre au cours de cette création primordiale, sont les agents véritables de son initiation. La création initiatique est la répétition de la création de l'Être surnaturel. Il n'est donc pas inutile de reprendre la traduction d'A. Leclère, d'ailleurs fautive par endroits, sur la base des documents originaux dont il se trouve encore de nombreuses copies :

\section{[1-A] Salutation à lui!}

Premièrement la goutte, Deuxièmement la hampe, Troisièmement la division,

(1) F. Bizot, Le flguier à cinq branches, "Recherches sur le bouddhisme khmer, I. , PEFEO, vol. GVII, Paris 1976, p. 74, etc. (cité : RBK. I).

(2) TL 14-II/47-A.

(3) Adhémard Leclère, Le Buddhisme au Cambodge, Paris 1899, p. 42.

(4) Pour la translittération des mots dans le texte, voir infra, p. 261. 
Quatrièmement la normalisation du corps,

Ginquièmement la tête.

L'ensemble des apparences,

L'ensemble des sensations,

L'ensemble des perceptions,

L'ensemble des constructions psychiques,

L'ensemble des pensées.

Les mérites, les démérites.

Frères, euy! Voilà la forme [virtuelle] des augustes qualités du Dhamma ${ }^{1}$ de l'auspicieuse période.

La terre, l'eau, le feu, le vent, l'éther, ne sont pas encore créés. Cette période est nommée "Chaos » [parce que], en ce temps-là, règne le néant absolu.

Alors Brah Kèv² aux divines oreilles, de sa connaissance, apparait dans la direction du levant pour créer la terre, l'eau, le feu, le vent et l'éther. Voilà pourquoi on nomme [cette direction] le levant ${ }^{3}$.

Frères, euy! Brah Kèv aux divines oreilles vient se placer au milieu de l'enceinte chaotique du pays des Jambosiers puis émet les "sixlumières ». Les 80.000 lumières ${ }^{4}$ se transforment en un trône de diamant haut de 700 lieues ${ }^{5}$. Il s'assoit sur le trône et s'abîme dans la concentration, l'auguste face tournée à l'est. [Alors il crée] ${ }^{6}$ le tronc du Dhamma, la tête du Dhamma, [1-B] les bras du Dhamma, les jambes du Dhamma, les oreilles du Dhamma, [soit] les 8 éléments du Dhamma au complet.

Au sud7, les 5 lettres NA MO BU DDHA YA de la tête du Dhamma. A l'ouest, les trois lettres MA A U des bras du Dhamma. Au nord8, les 7 lettres KU SA LA A KU SA LA $\bar{A}^{9}$ des jambes du Dhamma. Au nord-est, les 2 lettres A $\bar{A}$ de l'œil droit du Dhamma. Au sud-est, les 2 lettres $U \bar{U}$ de l'œil gauche du Dhamma. Au nord-ouest, les 2 lettres $\mathrm{E} O$ de l'oreille gauche du Dhamma. Au sud-ouest, les 2 lettres I I de l'oreille droite du Dhamma.

Ensuite, Brah Kèv réfléchit en lui-même :

"Qui peut créer la terre, l'eau, le feu, le vent et l'éther?».

De sa divine connaissance [il voit] celui que l'on nomme Buddhagun. Alors Buddhagun en personne se concentre sur les 5 augustes caractères de la tête du Dhamma et produit l'ignorance de 5 [sortes] ${ }^{10}$.

(1) A. Leclère (ibidem, p. 43 et suivantes) a lu " Préas Thorní * (dharañi), la terre.

(2) A. Leclère (ibidem, p. 42 et suivantes) a traduit par le dieu Soleil ? (?).

(3) koet, signifie proprement "créer ".

(4) Traduction fautive de chabvannarañsi ?

(5) yojana; 1 yojana $=400$ sin, soit : 1.600 mètres.

(6) TL $222 / \mathrm{ka}$-B.

(7) tpūn, le sud, signifie proprement la tête.

(8) joen, le nord, signifie proprement les jambes, les pieds.

(9) kusalā akusalā, les mérites et les démérites.

(10) Quelles sont les 5 ignorances? 
Puis il se concentre sur les 2 augustes caractères $\mathrm{NA}^{\mathrm{M}} \mathrm{MA}^{\mathbf{1}} \mathrm{du}$ Dhamma et produit la terre-initiale ${ }^{2}$ et l'eau-initiale. Alors l'ignorance assemble la terre-initiale et l'eau-initiale juste le temps d'un claquement d'ongle, ce qui les accroit de cent vertus, [2-A] de mille vertus, de dix mille vertus, de cent mille vertus, [etc.]. On ne peut les compter.

Puis Buddhagun se concentre sur les 3 augustes caractères BU DDHĀ YA du Dhamma et produit le feu-initial, le vent-initial, l'étherinitial. Il se concentre [encore] profondément sur les 10 caractères $^{3} \mathrm{du}$ Dhamma et crée de la crasse-humorale du Dhamma qui donne un homme ne sachant ni parler, ni voir, ni entendre, sans conscience, possédant seulement un corps.

Alors Buddhagun se concentre sur les yeux, les oreilles du Dhamma, soit sur les 8 éléments A $\bar{A}$ I I U $\bar{U}$ E O et transforme [cet être en] une personne éveillée ${ }^{4}$ ayant une conscience, des yeux sachant voir, des oreilles sachant entendre, des bras et des jambes sachant se mouvoir. Cette personne possède seulement une ombre, ce qui fait deux individualités. [Cette ombre n'est pas lucide] ${ }^{5}$. Lorsqu'elle devient capable de réaction ${ }^{6}$, elle ne sait pas encore parler. Quelque temps après, elle est en mesure d'absorber de l'air ${ }^{7}$ puis assiste les êtres ${ }^{8}$.

Ainsi, dès le commencement absolu, ce sont les caractères NA MO BU DDHĀ YA, MA A U, etc., qui président à la formation de l'Etre primordial, le Dhamma personnifié, les mêmes qui, dans le ventre maternel, et toujours avec l'intervention de Brạ Kèv (infra, p. 251), sont invoqués à l'origine du développement embryonnaire ${ }^{\theta}$. Reprenons point par point ce passage du Dhammavinsun, mais cette fois dans une perspective non plus cosmogonique mais ontogénique.

Le chaos primordial représente l'obscurité prénatale. Puis c'est l'apparition de l'existence (la création du Dhamma par Brah Kèv) qui a lieu au pays des Jambosiers, et l'on sait que cette contrée mythique symbolise le ventre maternel ${ }^{10}$. Ensuite, c'est la naissance du germe (l'intervention de Buddhaguṇ) qui se développe par la méditation embryonnaire en ses diverses parties constituantes. Dans ce premier

(1) Sans doute NA MO, mais toutes les versions donnent NA MA.

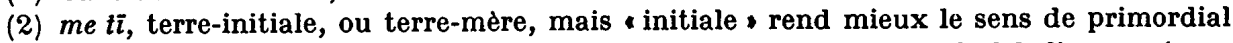
inclus dans me. A. Leclère (op. cit., p. 43) traduit par " chef de la terre ", "chef de l'eau ", etc.

(3) MA A U + KU SA LA A KU SA LA.

(4) ang samāpatti ; ou samāpeti, " complet "?

(5) TL 210/mo A et B : "e sramol noh bvam tin khluon loey ". l'acte].

(6) Je traduis ainsi l'expression soy phal dont le sens littéral est ici "jouir du fruit [de

(7) Je rends ainsi le sens de soy lambuni ākās.

(8) La lecture de ce paragraphe est diffcile et l'on hésite à identifler le concept qui est introduit ici par l'idée d'une ombre. Ce point sera repris dans la traduction complète du Dhammajhān, en préparation.

Le passage traduit est extrait de TL 443. Les versions suivantes ont également été consultées : TL 168, TL 210, TL 222, TL 90, TL 437 et TL 445. Voir la translittération de TL 443 en appendice.

(9) RBK. I, p. 124 et suivantes.

(10) RBK. I, p. 84, 121, 124. 
stade de formation, le fotus possède seulement un corps inanimé (ne sachant ni parler, ni voir...). Enfin, il est pourvu des cinq agrégats (la conscience, les yeux...) et c'est le passage de l'état fœtal à l'état achevé.

On a bien là la description des étapes de la formation embryonnaire et c'est cette ontogenèse que le Yogāvacar apprend à connaître au cours de son initiation. Mais cette initiation qui doit mener le candidat à parachever sa propre naissance mystique ne reproduit pas seulement le schème primordial de la création. On s'aperçoit qu'elle se fonde encore sur un autre scénario déjà connu, celui de l'Éveil du Bouddha : Brạ̣ Kèv a la face tournée à l'est, il est assis sur le trône de diamant, il émet les "six lumières " puis s'abime dans la concentration. L'Illumination est donc présentée comme une copie de l'actualisation des « augustes qualités du Dhamma " au début des temps.

Bien entendu, cette revalorisation du mythe de la création n'est pas vécue par le candidat comme un effort pour se rattacher à un temps primordial. Les faits religieux ne sont pas ressentis à l'état brut de structure. Ici, ce renvoi à la création de l'Etre surnaturel est une marque d'authentification, une justification a posteriori de l'Éveil, de celui du Bouddha comme de celui de l'Arahant, par rapport à l'ordre qui règle les croyances et qui seul régit l'efficacité du rite dans le monde clos et spécifique des initiations mahānikāy.

Ce retour au mythe révèle au candidat un autre point fondamental : il lui montre que l'homme accompli, l'initié, n'est pas le résultat d'un processus naturel. Les facteurs qui président à la réalisation du mode d'être supérieur auquel il aspire sont ceux d'un autre monde. Ce n'est qu'après avoir aboli son statut premier pour être recomposé selon les normes d'un canon exemplaire (les cheveux du Dhamma, les poils du Dhamma, etc.), qu'il aura pleinement assumé son initiation. On devinait déjà que la maturation physiologique de l'embryon n'est pas suffisante en soi puisque l'enfant doit être retouché après l'accouchement (la coupe des cheveux sauvages) puis être finalement parachevé par l'ācāry, après plusieurs années, au cours de la cérémonie de la tonte de la houpe. La régression à l'état embryonnaire du néophyte puis sa renaissance ne sont donc pas la répétition de la gestation biologique et de la naissance charnelle. L'utilisation de symboles obstétriques ne doit pas faire illusion. La démarche vise, en réalité, la naissance à un mode d'être supérieur. Il s'agit d'une régression provisoire au monde virtuel, d'un retour à une situation à la fois embryonnaire et primordiale, d'un retour à l'état de semence. Chez les Khmers, cet état spermatique est solidaire de la condition de l'esprit. Les rites d'initiation individuelle relèvent donc généralement d'un degré déjà élevé d'expérience religieuse. Les candidats possèdent nécessairement les connaissances justifiant leur aspiration, ont subi les épreuves de puberté (le noviciat), et connaissent par conséquent le mythe de Cittakumārā et Cittakumārīîn. Ils sont conscients de suivre leurs traces sur le même chemin et recouvrent naturellement la condition de l'esprit. Ce faisant, ils se mélangent aux

(1) RBK. I, p. 112. 
eaux paternelles et maternelles " heureux comme grenouilles et rainettes dans l'eau de pluie $"{ }^{\mathbf{1}}$.

Dès lors, l'épopée commence. Qu'on se souvienne de la fabuleuse aventure tentée hérö̈quement par Cittakumārā Cittakumārī, dans un temps mythique : pour obtenir l'éternité, ils doivent s'emparer du trésor (les globes de cristal) caché dans les fruits du figuier cosmique (le Dhamma) que gardent, au milieu de la terre des Jambosiers, les oiseaux Indriy; et cela afin de pénétrer dans la ville Nibbāna dont les sept enceintes précieuses ne comportent aucune ouverture ${ }^{2}$. L'exploit constitue une épreuve initiatique par excellence. Il est manifestement aussi difficile d'entrer dans le jardin des Hespérides ou de passer entre deux roches qui s'entrechoquent, que d'échapper au bec vorace des oiseaux Indriy ou de provoquer le transfert paradoxal qui permettra de s'introduire dans le Nibbāna. Celui qui sort victorieux d'une telle épreuve est qualifié pour partager la condition du héros, de l'immortel. M. Eliade a bien observé que, d'une manière générale, ces épreuves ne sont pas susceptibles d'être surmontées physiquement mais qu'elles doivent être résolues par un acte de l'esprit ${ }^{3}$. C'est la quête du Yogāvacar dont le mot même désigne ésotériquement l'«esprit 》 de l'initié.

En outre, en réactualisant le rite primordial institué au début des temps par l'Etre surnaturel, la nouvelle naissance devient œuvre divine. L'expérience religieuse déclenchée pendant l'initiation fait accéder le néophyte au sacré. Cette transmutation ontologique n'est pas une simple image : le candidat est transformé, non seulement par une substitution d'organes et de viscères qui sont ceux de l'Etre primordial ${ }^{4}$, mais à l'aide de qualités (gun) nouvelles, sacralisantes, qui lui font transcender la condition humaine et prendre conscience de son essence virtuellement parfaite. Nous verrons que l'appréhension de cette transcendance qui vise la transformation du corps mortel en corps immortel de l'initié, se fait à l'aide d'une série d'opérations et d'équations mystiques.

Divers procédés sont employés au Cambodge pour passer de l'existence mortelle à l'existence divine. L'objet du présent article est d'étudier le rituel de cette fabrication d'un corps nouveau, tel qu'il avait lieu dans la province de Battambang en particulier, à l'intérieur d'une caverne nommée la "grotte de la naissance" (raānn prasüt). Il est difficile de dire aujourd'hui si cette grotte, dont le symbolisme se fonde sur l'application des thèmes initiatiques que l'on vient de voir, représente le vestige d'un rite étendu jadis sur une vaste aire géographique qui pouvait fort bien dépasser les frontières du Cambodge, ou s'il s'agit plutôt d'un fait circonscrit régional. Son existence m'a été

(1) RBK. I, p. 86.

(2) RBK. I, p. 74.

(3) M. Eliade, Initiation, rites et socielés secrètes, Paris 1976, p. 143.

(4) RBK. I, p. 100. 
révélée fortuitement par une invitation à suivre le pèlerinage d'un groupe de médiums. Le périple visait principalement à honorer sur place la mémoire d'un personnage légendaire, "l'auguste demoiselle aux cheveux parfumés ", mais, conjointement, les pèlerins avaient l'habitude de profiter du déplacement pour pénétrer dans l'anfractuosité d'une crypte dissimulée, faisant ainsi revivre périodiquement l'un des rites les plus typiques de l'ancien Cambodge bouddhiste. Les cérémonies auxquelles j'ai pu assister n'avaient plus l'appareil fastueux d'antan; la valeur du rite s'est dégradée. Les entrailles de la terre sont devenues l'expression à la fois de superstitions confuses et de croyances mal définies. A travers les faits, une reconstitution approximative du cérémonial ancien est restée cependant possible.

Dans le premier chapitre, je situe, par rapport à sa légende, à son histoire et à ses habitants, le Phnom Sampau (bhnam sambau), c'est-àdire le "mont de la jonque "; je relate ensuite l'excursion sur les lieux telle que j'en ai été le témoin. Les éléments de l'enquête sont repris dans le second chapitre à l'aide de la documentation manuscrite. Enfin, l'expérience religieuse vécue par le postulant est étudiée dans la conclusion. 


\section{Chapitre PREmier}

\section{LES ENTRAILLES DE L'AUGUSTE MÈRE}

\section{Le Mont de la Jonque. - Fondation de l'ermitage. - Les derniers témoins}

Le Phnom Sampau fait partie d'un ensemble montagneux situé au sud de Battambang. Des collines calcaires aux flancs raides sortent brusquement des rizières et prennent un relief saisissant. Rongées par les dissolutions karstiques depuis des millions d'années, ces buttes témoins sont fouillées de failles énormes. La pénétration des eaux y a provoqué l'enfouissement d'un réseau souterrain et le creusement de cavernes impressionnantes. La plupart de ces curiosités pittoresques recèlent des ermitages saisonniers, individuels ou collectifs. Le Phnom Sampau, dont l'abrupt de 150 mètres marque le $\mathrm{km} 13$ sur la route de Païlin, est l'un de ces vestiges et le plus important de la région.

La toponymie de cet ensemble calcaire se réfère à une légende locale. Un jour, la belle Sovann Mecha, qui possédait un crocodile apprivoisé, était évincée dans le cœur du roi, son amant, par une princesse appelée nā̃n Sok Koop, la demoiselle aux cheveux parfumés. Cette princesse avait le pouvoir de transformer l'eau en terre ferme par un simple geste de la main passée dans ses cheveux. Lorsque le roi fit armer une jonque chargée de présents pour se rendre auprès de sa nouvelle fiancée, nā̃n Sovann Meccha, jalouse, envoya son crocodile faire sombrer l'embarcation. L'équipage, affolé à la vue du monstre, jeta par-dessus bord des cages pleines de poules et de canards, dans l'espoir de détourner son attention. Avertie du danger, la demoiselle aux cheveux parfumés passa la main dans son chignon, métamorphosant le crocodile en une montagne connue aujourd'hui sous le nom de Phnom Krapeu, le Mont du Crocodile. La jonque devint le Phom Sampau, le Mont de la Jonque, et la voile, violemment arrachée, devint le Phnom Kdong, le Mont de la Voile. Les cages jetées du navire formèrent les Phnom Trong Moan et Trong Tie, les Monts de la Cage à poules et de la Cage à canards. Sovann Meccha fut suppliciée et ses membres dispersés en plusieurs endroits donnèrent un nom aux autres collines de la région ${ }^{1}$.

(1) Cf. Prajum roèn prèn khmèr, V, Phnom Penh 1969, p. 137; cr. également René Laporte, La légende du Phnom Sampeou, "Réalités Cambodgiennes *, no 771 du 19 novembre 1971 ; et E. Porée-Maspéro, Étude sur les rites agraires des Cambodgiens, Paris 1962, p. 97. 
$\mathrm{Au}$ début du $\mathrm{xx}^{\mathrm{e}}$ siècle, alors que le protectorat français s'efforce d'opérer un remembrement des terres pour regrouper les paysans, le Vénérable Kev Ghuon vient s'installer sur le Phnom Sampau. Dans un premier temps, il habite une construction rustique sur le flanc est de la montagne dont le relief accidenté offre un emplacement d'une exceptionnelle beauté pour ses exercices de méditation. Bénéficiant de l'appui de l'administration provinciale qui compte l'utiliser pour introduire dans cette zone les réformes religieuses nouvellement décidées par le gouvernement ${ }^{1}$, il acquiert rapidement une grande influence. Nommé Mékon, il est chargé de distribuer des terres aux paysans et les différentes formes de son action jouent un rôle de premier plan dans l'expansion régionale. Sur son initiative, la roche calcaire du Mont est mise en exploitation et la Compagnie Française de Phosphate emploie sur place une centaine de travailleurs. Cinq fours à chaux sont construits. Un circuit régulier relie la carrière avec le chef-lieu de province, faisant parallèlement prendre à la récolte artisanale de guano de chauve-souris une importance considérable. Les fonds pour construire un monastère sont rapidement collectés et le Vat Savann Kiri Phetra, aujourd'hui connu sous le nom de Vat Phnom Sampau, est édifié au pied de la colline. Ce nouveau sanctuaire attire des pèlerins qui vont pratiquer la méditation dans les cavernes du Phnom. Bref, en peu de temps, la notoriété du Mont de la Jonque dépasse les frontières provinciales.

Le Vénérable Kev Chuon se retire fréquemment sur la montagne, dans l'aven dit du Grand Trou (raān dham), mais sa vraie résidence est le monastère qu'il a fait construire en bas. Le premier bonze à s'être installé de façon permanente sur le Phnom est le $t \bar{a}$ Dor Ghen. Né en 1896 dans la rizière du piémont, ordonné en 1920 par le Vénérable Chuon lui-même, il demeure vingt-huit ans sur place. Il se crée une légende autour de ce moine rude et pittoresque, respecté de tous, qui fait bon ménage avec les militaires français, trinque volontiers et ne se déplace jamais sans armes. Mais à la mort du vieux Kev Chuon en 1947, Phnom Penh reprend en main le fief intouchable et le $t \bar{a}$ Chen est déplacé au Vat Unalom de la capitale.

Jusqu'à cette date, et pour des raisons devenues incompréhensibles aujourd'hui où l'on n'imagine pas un ermite attentif à l'environnement, le cadre rupestre et la végétation dense du Phnom Sampau sont restés intacts. Mais avec l'avènement du Vénérable Duong Set, le nouveau Supérieur du Vat Phnom, on va procéder à certains aménagements. Pour faciliter le séjour des bonzes qui résident sur le Mont pendant la période du vassā et celui des laïques qui s'y rendent le reste de l'année, $s \bar{a} l \bar{a}$, cabanes et citernes sont mises en place. Ces travaux dans un site encore vierge deviennent fatalement le prétexte des premiers déboisements. La même année, le Vénérable Chao, un orphelin vietnamien qui avait suivi le Vénérable Ghuon depuis le Sud-Vietnam et était devenu son disciple, demande à s'installer en haut du Phnom pour engager des travaux d'embellissement en mémoire de l'auguste défunt. Un autre

(1) RBK. I, p. 8 et suivantes. 
bonze également, métis chinois cette fois - il est baptisé $t \bar{a}$ Chen (cen, chinois) et il jouera tacitement de cette homonymie pour bénéficier de la notoriété de son prédécesseur - s'établit sur le Mont et entreprend la construction d'escaliers en béton accrochés au flanc est. En 1960 enfin, le Vénérable Yeak quitte Battambang et met en chantier sur le sommet de la colline l'édification d'un petit sanctuaire. Un comité du Phnom Sampau est créé. Les associations cultuelles sont contactées pour collecter des fonds. La ville de Battambang appuie le projet d'aménagement du Phnom et la Province, active et ouverte au tourisme, favorise les initiatives. Ces transformations coûteuses, approuvées sans réserve au même titre qu'une offrande, sont fatales pour le site. Aujourd'hui, les stalagmites et les curiosités millénaires, dont la majesté et le mystère ont séduit les premiers anachorètes, sont irrémédiablement noyées dans la maçonnerie et la peinture cellulosique.

Alors que jusque-là n'avait pas existé de communauté régulière sur le Phnom, un véritable centre de méditation est créé à la suite des travaux, consacrant le Haut Lieu comme tel et brisant sa dépendance d'avec le monastère du bas. Cette séparation est également provoquée par les fidèles qui viennent directement mettre en pratique l'enseignement qu'ils ont acquis auprès de divers professeurs, sans plus passer par l'autorité du Supérieur local, à l'image du sangha thaï réformé qui a fondé de nouveaux centres de méditation pour coiffer les anciens ermitages. A grands frais mais en peu de temps, les chemins sont empierrés et les cavernes nombreuses dispersées sur la montagne sont dégagées, aménagées et signalées par des pancartes aux visiteurs.

Or, en dépit de l'ardeur dans les initiatives concernant l'agencement et la distribution des lieux, on ne trouve aucune indication touchant l'endroit le plus frappant du Mont : la Grotte de la Naissance. Le Vénérable Yeak me fait cependant remarquer que l'édifice de couleurs vives qu'il a fait construire et qui couronne désormais la colline est exactement situé dans l'axe de la crypte mystérieuse (voir le plan) pour en marquer à la ronde l'emplacement. Mais il ajoute que le trajet menant à celle-ci a été laissé en friche et se perd dans la rocaille, parce que le lieu possède virtuellement une puissance redoutable qui fait qu'aucun retraitant ne doit s'y introduire pour simplement trouver la solitude favorable à la méditation. L'endroit doit être aussi protégé des touristes maintenant nombreux qui tentent les jours fériés de s'y introduire avec des lampes-torches et gravent les parois de leurs initiales.

Installé sur ses parterres de maçonneries qu'envahit une végétation en pots et en ciment, le Vénérable Chao admet à peine, quant à lui, l'existence du souterrain. Lorsqu'on avance des précisions indiscutables sur le lieu, il explique alors brièvement, le regard de côté, que l'antre servait autrefois à un culte qui avait encore cours chez les paysans de la région lorsqu'il arriva sur place en 1947, mais qu'il n'a jamais voulu y pénétrer et que l'ermitage a définitivement mis fin à ces sottises de "matrice et de mère ". Puis il détourne la conversation, visiblement mal à l'aise, craignant de se voir soupçonné de sympathie pour ce qui est à ses yeux des croyances rétrogrades.

Le Vénérable Dor Chen qui a passé sa jeunesse à courir dans la brousse 
des environs du Mont et se trouve maintenant, comme on l'a vu, au Vat Unalum de Phnom Penh, dans un réduit sombre au fond d'une impasse, se souvient en effet, avec émotion, des fêtes que les habitants de la région célébraient sur la montagne. Les villageois de Kok Ponley, Ta Kriem, Ba Non, etc., de même que les paysans dispersés dans les paillotes isolées des rizières, comme ses propres parents, venaient y fêter la nouvelle année par des jeux et des danses traditionnels. Il explique qu'une partie des festivités se déroulait sur l'esplanade de la grotte Prasūt. Un certain nombre de villageois pénétrait ensuite dans la cavité symbolique. L'introduction des postulants dans un orifice aussi étroit se faisait après une préparation collective sous la direction d'un $\bar{a} c \bar{a} r y$. Ceux qui encouraient l'épreuve déclaraient qu'ils "allaient mourir " (dau rok nääb'). Le fait de réapparaitre ensuite était considéré comme une résurrection, comme une nouvelle naissance. Certains apportaient avec eux une gourde afin de puiser de l'eau dans un bassin souterrain du lieu. La clarté du liquide indiquait les mérites de chacun. D'autre part, ceux qui avaient été pris de malaise pendant ce voyage dans l'obscurité, se voyaient ainsi signifier la nécessité pour eux d'accomplir davantage d'actions méritoires. L'accès aux entrailles chtoniennes permettait en outre de formuler des vœux de santé et de bonheur pour la nouvelle année.

Les cultes primitifs du monde entier se servent de thèmes initiatiques ordonnés et construits autour d'une nouvelle naissance. Ces épreuves qui impliquent une régression utérine peuvent d'une part régénérer l'initié moyennant sa gestation et son enfantement par la Grande Mère, d'autre part, et c'est précisément le but des rites du Nouvel An, provoquer par la réitération périodique d'une mort puis d'une renaissance initiatiques, le renouvellement des énergies comisques, de même que la régénération collective de la société, pour un nouveau cycle annuel. On sait que l'idée s'exprime généralement par une mise en scène simulant la pénétration des postulants, soit dans une hutte initiatique, soit dans une crevasse assimilée à l'utérus de la terre ou au ventre d'un monstre marin ${ }^{1}$.

Notons que cette dernière image devient saisissante lorsqu'on fait les trois kilomètres qui séparent à l'est le Phnom du Mont du Grocodile. De cette colline allongée, pointant son nez vers la jonque, le souvenir populaire a conservé le nom de l'aven qui s'ouvre sur l'échine du monstre. C'est la "gorge du crocodile " (kaka krapoe) qui mène aux entrailles de l'engloutisseur. L'entrée ouest de ce gigantesque souterrain s'ouvre sous une voûte profonde pourvue en son milieu d'un appendice calcaire qui figure la luette d'un gosier béant. Bien d'autres grottes servaient encore de cadre aux épreuves de Nouvel An. H. Mouhot relate des pèlerinages dans les grottes impressionnantes de $\mathrm{Ba} \mathrm{Non}^{2}$. Des fêtes similaires avaient périodiquement lieu à l'intérieur de sites semblables, et cela

(1) Voir notamment M. Eliade, Naissances mystiques, Paris 1959, p. 110.

(2) Henri Mouhot, Voyage dans le Royaume de Siam, de Cambodge et de Laos, Paris 1868, p. 185. 
non seulement au Cambodge mais dans toute l'Indochine. Par exemple, au début de la nouvelle année, la réunion générale d'une tribu de Tai blancs de la région de Quynh-Nhai (Tonkin) se faisait à l'intérieur de l'excavation d'un rocher isolé. Le seul accès permettant de s'introduire dans la grotte était une fente très étroite. Dans l'obscurité totale, les hommes et les femmes procédaient alors à une union sexuelle collective qui servait à des fins divinatoires pour la nouvelle année et provoquait une régénération individuelle ${ }^{\mathbf{1}}$.

En dehors de ces rites annuels, un autre type de célébration semble avoir frappé particulièrement l'imagination du vénérable Dor Chen lorsqu'il était enfant. Il rapporte qu'on amenait le candidat en grande pompe sur le Phnom. Une partie des rites pouvait se dérouler dans la grotte au vent (rāàn khyal) à l'intérieur de laquelle circule un courant d'air permanent comparé au vent kammajavät ${ }^{2}$ ou au vent de l'auguste Sūtr ${ }^{3}$. On faisait ensuite pénétrer le postulant dans la grotte Prasūt. Il devait accomplir seul le parcours obscur sur la base des directives que lui avait au préalable communiquées l'äcäry. Il était admis que cette pénétration terrifiante le faisait accéder aux sphères utérines. Un Grū l'attendait à l'intérieur qui l'initiait aux principes de la respiration embryonnaire et lui livrait les formules rituelles d'initiation. Ce Grū avait pour nom Mahā Pațthhă $\bar{a}^{4}$ A l'époque où ces rites se faisaient encore, le vieux Chen n'avait pas l'âge d'y prendre part, et par la suite ils ne furent plus célébrés. Le recoupement avec les données exposées dans les textes montrera (infra, p. 247 sq.) que les détails qu'il fournit ne sont pas inventés.

Le vieux laïque Pec Gniou, âgé de soixante-dix ans, qui hante le Phnom depuis plus de vingt ans et occupe aujourd'hui avec son frère âné une coquette maison enfouie dans les fourrés du flanc occidental face à une gigantesque gerbe de bougainvillées rouges, fait remarquer que le symbolisme des initiations qui se déroulaient dans la grotte Prasūt est en rapport avec le processus de gestation du fœtus auquel le mūl kammatțhān se réfère ${ }^{5}$. Il explique que parallèlement au rite consistant à fabriquer un nouveau corps par un retour dans la matrice, le souterrain servait d'autel aux adeptes du "chemin de gauche " (phlüv chveñ). Contrairement au "chemin de droite " (phlūv stām), le chemin de gauche est l'itinéraire mystique suivi par l'esprit du méditant et dont le parcours n'est pas directement marqué par des événements en relation avec le Bouddha mais avec un Grū ou d'autres divinités. Il se souvient que des manuscrits sur dépliant (kräṃn்) et sur feuillets de latanier

(1) Colonel Henri Roux, Quelques minorités ethniques du Nord-Indochinois, France-Asie, Numéro spécial, 1954, p. 110. Cf. également la Brahmayoni mentionnée en Inde par Claude Jacques (Gayä Mähätmya, Publication de l'Institut français d'Indologie $\mathrm{n}^{\circ} 20$, Pondichéry 1962, p. XIX, XXI, XXIII, etc.); ce passage dans un rocher au sommet d'une colline située au sud-ouest de la ville de Gayā, libère celui qui le traverse de toute autre renaissance.

(2) RBK, I, p. 122 et 124.

(3) Infra, p. 254.

(4) RBK. I, p. 88 ; également infra, p. 247 (B 2-3).

(5) RBK. I, p. 115. 
étaient entreposés dans ce lieu obscur, près du "cordon placentaire " (infra, p. 238). L'incubation tellurique donnait une grande puissance à ces traités que des Grū venaient consulter sur place pour exécuter des yantra ${ }^{1}$. Ils introduisaient avec eux le matériel nécessaire et recopiaient formules et diagrammes sur du tissu ou des lames d'or ou de plomb. Le support était ensuite sacralisé (prasiddhī) en y insufflant (phlum) des mantra, en le frictionnant ( $\tilde{n} \bar{l})$, en l'aspergeant (proḥ) d'eau - de celle du bassin souterrain - et même parfois en sanctionnant la cérémonie par une transe. En effet, les Grū sont souvent possédés par le maitre de leur lignée initiatique et peuvent l'être aussi par une divinité, comme un Bouddha historique ou un dieu du panthéon brahmanique.

\section{Les apprêts du pèlerinage.}

\section{- L'excursion annuelle sur les lieux}

C'est par le biais d'un pèlerinage au départ étranger aux rites de renaissance que j'ai été amené à connaitre l'existence de ce souterrain symbolique et à entreprendre une enquête sur le sujet. Je fais donc commencer le récit des événements par la fête d'hommage annuel au génie tutélaire du Phnom Sampau, à la suite de laquelle les médiums allaient me conduire le lendemain dans la Grotte de la Naissance. Cette fête, qui est en même temps une séance de transe collective et une cérémonie bouddhique prenant place au début de la retraite de saison des pluies, fait sortir du sujet. Elle témoigne cependant de la diversité des faits religieux vécus et de leur imbrication, et permet, en outre, d'apprécier la valeur du regressus opéré par ces médiums. Celui-ci n'est pas pour eux l'objectif premier du pèlerinage. Ils n'y sont pas préparés. L'ācāry qui les conduit non plus. Leur comportement dans ce lieu est empreint de respect et de crainte mais il n'est pas dicté, on le sent, par les règles précises des rites de régression qui mènent à la renaissance $d u$ candidat. De cette façon, en relatant le pèlerinage depuis son commencement, je crois qu'on prend mieux conscience que le passage opéré par les médiums dans les entrailles de l'auguste mère n'est qu'un simulacre des rites anciens, qu'il ne peut servir de modèle mais devra être réinterprété sur la base des valeurs de ces rites anciens que l'on tentera de mettre au jour dans le chapitre suivant.

Phnom Penh, le 29 juin 1971.

Dans l'atmosphère enfumée du boulevard Monivong, des passants stationnent devant une bâche tendue sur des tréteaux et décorée de guirlandes multicolores. Dressé périodiquement au moment des fêtes pour abriter les tables garnies d'offrandes et de mets rituels, le pavillon forme appentis et sert de hall d'apparat. Il est tapissé intérieurement de

(1) Voir F. Bizot, "Notes sur les yantra bouddhiques d'Indochine ", in : Mélanges R. A. Stein, "Tantric and Taoist Studies ", Melanges chinois et bouddhiques, Louvain 1981 (sous presse). 
chromos représentant des scènes bouddhiques dans le goût indien, et conduit à l'étage d'une maison d'où s'échappe le tintement joyeux d'un orchestre. Sur le palier de la maison jonché des sandales des invités, on a disposé les présents destinés à la retraite de saison des pluies pour la petite communauté religieuse de l'ermitage du Mont de la Jonque : des pochettes de papier cellophane contenant des cigarettes, un crayon, un cahier et un coupon de tissu safran; un bidon de vingt litres de pétrole, deux énormes cierges (dien vassā), une sébile pleine de billets de banque (vingt mille riels environ) et les sept pièces d'un habit monastique. Le tout est présenté sur un bat-flanc avec des fleurs, des gerbes, des lotus, des soucoupes et un oreiller couvert d'une taie précieuse pour recevoir les devata. Arrivés depuis plusieurs jours pour préparer leur déplacement, les pèlerins retrouvent comme tous les ans les fidèles du quartier qui participent au voyage par des dons, et l'on s'interpelle dans une ambiance chaleureuse où se mêlent le tintouin du boulevard et les cris des marmots. Or ils ne sont pas ordinaires ces gens qui se pressent dans l'étroit domicile! Tous sont des rūp, des médiums, unis selon les liens inspirés d'une famille mythique dont le patriarche est le maitre de maison.

Chacun s'active. Brocarts chamarrés, chemisiers de soie et gilets brodés sont orgueilleusement dépliés et l'on apprête les plus belles parures. Brusquement, un rūp tombe en transe. L'orchestre attaque aussitôt et l'on s'affaire autour de l'incarnation tremblante pour la vêtir des atours appropriés. Puis, par attouchement ou interpellation, les uns et les autres sont saisis à leur tour dans un chahut général. Le maître de maison trône sur un divan, la figure crispée, le corps animé de tremblements convulsifs. Autour de lui, des groupes se forment. On mime des scènes imaginaires, on échange avec emphase des propos inintelligibles. La transe est collective.

La nuit venue, un tapis est déroulé jusqu'au bat-flanc où sont exposés les présents. La maîtresse de maison, vêtue d'un magnifique sampot blanc brodé de fils d'argent, s'agenouille devant l'autel pour recevoir l'esprit tutélaire du Phnom Sampau, la demoiselle aux cheveux parfumés ${ }^{1}$. Le calme se fait. Soudainement le corps du rūp s'affaisse et tombe inanimé à la renverse. Après quelques minutes, c'est l'auguste demoiselle aux cheveux parfumés qui se dresse, souveraine, presque hautaine, mais visiblement émue de retrouver ses fidèles. Elle observe les lieux avec attention, se dirige vers le palier pour prendre connaissance des dons destinés à l'ermitage et donne des indications concernant certains détails à modifier dans la préparation des offrandes. Elle revient ensuite sur ses pas, entourée des autres génies qui s'empressent à ses côtés, et, se tournant vers l'assistance, elle formule des vœux de bonheur. Elle bénit les deux chauffeurs de taxi qui conduiront demain la troupe au Phnom Sampau et assure que le voyage se passera bien sans qu'il soit nécessaire de suivre le convoi ${ }^{2}$. A la suite

(1) Voir supra, p. 230.

(2) La route menant à Battambang est fréquemment coupée par des opérations militaires et le risque couru montre l'importance attachée au pèlerinage. 
de cela, elle s'évanouit et tombe à la renverse dans les bras de deux personnes placées derrière elle pour la recueillir.

Le soleil du matin porte sa lumière encore frisante sur le bocage des rizières, et l'effet est magnifique vu du Phnom, quand les pèlerins de Phnom Penh, parvenus la veille au monastère du pièmont (Photo 1), arrivent à la porte de l'ermitage. La mousse fraîche des premières pluies couvre les marches de béton d'un tapis glissant gonflé de rosée.

Le Vénérable Yeak accueille la troupe avec chaleur. Les nattes de la $s \bar{a} l \bar{a}$ de passage sont déroulées et les femmes de l'ermitage préparent posément la première chique de bétel de la journée, invitant les arrivants à s'asseoir. Dans la matinée, on procède rapidement à l'exposition des offrandes et la remise des dons ainsi que les salutations aux génies de la montagne sont fixées pour le lendemain. Une rapide cérémonie a lieu ensuite où le Vénérable prononce des formules et jette de l'eau dans les quatre directions pour "ouvrir " aux pèlerins le chemin menant à la grotte Prasūt. L'ācāry du groupe s'engage le premier sur une sente escarpée à l'ouest de l'ermitage.

A même la roche calcaire grêlée par l'érosion chimique, un fourré épais mais discontinu laisse échapper çà et là des Dracoenia arborescents et cache à moitié une dépression ravinée qui mène à un tunnel profond ${ }^{1}$. La troupe s'accroche aux racines d'un banian, chemine dans la rocaille et arrive sur un terre-plein. Une niche de la paroi ouest fermée par une cloison est transformée en loge suspendue (Photo 2). Des failles de la voûte supérieure laissent entrevoir le ciel par endroits. Au sud, l'aven s'élargit et débouche sur une esplanade en cuvette encombrée de taillis et d'éboulis. En retrait, dans une fissure du mur est, s'ouvre une antre obscure (Photo 3) qui porte un écriteau : "Entrée interdite aux femmes enceintes $\|^{2}$. On allume les bougies et l'ācāry pénètre le premier.

$\mathrm{Au}$ bout du couloir, il faut monter sur une échelle (Photo 4) pour aller buter au fond d'un vestibule contre l'orifice étroit d'un boyau situé au niveau même du sol (Photo 5). Dans un recoin, un petit Bouddha de plâtre est abrité sous une niche. Fichés un peu partout sur le seuil ou pincés dans la roche, d'anciens faisceaux de bâtonnets poussiéreux reçoivent une nouvelle charge d'encens. L'ācāry se déchausse et invite chacun à prendre conscience de l'importance de cette démarche consistant à pénétrer par la "porte d'or " (dvār mās) pour s'introduire dans la matrice maternelle (Photo 6$)^{3}$. Il révèle la formule, les trois

(1) Pour cette description des lieux, se reporter au plan.

(2) Le fait de devoir ramper pour s'infiltrer dans un passage très étroit est évidemment dangereux pour les femmes enceintes, mais on considère que le caractère magico-religieux du lieu peut avoir aussi une influence néfaste sur le fœtus.

(3) Une dame du groupe de forte corpulence venue en pèlerinage pour la première fois (debout sur la photo 5), constate par elle-même le bien-fondé des avertissements qui lui avaient été donnés quant à l'extrême exiguité du goulet d'accès. Mise au fait, elle s'effondre dramatiquement en larmes. Devant son désarroi, quelques personnes l'encouragent à tenter malgré tout l'expérience et, joignant le geste aux encouragements, la pousse en force dans l'orifice. Mais c'est peine perdue et la pauvre femme n'est pas dégagée sans mal. Révoltée contre sa propre nature, elle s'allonge alors en gémissant devant la Porte d'or et reste ainsi jusqu'au retour des autres. 
caractères A RA HAṂ, qu'il faut réciter sans interruption pendant le processus de régression ${ }^{1}$. Puis, un par un, chacun s'introduit dans le goulet (Photo 7) juste assez large pour recevoir les épaules d'un homme, tête en avant, à grand-peine, sur un trajet d'une dizaine de mètres environ (Photo 8). Au bout du dernier ressaut qui force le buste à se cambrer pour adopter une position presque verticale, l'œil devine soudain la voûte spacieuse d'une salle d'environ cinquante mètres carrés. La respiration précipitée, on se dresse pour prendre pied sur un sol humide et boueux par endroits. Au fond de la salle, la lumière vacillante des bougies anime quelques blocs détachés du plafond. L'ācāry dit au passage que ces pierres se transforment en tigres sous l'effet de la méditation, puis s'infiltre à l'est, à l'opposé de l'orifice d'accès, dans une crevasse menant au pied d'une haute cheminée. Il explique que ce sont les vertèbres du tronc maternel. La troupe revient sur ses pas et longe le dédale d'une large galerie (Photo 9). L'ācāry s'arrête devant le cône lustré d'une stalagmite que le mince pan d'une voûte suspendue au-dessus d'un bassin d'eau claire relie à la paroi (Photo 10). Nous sommes là, commente-t-il, au centre de la matrice, là où l'embryon suce l'eau de la mère, agrippé au "cordon placentaire " (dan் suk) que voici (Photo 12). L'aspect cireux et vergeté de la calcite aux couleurs pâles et marbrées, les bulbes des parois, les alvéoles béants et humides, tout cela évoque les replis muqueux des organes internes tels que chacun les projette à travers ses fantasmes. La galerie se prolonge ensuite pour aboutir à une autre salle plus spacieuse. A l'est de cette salle, une poche s'ouvre sur un puits sinueux qui serait le repaire d'un énorme cobra mythique. Une corde de plusieurs dizaines de mètres permet d'y descendre et se termine sur un dépôt calcaire ${ }^{2}$.

Après s'être lavé le visage avec l'eau du bassin, l'ācāry invite chacun, maintenant haletant dans l'air raréfié et opacifié par l'accumulation de la fumée d'encens, à réciter les prières d'introduction (ārādhanā) aux exercices de méditation (Photo 11). Les voix sans timbre, comme étouffées par les replis des parois, entonnent les formules prescrites. Les bougies sont éteintes et les têtes incandescentes des bâtonnets de santal apparaissent dans le silence. D'une manière générale, le méditant doit maintenir sa concentration le temps que met une baguette d'encens

(1) Claude Jacques rapporte (op. cit., p. xIx) que les pèlerins de Gayā obtenaient du Gayāvāl qui les prenait en charge le suphal, mot grâce auquel ils avaient la certitude que le pèlerinage porterait fruit.

(2) J'ai interrogé l'ācãry sur l'utilité de cette corde, mais il n'a pas su me répondre. Sur le Phnom Bak, dans la région de Mongol Borei, il y a une grotte habitée par quelques moines au fond de laquelle se trouve une chambre fermée par une cloison. Cette chambre donne accès à l'orifice d'une cavité circulaire naturelle, étroite et profonde d'une trentaine de mètres qui part en pente douce. Les religieux de la grotte m'ont donné le nom de plusieurs vénérables qui s'y seraient laissés glisser après une longue préparation spirituelle, pour y opérer un ultime voyage sans retour. Ces maitres ne se conformaient à aucun procédé d'automomification (voir sur ce sujet Andỏ Kôsei, Des momies au Japon et de leur culte, "L'homme ", EPHE, VIe section, vol. VIII, 1968, traduit par Jacques Lemoine). D'ailleurs leur dépouille aurait été reprise par la suite et incinérée. Il ne semble pas, toutefois, que des faits semblables aient eu lieu dans le puits de la Grotte de la Naissance. 
à se consumer, c'est-à-dire une bonne heure. Mais la séance est interrompue au bout d'une vingtaine de minutes par une personne qui ne peut contenir un violent mal de tête. L'ācāry recommande alors de se baigner une nouvelle fois le visage dans le bassin, et ceux qui ont apporté des gourdes puisent leur provision annuelle d'eau miraculeuse. Au moment de sortir, l'ācãry rappelle les trois caractères A RA HAM qu'il faut réciter pendant l'expulsion (Photo 13). Le groupe se reforme devant la Porte d'or et psalmodie une dernière fois les prières bouddhiques. L'äcäry explique finalement : "Nous venons d'entrer dans cette grotte et avons acquis de grands mérites, car il s'agit de la matrice de l'auguste mère (garbh brah mätä). L'orifice que voici est la Porte d'or. En y pénétrant pour pratiquer l'ascèse, nous avons régressé dans le ventre maternel. Nous sommes ainsi nés une nouvelle fois. Demandons pardon d'avoir souillé l'auguste mère! " ${ }^{\mathbf{1}}$.

(1) Ce qui s'est dit au cours de la séance souterraine a été enregistré au magnétophone. Le passage final entre guillemets est la traduction des paroles de l'äcäry prononcées le 1 er juillet 1971. 


\section{Chapitre II}

\section{MÉDITATION EMBRYONNAIRE}

Le Vénérable Sovann Muni, futur successeur du vieux Yeak qui mourra l'année suivante (1972), est établi depuis quatre ans dans la loge suspendue qui domine le terre-plein et s'introduit tous les jours dans la grotte. Pour protéger ses vêtements et ramper plus librement, il fourre sa robe, son manteau et sa ceinture de poitrine, dans sa sébile de métal, puis se glisse à l'intérieur du boyau en poussant le tout devant lui. Des religieux venant de Kompong Chnang, de Siemreap, de Ta Kèo, se joignent parfois aux fidèles de l'ermitage qui désirent l'accompagner. A l'intérieur du ventre, le Vénérable se dirige vers la chambre nord, va tremper son visage dans le "réservoir amniotique ", s'adosse confortablement au "cordon placentaire " et s'adonne à l'exercice des cinq pïti, puis des cinq jhän, en s'orientant dans la direction du moment la plus favorable à ses formations mentales. Leur apparition fait naitre en lui la sensation d'états physiologiques particuliers ainsi que la vision de couleurs spécifiques.

Mais l'itinéraire mystique que parcourt mentalement le Vénérable n'est pas celui de l'utérus maternel à proprement parler, puisqu'il passe par la pointe du nez. Il explique en effet qu'il s'agit indistinctement, et du nez de l'auguste mère, et de son propre nez. Ceci est conforme au parcours du chemin de la naissance, car on sait que le nez est le "portail du monde utérin "1. Prononçant interminablement la formule A RA HAM, le Vénérable distingue dans le siège du nez la lettre NA de couleur violette. Il longe la narine, passe une porte, s'engage sur une échelle qui aboutit, dans l'épiglotte, à la lettre MO de couleur bleue. Il descend d'autres échelons et parvient à la lettre BU de couleur jaune, dans le cou. Il suit la pente du chemin jusqu'à la lettre DDHĀ de couleur rouge dans le sternum. Puis il parvient au nombril où se trouve la lettre YA de la couleur du cristal. Il se concentre dans le siège du nombril pour faire apparaitre le Bouddha assis sur le trône de l'Illumination. Il aspire l'air, puis fait monter et descendre son souffle du nez jusqu'au nombril. L'exercice doit le conduire à distinguer une ile lointaine qu'il faut atteindre en traversant l'océan. On étudiera plus particulièrement cet itinéraire spécial dans un travail suivant. Il ne s'agit pas là d'une régression initiatique rituelle. En s'engageant de l'autre côté du huis clos

(1) TC 302/7 : "khlon dvā lokakuttar gĩ cramuḥ stām ». 
utérin pour pratiquer quotidiennement ses exercices, le Vénérable vise à se soumettre aux conditions de l'embryon établi dans la matrice, comme le recommandent tous les textes de Vipassanākammațthān, mais pas à réitérer formellement, par un regressus vécu, le parcours de la naissance.

Quelles sont précisément les idées, les images, les représentations formées par la tradition pour expliquer ce qui se passe le long de ce parcours dans le viscère utérin? On connaît déjà les étapes de la formation de l'embryon ${ }^{1}$. Il faut savoir maintenant ce qu'il y a avant la gestation, ce qui se passe pendant et comment est représenté le milieu dans lequel agissent ces forces créatrices du développement fœtal. Voici la traduction de quatre extraits empruntés à la littérature mahānikāy qui donnent des renseignements là-dessus. Leurs applications sont en fait multiples. Mais dans le cadre présent, ils permettent de se rendre compte des conceptions religieuses et des règles qui marquèrent nécessairement les rites à l'intérieur de la Grotte de la Naissance.

\section{A) Traduction de $T L 133^{2}$}

1. [koe-A] Frères, euy! Révélons encore [ceci] pour expliquer la question des 4 nobles dhamma appelés augustes Sūtr, [koe-B] auguste Vinay, auguste Abhidhamm, auguste Dhammasit ${ }^{3}$.

2. Ces 4 nobles dhamma donnent naissance à 4 lettres : NA MA BA DA.

3. Voici ce qui réside dans notre forme corporelle. Le Seigneur l'a fait savoir. Ainsi l'on est pleinement et complètement un homme.

4. NA [crée l'élément vent.

MA crée l'élément eau.

(1) RBK. I, p. 86 et suivantes.

(2) Par commodité pour les renvois, les textes sont présentés dans ce chapitre à l'aide d'alinéas numérotés.

La traduction de cet extrait de la première liasse du Dhammatray inventorié TL 133 repose également sur dix autres versions d'origine et de composition différentes : TL 76, TL 119, TL 191, TL 191-IX, TL 257, TL 272, TL 370, TL 422, TL 247 et TL 133-IX. Voir la translittération de TL 133-I en appendice. Les variantes entre ces versions sont données en note dans la traduction.

(3) Cette mention du Dhammasit montre d'emblée qu'il faut ici mettre de côté la notion habituelle de "recueil "en ce qui concerne la série avec laquelle ce mot est associé : Sūtr, Vinay et Abhidhamm. Pour éclairer le fidèle sur le sens du mot dhammasit, TL 133, TL 191, TL 272 et TL 422 écrivent dhammasitanisìdana. On sait que le nisìdana désigne un carré d'étoffe pouvant servir à envelopper les manuscrits (RBK. I, p. 19, n. 5) ainsi que les vêtements monastiques lorsque ceux-ci sont pliés. C'est précisément le rôle prêté au Dhammasit dans le texte. Toutefois, on s'aperçoit que ce rôle s'exerce exclusivement à l'égard du symbolisme corporel accordé aux trois parties du Tipițaka, lesquelles ne sont définitivement plus considérées en tant que corpus. Il ne s'agit donc plus des livres ni des vêtements (RBK. I, p. 34), mais des trois parties du composé physique. Le mot dhammasit se divise en dhamma-sit; en khmer sit a le sens de "couler ", "fondre ", et en päli sita désigne un "lien ", une "attache ". Le Dhammasit est donc le \& lieur de dhamma. Il personnifie le principe unificateur des dhamma constitutifs de l'être. Les graphies dhammasid, osiddh, peuvent ajouter à ce concept une notion de puissance, de merveilleux (siddha). 
BA crée l'élément terre.

DA crée l'élément feu. $]^{1}$

Ces désignations sont conformes à l'auguste parole léguée pour faire connaitre les 4 éléments.

5. Le caractère NA, l'élément vent, le Seigneur l'appelle vent-eau.

Le caractère MA, l'élément eau, le Seigneur l'appelle eau-terre.

Le caractère $[\mathrm{BA}]$, l'élément terre, le Seigneur l'appelle terre-feu,

Le caractère DA, l'élément feu, le Seigneur l'appelle feu-vent.

6. Le Seigneur avertit de ne point s'étonner. Si l'on s'étonne, la présence d'esprit qui réside dans le corps ${ }^{2} \mathrm{~s}^{\text {'éloigne. }}$

7. Répétez les 4 nobles dhamma, qui donnent naissance à ces caractères, afin de s'en souvenir : auguste Sūtr, auguste Vinay, auguste Abhidhamm, auguste Dhammasit.

8. L'auguste Abhidhamm [kie-A] crée le caractère NA.

L'auguste Vinay crée le caractère MA.

L'auguste Sūtr crée le caractère BA.

L'auguste Dhammasit crée le caractère DA.

9. L'Auguste a révélé [ce qui suit] afin de faire comprendre la naissance de tous les êtres humains :

10. Quand l'auguste Sūtr, l'auguste Vinay, l'auguste Abhidhamm, l'auguste Dhammasit créent notre forme corporelle, le caractère NA donne naissance au globe vital, au vent, à la conscience, à l'esprit.

11. Le caractère MA donne naissance à l'eau, au sang, à la graisse, au cerveau, à la couleur, à la bile.

12. Le caractère BA donne naissance à la chair, aux os, aux veines, au gros intestin, à l'intestin grêle, au foie, aux poumons, au cœur.

13. Le caractère DA donne naissance à la peau, aux cheveux, aux poils. Ce caractère DA vient envelopper les trois parties [précédentes] pour les assembler fermement. [kie-B] Ces trois parties sont l'auguste Abhidhamm, l'auguste Vinay, l'auguste Sūtr.

14. Il y a trois cordons pour lier les trois pièces du vêtement ${ }^{3}$,

(1) TL 76, TL 119, TL 370 ; les autres versions inversent les termes et sont en contradiction avec la suite de l'exposé.

(2) Peu clair dans le texte. Mais cette conception ne serait pas impossible puisque les Mahāsānghika tardifs semblent bien avoir fait résider dans le corps les facultés mentales, la pensée, la présence d'esprit, etc. C.. André Bareau, Les sectes bouddhiques du Petit Véhicule, PEFEO, 1955, vol. XXXVIII, p. 74.

(3) Car les trois vêtements, la jupe, la robe, le manteau, sous la forme de trois liasses de feuilles de latanier, sont comparés aux trois livres exemplaires qui contiennent, selon la tradition, les sections du Tipițaka. De même, les trois ceintures sont associées aux cordons maintenant ces trois liasses. En effet, les références faites au Tipițaka permettent de penser que l'existence d'un corpus volumineux comprenant en réalité, non pas trois, mais une quantité impressionnante de liasses manuscrites, était ignorée du Cambodge bouddhiste traditionnel. Ce n'est qu'avec la création de la "Commission du Tipițaka " (RBK. I, p. 15) que l'idée d'une collection importante est apparue, sans d'ailleurs mettre en cause le concept ancien de trois recueils complets et uniques. 
à savoir : l'écharpe qui est l'attache de l'auguste Abhidhamm, la ceinture de poitrine qui est l'attache de l'auguste Vinay, la ceinture de taille qui est l'attache de l'auguste Sūtr.

15. L'auguste Dhammasit, c'est le gardien des trois. Il lie habituellement les trois vêtements ${ }^{1}$.

16. Puis l'Auguste révéla [ce qui suit] :

Dans notre forme corporelle il y a quatre portions [étant donné que 4 seigneurs y produisent (chacun) une portion $]^{2}$, à savoir : la portion de l'auguste Dhammasit, la portion de l'auguste Abhidhamm, la portion de l'auguste Vinay, la portion de l'auguste Sūtr.

17. Décrivons ces portions :

L'auguste Dhammasit donne naissance [à la partie allant] de la tête au cou; ceci est une portion.

18. L'auguste Abhidhamm donne naissance [à la partie allant] du cou à la poitrine; ceci est une portion.

19. [ke-A] L'auguste Vinay donne naissance [à la partie allant] de la poitrine au nombril; ceci est une portion.

20. L'auguste Sūtr donne naissance [à la partie allant] du nombril à l'anus; ceci est une portion.

Voilà ce qu'on appelle les 4 portions ${ }^{3}$.

21. [L'Auguste a révélé (ce qui suit) pour expliquer] ${ }^{4}$ [la question de] la contemplation de la répugnance ${ }^{5}$.

22. Dans le pays ${ }^{6}$ se trouve un noble emplacement? qui est un lieu où l'on demeure mutuellement l'esprit heureux, où s'éteint principalement la soif du désir des objets sensuels.

23. [L'Auguste en a révélé les causes en partie seulement. Si l'on veut connaitre cette question (en totalité) se reporter à l'auguste Dhammajhän $\left.{ }^{8}\right]^{9}$.

(1) De fait, comme les trois livres sacrés sont dits enveloppés dans le nisĩdana, l'ensemble des vêtements exposés au cours des cérémonies d'offrande (ivai trai) est entouré et maintenu dans le nisídana. Le Dhammasit enveloppe donc les trois vêtements comme la peau le corps.

(2) TL 133-IX/tū-B : "tpid mān à̉g 4 lok mak pankoet jā kandh knuñ añg yoen neh ".

(3) On retrouve les quatre centres vitaux : la fontanelle, la base de la langue, le nombril, le coccyx (RBK. I, p. 131).

(4) TL 76/tru-B : hoey braḥ ang drun trāḥ samtèn duk țāk uy țin *.

(5) pațikūlapaccavekkhaña.

(6) Ceci est une allusion au nagarakāy, la citadelle du corps, ici comparée à un pays.

(7) ãsana, "noble emplacement *; ce mot désigne un emplacement où l'on s'assoit, où l'on s'allonge, et au Cambodge, il s'applique spécialement à un lieu réservé pour la prière face auquel se dresse un autel à gradin garni des objets rituels.

(8) Cf. supra, p. 224. Le Dhammajhān est un texte composé de quatre liasses. Ce manuscrit est avec le Dhammavinsun en cinq liasses auquel il s'identifie en maints passages, le texte de la littérature mahānikāy le mieux conservé au Cambodge.

(9) TL 119/na4-A : "braḥ añg druń saṃtèn yak tèr jā hèt pāntic 2 poer cañ tīn kic noh uy moel knuñ brah dhammajhän *. Notons que cet ajout qui fait allusion à l'enseignement incomplet de l'Auguste semble assigner au Dhammajhān une source dont l'origine n'est pas directement la parole du Bouddha. 
24. Au commencement, lorsqu'on s'unit dans l'obscurité ${ }^{1}$, il y a le caractère SA. Celui-ci donne naissance au caractère $\mathrm{U}^{2}$. Alors l'on appelle cela l'eau du désir.

25. Sachez quelles sont la forme, la couleur et la teinte de ce suc vertueux!

Celui-ci est rond comme le dos d'une punaise. Il a la couleur [ke-B] des yeux du paon et la teinte blanche du diamant kesarasit ${ }^{3}$ posé sur la feuille du lotus. Il est d'une force vertueuse. [Sa grosseur] $]^{4}$ est celle d'une tête de mouche. Il se conforme [à la loi] du Grand Prohm ${ }^{5}$. Il ressemble à une bourse ${ }^{6}$.

26. Ce [suc] $]^{7}$ est l'objet sensuel pour lequel on s'unit mutuellement dans l'obscurité.

27. Il y a trois personnes. Sachez ce à quoi elles donnent naissance!

Le caractère NA crée le cou en premier.

Le caractère KA crée la poitrine en premier.

Le caractère AM crée les cinq branches.

28. Revenons au caractère NA. Ce caractère crée encore trois [autres] caractères destinés à conduire tous les êtres : ce sont les trois lettres A RA HAM.

29. Le Seigneur a confié ces trois caractères à tous les humains, hommes et femmes, à tous les êtres, afin qu'ils les prononcent continuellement et atteignent le séjour de la Grande Félicité.

30. Vous tous, frères, euy! Lorsque la forme est [kè-A] amenée [sur le chemin de la naissance], il y a les lettres suivantes : NA KA AM.

31. [Celui] qui entre en réclusion et honore les trois vêtements doit s'appliquer à la contemplation de la répugnance, [connaitre] le laid et le beau, et observer un noble emplacement à l'intérieur comme à l'extérieur.

32. [Gelui] qui entre [en réclusion pour] respecter la vertu doit connaitre les objets intérieurs et observer les postures corporelles comme l'Auguste l'a enseigné de sa noble parole.

(1) smandha andhakara; l'expression désigne le rapport sexuel.

(2) SA et U correspondent à la $4^{\mathrm{e}}$ de la $7^{\mathrm{e}}$ classe (sa) et au $6^{\mathrm{e}}$ des sons (ū) dans le yoga indien (commentaire de Samkara sur la Śvetāśvatara-upaniṣad; Ed. Ãnandāçrama, vol. 17, Poona 1889, p. 42).

(3) tpuñ kesarasit pose un problème de lecture. L'expression peut avoir le sens, soit de " crinière argentée/coiffée de la tête du lion *, soit, en langue siamoise plus particulièrement, de "diamant de pollen pur ", image qui convient mieux au texte ; mais il peut s'agir également d'une déformation de käyasiddh qui est le nom donné à une pierre fabuleuse.

(4) TL 119/na4-A : " män dumhummm pun ".

(5) Lecture difficile.

(6) than krabat désigne un petit sac fermé par un cordon servant à contenir les pièces de monnaie, le briquet, etc.

(7) TL 191/loe-B : "dik noḥ". 
33. [Les objets] à l'extérieur et à l'intérieur sont entièrement semblables ${ }^{1}$.

34. Si l'on reçoit les offrandes d'un fidèle, qu'il y ait suffisamment de pièces de vêtement pour s'accorder [avec les différents éléments situés] dans la matrice de l'auguste mère. Alors on aura suivi les règles de l'auguste Vinaya.

35. Vous tous, frères, euy! Révélons [ce qu'il advient] lorsqu'on réside dans le séjour utérin ${ }^{2}$, c'est-à-dire dans le ventre maternel [pendant] 10 mois.

36. [On est] agrippé au cordon placentaire de l'auguste mère, assis, les genoux relevés, les yeux fermés, [kè-B] la bouche prononçant les augustes lettres NA KA AM.

37. Lorsque l'on est expulsé à la naissance, l'on est étourdi, égaré, perdu, inconscient. On cherche en vain à se rappeler les trois augustes lettres [intérieures]. C'est pourquoi l'Auguste a exhorté à se prosterner pour réciter les augustes lettres extérieures : A RA HAM.

38. Celles-ci sont les choses extérieures. Se prosterner pour réciter comme si l'on résidait dans la matrice.

39. Le Seigneur fait plier les jambes, poser la main droite dans la main gauche, et prononcer les caractères de l'auguste A RA HAM ${ }^{3}$.

40. Si, par exemple, l'on s'apprête à recevoir la collation, il faut se conformer à la posture [observée] dans la matrice.

41. Si l'on reçoit [le don] des huit articles ${ }^{4}$, les [pièces du] vêtement doivent être conformes aux objets du noble emplacement, comme dans le séjour utérin, le ventre maternel. Alors on s'accorde avec la noble parole [que l'Auguste a] prêchée.

42. Lorsque l'on est établi dans le séjour utérin, le ventre maternel, [kai-A] on possède tous les objets. [Ceux-ci] sont de la couleur du sang, rouge comme une pelote de gomme-gutte. On possède tous les objets au complet. $\mathrm{Si}$, dans le séjour utérin, le ventre maternel, ces objets ne sont

(1) Ceci éclaire le symbolisme des objets rituels ( $p \bar{a} y s \bar{i}$, slä dhamm, bougies, baguettes d'encens, etc.) qui garnissent l'āsana élevé à l'occasion des cérémonies. Les études relativement nombreuses faites sur ce sujet ont rarement fourni d'indications suffisantes. Cette lacune est d'autant plus regrettable que la signification de ces objets usuels de la vie au Cambodge pose immédiatement les jalons du bouddhisme à mystères tel qu'il est vécu et compris. En fait, ces éléments du rituel ont généralement pour fonction de reconstituer le noble emplacement intérieur ", de matérialiser le ventre maternel.

(2) sthan kuttara ; l'origine du mot kuttara = matrice s'explique de la manière suivante : l'expression sțhan kuttara est une conversion de lok kuttara. On a vu (RBK. I, p. 120), en effet, que lokuttara (supramondain) est assimilé par les Khmers à loka-udara (monde utérin). Ce mot s'écrit lokkuttara. De là, lok, le monde a fait place à sțhan, le séjour, pour donner sțhan kuttara (le séjour utérin). D'ailleurs, TK 257/B-84 et TL 119/na4-B ont conservé lokkuttara, et TL 247/ 18-B donne : thān gär (sțhan garbh), le séjour de la matrice.

(3) Ou plutôt, les " auguste caractères A RA HAM"?

(4) Les huit articles sont les sept vêtements plus la sébile. 
pas au complet, notre forme corporelle [fœtale] se détériore et ne peut croitre.

43. Vous tous, frères, euy! Si, entrés en réclusion pour honorer la moralité et les préceptes, vous ne possédez pas les 7 pièces [du vêtement] au complet, la moralité et la vertu que vous honorez se dégradent puis se dissipent.

44. Continuons de révéler ce qui [existe] à l'intérieur : la jupe, la ceinture de taille, la robe, la ceinture de poitrine, le manteau, l'écharpe, l'étole. Voici les 7 éléments. Sachez qu'ils sont les éléments intérieurs!

45. La ceinture de taille, c'est le "cordon ombilical " $\mathbf{1}$.

46. La ceinture de poitrine, c'est la "queue cousue $»^{2}$. mère.

47. L'écharpe, c'est le "cordon placentaire $»^{3}$ [kai-B] de l'auguste

48. L'étole, c'est la "cruche des eaux $\|^{4}$ qui contient un peu de sang5.

49. Le manteau, c'est l'amnion'.

50. La robe, c'est le placenta?

51. La jupe, c'est la "poche à méconium " $^{8}$.

52. Lorsque le corps est établi dans la matrice de l'auguste mère excellente, les eaux sont placées par-dessus notre tête et coulent continuellement goutte à goutte sur notre forme corporelle. Si cette eau n'arrose pas notre corps, nous ne pouvons pas vivre.

53. C'est pour cela que l'on doit connaitre l'intérieur comme l'extérieur, que l'on doit observer les postures corporelles conformément aux lois de l'intérieur et de l'extérieur.

(1) dañ phcit, c'est-à-dire, par opposition à dań suk (voir note 3 suivante), l'extrémité du cordon reliée à l'ombilic, après section.

(2) kanduy lin, c'est-à-dire, avant section du cordon, l'extrémité de celui-ci directement reliée au placenta. Ce segment est dit cousu a au placenta. C'est ainsi que l'on parle d'un enfant mort-né parce que cette couture a lâché. Il est précisé que si le fotus n'a pas de dent c'est pour qu'il n'arrache pas cette "queue cousue (TL 53/ka-B).

(3) dañ $s u k$, c'est-à-dire la partie du cordon reliée au placenta après section. Dans un sens courant, l'expression désigne simplement le cordon.

(4) $k$-am dik bhloh, c'est-à-dire le sac des eaux placé sur la tête du fotus, comme l'atteste la poche qui apparaît, puis se déchire, pour faire place au crâne de l'enfant. n. 4).

(5) Ce sang est symbolisé par la couleur rouge de la doublure de l'étole (RBK. I, p. 19,

(6) srom sbèk khluon, c'est-à-dire l'"enveloppe de peau du corps * qui parfois recouvre encore l'enfant après l'expulsion.

(7) srom dañ suk, c'est-à-dire l' enveloppe du cordon placentaire " ainsi qu'il apparait lorsqu'on observe, après évacuation, le cordon enfoui dans les replis du placenta.

(8) ghlāmnn lāmak, c'est-à-dire le "dépót à excrément " traditionnellement situé dans le ventre maternel pour recevoir les évacuations intestinales de l'embryon. Cette poche peut se crever, comme le prouvent les souillures relevées quelquefois dans les eaux. 
54. Il ne doit y avoir de couleur que le rouge semblable au sang ${ }^{\mathbf{1}}$. Si une autre couleur y est mélangée ${ }^{2}$, la forme ${ }^{\mathfrak{s}}$ ne peut pas naitre.

55. [De même] si la moralité et les préceptes ne sont pas observés correctement, [le religieux] se décompose comme le corps [du fœtus].

\section{B) Traduction de TL2354}

Dans la Grotte de la Naissance, le néophyte était initié par Mahā Pațțhān aux principes de la respiration embryonnaire (supra, p. 234). Voyons cet enseignement de Mahā Pațțhān tel qu'il est exposé dans les textes :

1. [kka 34-A] "A $\bar{A}$ I I U U Rุ Ṛ L L E AI O AU AM AḤ ". Réciter ces 16 lettres pendant 10 mois.

2. Puis l'auguste Mahā Pațthān dit :

- Hey, enfant, euy! [le moment] arrive d'évacuer la matrice maternelle. Six ${ }^{5}$ bandits attendent à la Porte d'or. N'oublie pas l'auguste $g \bar{a} t h \bar{a}$ des 16 lettres qu'il faut réciter. [kka 34-B] Alors tu n'auras rien à craindre.

3. Lorsque l'enfant a retenu l'auguste gāthā que Mahā Pațthān lui a recommandé d'apprendre, il s'accroupit en repliant les jambes, joint les mains et énonce la création mentale [du gāthā] jusqu'au $10^{\mathrm{e}}$ mois.

4. Puis l'enfant nait et s'extrait de la matrice maternelle. A ce moment-là, la respiration de l'enfant s'arrête, [hésitante, interrompue pour $]^{6}$ un instant. Voilà ce qu'on appelle [le vent de] l'auguste Sūtr aux 5 livres.

5. Lorsqu'il demeure dans la matrice de sa mère, l'enfant respire seulement du nombril [ka 35-A] jusqu'à l'intérieur du nez. Voilà ce qu'on appelle [le vent de] l'auguste Vinay aux 5 livres.

6. passāsa - ceci désigne le vent qui entre dans le nez. assāsa - ceci désigne le vent qui sort du nez.

nissāsa - ceci désigne le vent de l'auguste Abhidhamm aux 7 livres, c'est-à-dire le vent qui stationne dans le ventre, au niveau du nombril.

(1) Littéralement : ‘à une pelote de sang ». TL 119/na5-B répète : gomme-gutte.

(2) La couleur de la sanie présente dans les matières expulsées avec l'avorton mort.

(3) Il y a ici association d'idée entre rūp qui est le numéral pour les religieux et rūp qui désigne la forme du fœtus. Cela signifie que le religieux dont la couleur des vêtements n'est pas conforme ne peut pas naftre, ne peut pas atteindre son terme : le Nibbāna.

(4) Six autres versions du même passage ont en outre été consultées pour établir la traduction de TL 235 : TK 20, TL 40, TK 176, TK 257, TL 413, TK 459. Les variantes entre ces versions sont données en note dans la traduction. Voir la translittération de TL 235 en appendice.

(5) Soit les six facultés. D'autres versions (TK 257/B-37) font mention de 500 bandits.

(6) TK 257/B-38 : « sụoer nin tece khsal . 
7. Si l'on crée mentalement ce gāthā, on atteint l'extinction. [L'atteinte de l'extinction, c'est le vent au niveau du nombril.] ${ }^{\mathbf{1}}$.

8. Puis on invite les huit nobles moines. [ka 35-B] [Inviter les nobles moines, c'est faire (en sorte que) le corps inspire le vent à l'intérieur du nez. C'est (le vent de) l'auguste Sūtr aux 8 livres. (Voilà ce qu'on) appelle "inviter les huit nobles moines ".] ${ }^{2}$.

9. Le vent descend du nez jusqu'au cou. Voilà ce qu'on appelle le vent de l'auguste Vinay aux 5 livres. C'est la Voie de gagner-lecourant $^{3}$.

10. Le vent descend du cou jusqu'au sternum4. C'est [le vent de] la Voie du retour unique ${ }^{5}$.

11. Le vent [descend] du sternum jusqu'au nombril. C'est le vent de la Voie du non-retour ${ }^{6}$.

12. Le vent descend du nombril jusqu'au [ki 36-A] coccyx, sans sortir ni entrer. C'est le vent de la Voie de l'état d'Arahant?

13. On atteint l'extinction.

Concentrer son attention correctement et l'on se trouve [dans une situation] semblable [à celle que l'on avait] lorsque l'on résidait dans la matrice maternelle.

14. Ne pas laisser le vent sortir ou entrer.

15. Se conformer à ces instructions, c'est inviter les huit nobles moines [à s'engager dans la voie de l'atteinte de l'extinction, sur les quatre chemins $]^{8}$.

16. Le vent descend du nez jusqu'au cou. Énoncer les créations mentales correctement et l'on peut contempler l'auguste lumière [ki 36-B] semblable à la luciole. Voilà ce qu'on appelle obtenir le Fruit de gagner-le-courant ${ }^{9}$.

17. Le vent descend du cou jusqu'au sternum. Énoncer les créations mentales correctement et l'on peut contempler l'auguste clarté semblable à l'étoile du matin. Voilà ce qu'on appelle obtenir le Fruit du retour unique ${ }^{10}$.

18. Le vent descend du sternum jusqu'au nombril. Énoncer les créations mentales correctement et l'on peut contempler l'auguste clarté

(1) TK 459/A-54 : "e nirot sammāpād noh khyal dim phcit ".

(2) TK 459/A-55 : "ūy nimun ariyasag̃h dāmin 8 noh ūy rūp srūp khyal cūl knañ cramoh gi braḥ sūt dāmn் 8 kāmmmbiy hov nimun ariyasağh dāṃn 8 ॥.

(3) sotāpattimagg.

(4) țoem țanhoem désigne plus précisément l'appendice xiphoïde du sternum.

(5) sakadāgāmimagg.

(6) anāgāmimagg.

(7) arahattamagg.

(8) TK 257/B-39 : "toer cūl phlūe nïrodh sammäpādd knuñ mag dāminn 4 hon் ".

(9) sotāpattiphal.

(10) sakadägāmiphal. 
semblable à la pleine lune. Voilà ce qu'on appelle obtenir le Fruit du non-retour ${ }^{1}$.

19. Le vent descend du nombril jusqu'au coccyx. Énoncer les créations mentales correctement et l'on peut contempler [ki 37-A] l'auguste clarté semblable au soleil levant. Voilà ce qu'on appelle obtenir le Fruit de l'état d'Arahant'.

20. On atteint l'extinction.

21. [Sortir $]^{3}$ de l'extinction.

22. Le souffle se retire du coccyx et parvient au nombril. Énoncer les créations mentales correctement et l'on peut contempler [l'auguste clarté étincelante pareille à l'éclat du soleil et de la lune $]^{4}$.

23. Le souffle se retire du nombril et parvient au sternum. Énoncer les créations mentales correctement et l'on peut contempler la lune et les étoiles.

24. Le souffle se retire du sternum [ki 37-B] et parvient au cou. Énoncer les créations mentales correctement et l'on peut contempler l'auguste clarté pareille à l'éclat conjugué du soleil, de la lune et des étoiles.

25. Apparait une lumière étincelante qui scintille. On contemple les 10 portes. On contemple véritablement le séjour du Nibbäna.

26. Le souffle [se retire] du cou et se dirige vers la fontanelle. Énoncer les créations mentales correctement et l'on voit l'auguste lumière ${ }^{5}$ ouvrir la porte du Nibbāna.

27. L'esprit, égal et concentré, doit être ténu comme le cheveu d'un habitant du continent Aparagoyana ${ }^{6}$. Alors l'esprit peut entrer dans le Nibbāna, le séjour paisible et glorieux de la Grande Félicité.

\section{G) Traduction de $\mathrm{TL}_{12}{ }^{2}$}

On a vu que le processus de gestation renouvelé dans la Grotte de la Naissance était mis en relation avec les pratiques relevant du $m \bar{u} l$ kammaț̣hān (supra, p. 234). Cela revient à associer le néophyte du Phnom

(1) anāgāmiphal.

(2) arahattaphal.

(3) TK 176/B-67, TK 257/B-40, TK 20/A-36 : "rī ceñ niroddh ".

(4) TL 40/ța-B : "braḥ rākkhsmìy ruń roeń smoeh sè[n்] sūyryā braḥ aditth braḥ cand' hon ".

(5) C'est-à-dire le globe de cristal; cf. RBK, I, p. 74 et suivantes.

(6) Dans ses commentaires du Saṃyuttanikāy, Buddhaghosa se réfère aux cheveux des habitants du continent Uttarakuru, mais pas à ceux de l'Aparagoyana. Il explique qu'à l'origine de l'être, la goutte d'huile de sésame est si infime qu'il faut la comparer à la goutte de lait que retiendrait la pointe d'un cheveu des habitants d'Uttarakuru, après que l'on ait secoué ce cheveu sept fois (Sāratthappakāsinī, Yakkhasamyutta, Sagätavagga, vol. I, Bangkok 2463, p. 351). L'image montre que ces cheveux passent pour être extrêmement fins.

(7) Une autre version du même passage a en outre été consulté pour établir la traduction de TL 12 : TL 461. Les variantes entre ces deux versions sont données en note dans la traduction. Voir la translitteration de TL 12 en appendice. 
à Cittakumārā-Cittakumārī. C'est en effet ce mythe primordial qui fait de la quête spirituelle du Yogāvacar une opération consistant à fabriquer un corps nouveau à la suite d'une transformation en embryon (supra, p. 228). Les Enfants-esprits vont renaitre pour cela au pays des Jambosiers et deviennent un figuier à cinq branches :

1. [ga-B] Le figuier, c'est d'abord le tronc.

2. Les branches sont les deux bras et les deux jambes.

3. Les feuilles sont les deux oreilles.

4. La fleur du figuier est le cordon ombilical.

5. Le fruit, c'est l'enfant établi dans le ventre.

6. Les racines sont les trois $^{1}$ [parties $d u$ ] sexe viril qui contient la lignée, [gha-A] c'est-à-dire l'eau précieuse qui s'écoule et vient donner naissance dans le séjour aux 7 enceintes de cristal ${ }^{2}$. Se dissimuler afin que personne ne voie.

7. Les globes de cristal sont les deux yeux du Dhamma, la vésicule biliaire, le cœur et l'enfant dans le ventre. Voilà les 4 globes de cristal ${ }^{3}$.

8. Puis l'auguste Kammațthān ${ }^{4}$ recommande à nāñ Cittakumārā et nāñ Cittakumārī de quérir les 4 globes de cristal [contenus] dans les fleurs et les fruits du figuier. Qu'ils y parviennent, et ils [pourront] sortir par la porte à 8 degrés $^{5}$ [en vertu de] la force de celui qui possède les globes précieux.

9. MA A U

MA, l'auguste Abhidhamm aux 7 livres; A, l'auguste Sūtr aux 5 livres; $\mathrm{U}$, l'auguste Vinay aux 5 livres.

10. MA donne naissance à la tête qui est le Nibbāna.

A [gha-B] donne naissance à la rotule droite.

$\mathrm{U}$ donne naissance à la rotule gauche.

11. Les 7 augustes Abhidhamm sont les deux yeux, les deux narines, les deux oreilles et la bouche. Voilà ce qu'on appelle les 7 augustes Abhidhamm. L'auguste Abhidhamm est la bouche.

12. Les 5 augustes Sütr sont les 5 doigts de la main [droite] ${ }^{6}$.

13. Les 5 augustes Vinay sont les 5 doigts de la main gauche.

14. Ensuite, une mère vient créer une partie du crâne. Une autre mère apporte la [seconde] partie du crâne. Une [autre] mère apporte la [dernière] partie du crâne. Ces parties sont réunies pour composer la tête.

(1) Les deux testicules et le pénis.

(2) L'image évoque habituellement le Nibbāna mais désigne ici, de toute évidence, la matrice.

(3) Les 2 yeux comptent pour 1 .

(4) Personnalisation du kammațthān.

(5) L'image se rapporte à l'utérus.

(6) TL 461/5-B : stāmm *. 
15. Puis Brah Kèvi vient dessiner l'orbite des yeux [et créer les quatre cristaux précieux $]^{2}$ rouge, noir, blanc, jaune, dont la luminosité éclatante fait voir [na-A] le paradis et l'enfer.

16. Puis les trois mères se concertent:

- Nous avons créé le haut. Créons maintenant le bas.

17. [Elles donnent naissance à la partie] appelée rotule droite, puis aux 2 chevilles droites et aux 5 orteils qui protègent le côté droit. Ceci est une mère.

18. Elles donnent naissance à la rotule gauche, aux 5 orteils et aux deux chevilles qui protègent le côté gauche. Ceci est une mère.

Ces trois mères ont un immense mérite.

19. Expliquons [la question des] 4 éléments :

Braḥ Kèv donne naissance à l'eau en la faisant couler du Nibbāna.

20. Brah Kèv donne naissance à la terre qui existe au séjour du milieu.

21. Brah Kèv donne naissance aux 6 feux.

22. [n்a-B] Brạ̣ Kèv [donne naissance au vent qui provient du] paradis.

23. Ainsi Brah Kèv crée-t-il les 4 éléments pour protéger la citadelle du corps en entier.

\section{D) Traduction de $T K 176^{3}$}

Enfin, les textes montrent encore le parachèvement initiatique du corps nouveau par l'octroi de valeurs immortelles :

1. [B-17) MA pasvāt, A asvāt, U nisvāt.

2. Ces trois caractères donnent naissance à SAM VI DDHĀ PU KA YA PA4.

3. [B-18] SAM produit NA

VI produit MO

PU produit BU

KA produit DDHĀ

PA produit YA

4. Ces cinq lettres ont donné naissance à NA MO BU DDHĀ YA. C'est le nom des cinq agrégats.

(1) Brah Kèv intervient à l'origine de la création ; cf. supra, p. 225 et suivante.

(2) TL 461/5-B : " mak pañkoet jār brah srī kèv dämñ puon ".

(3) Une autre version du même passage a en outre été consultée pour établir la traduction de TK 176 : TK 459 (B-14 à B-16). Voir la translittération de TK 176 en appendice.

(4) Sur le rôle de ces lettres, voir RBK. I, p. 79, 86, 138, etc. 
5. Restent les [deux] lettres DDHA YA.

Elles produisent SI DDHAM A $\bar{A}$ I I U $\bar{O}$ R R $R$ L L E AI O AU AM ĀM AH.

6. Soustrayons [ces deux lettres] des 10 moralités : on a les 8 directions ainsi que les 8 nobles moines ${ }^{1}$.

7. Prenons ensuite SAM VI DDHĀ PU KA YA PA que l'on ajoute à NA MO BU DDHĀ YA, ce qui fait 12 . Tenons cela pour les 12 vertus de la mère.

8. Puis additionnons kusala et akusala ${ }^{2}$ à SI DDHAM... etc., on obtient 21. Tenons cela pour les 21 vertus du père.

9. Totalisons les vertus maternelles et paternelles, ce qui fait 33 . Voilà ce qu'on appelle les 33 lettres qui créent tous les êtres humains.

10. [B-19] Additionnons les 33 lettres aux 5 agrégats, on obtient les 38 vertus de l'auguste Dhamma. Voici l'auguste Dhamma en personne.

11. Prenons NA MO BU DDHA YA - NA, les 12 vertus de la mère; $\mathrm{MO}$, les 21 vertus du père; $\mathrm{BU}$, les 6 vertus du roi; DDHĀ, les 7 vertus de la famille; YA, les 10 vertus du Grū-ācāry. On a les 5 agrégats qui donnent les 56 vertus de l'auguste Bouddha. Voici l'auguste Bouddha en personne.

12. Combinons les 3 pasvāt, asvāt, nisvāt, avec SAM VI DDHĀ PU KA YA PA et avec les 4 éléments NA MA A U. On obtient les 14 vertus de l'auguste Sangha. Voici l'auguste Sangha en personne ${ }^{3}$.

13. Le tout additionné fait $108^{4}$.

14. Ce [total] existe dans notre corps.

15. Voilà ce que tous les nobles fils, toutes les personnes, tous les gens, doivent chercher à percevoir [en eux-mêmes] et à connaître tout à fait clairement.

(1) Supra, p. 248.

(2) kusala, les actes bons; alcusala, les actes mauvais.

(3) Soit, le religieux. La notion de sangha en tant que "communauté "n'est pas une donnée exprimée clairement dans la tradition mahānikāy. L'existence de cette abstraction peut être décelée dans la vénération dont le religieux fait l'objet de la part du fidèle. Mais c'est moins la communauté à laquelle le moine appartient que l'état personnifié par lui qui est adoré.

(4) $38+56+14=108$, nombre qui symbolise la totalité, la plénitude (RBK. I, p. 141). 


\section{ConClusion}

Tel est donc l'enseignement qui imprégnait les rites dans la Grotte de la Naissance. Or quand on connaît le goût qu'avait l'ancien clergé pour les représentations mimées et théâtrales (ordination, tonte de la houpe, consécration d'une statue, joutes oratoires, etc.), on peut croire que les initiations qui avaient lieu à l'intérieur des entrailles du Mont n'étaient pas dépourvues de mise en scène.

Les textes nous instruisent des relations fondamentales qui existent entre les sections canoniques et les portions corporelles (A16-20). Les quatre NA MA BA DA, c'est-à-dire les quatre éléments (A4), pouvaient donc être figurés par des manuscrits, ou des vêtements (A14), enveloppés dans le nisidana $(\mathrm{A} 1,2)$. On y insiste sur la nécessité de ce qui est appelé la "contemplation de la répugnance " (A21) et qui n'est là rien d'autre qu'une réflexion sur ce qui se passe dans un utérus gravide. Il faut noter que le ventre maternel est comparé à un "noble emplacement"(A22). Ce lieu, exotériquement, c'est l'autel matérialisé par les objets rituels devant lequel le méditant prend place; ésotériquement, c'est la matrice matérialisée par les organes maternels dans laquelle l'embryon s'établit. D'où : l'autel est le ventre; le méditant, l'embryon; les objets rituels, les organes de la mère (supra, p. $245, \mathrm{n} .1$ ). Celui qui rentre en réclusion doit, en effet, observer un noble emplacement à l'intérieur comme à l'extérieur (A31).

Le néophyte du Phnom s'engageait ensuite sur le chemin indiqué par l'ācāry et pénétrait dans l'utérus en récitant peut-être les trois caractères NA KA AM (A30), formule que les pèlerins de Phnom Penh avaient oubliée. Etait-il vêtu de l'habit monacal ? Le froc symbolisait les membranes pellucides de l'œuf (A45-51). Il devenait un être en gestation dans les termes consacrés par la tradition : agrippé à l'appendice de calcite qui figure le cordon placentaire (A36), baigné dans le liquide amniotique (A52), les genoux relevés, les yeux fermés (A36), la bouche prononçant A RA HAM (A39). A l'intérieur de la Grotte de la Naissance, il était ensuite initié par Mahā Patțhān (supra, p. 234) à une pneumatique respiratoire : la création mentale du kāthā des 16 voyelles pendant un temps assimilé à celui d'une gestation $(\mathrm{B} 1,2,3)$, alliée à une technique de rétention du souffle.

Il y a trois souffles : passāsa, nissāsa, assāsa, attribués au Vinay, à l'Abhidhamm et au Sūtr $(B 5,6,8)$. Le premier souffle, passāsa, désigne en principe l'inspiration ${ }^{1}$ (B6), mais qualifie pour le Yogāvacar plus

(1) RBK. I, p. 129. 
précisément l'échange gazeux avec l'extérieur, autrement dit, la respiration du méditant, cette respiration qui apporte la vie. C'est le vent du Vinay aux 5 livres (B5). L'air pénètre à l'intérieur et circule dans les cinq sphères : le nez, le cou, le sternum, le nombril, le coccyx. Voilà, en fait, ce que sont les 5 livres du Vinay et comment il faut interpréter ici le mot gambïr dont le sens littéral est "profond ". A ce sujet, on peut d'ailleurs se demander si primitivement, dans la tradition mahānikāy, ce mot a jamais eu le sens de "liasse manuscrite " et s'il n'aurait pas plutôt pris ce sens après coup, par altération précisément de sa signification initiale. Le second souffle, nissāsa, désigne la rétention du vent au niveau du nombril (B6). C'est ce vent de l'Abhidhamm aux 7 livres qui élabore les sept stades de la transformation du fœetus dans le ventre ${ }^{1}$. Voilà ce que sont les 7 livres de l'Abhidhamm. Le troisième souffle, assāsa, désigne la circulation intérieure du vent, sans échange avec l'extérieur. Le mot se rapporte, en principe, à l'expiration' (B6), mais alors celle-ci ne se fait plus par la bouche ni par le nez. Il s'agit de l'évacuation du souffle, soit par le haut, par la fontanelle (B26), soit par le bas, comme on le verra dans une autre étude ${ }^{3}$. Mais il faut savoir que c'est ce vent dirigé vers le bas qui conduit à la délivrance et que c'est pour cela qu'on l'appelle le vent de l'auguste Sütr aux 5 livres : il souffle afin que l'enfant soit expulsé au moment de la naissance (brah Sütr = prasūt, naître) et les 5 livres sont les cinq branches du figuier ${ }^{4}$. Pour l'initié, cette parturition, cette image de l'enfant dans le ventre que la mère évacue - l'enfant dans le ventre est le globe de cristal (C7) c'est la voie très secrète à laquelle il est fait une allusion : le vent descend du nombril jusqu'au coccyx, sans sortir ni entrer $(\mathrm{B} 12,14)$. La tradition enseigne, en effet, comment libérer le souffle par l'anus et ce curieux procédé de vidage stercoraire, qui renvoie en réalité à la technique de méditation du Vénérable Sovann Muni dans la Grotte de la Naissance (supra, p. 240), a pour but de faire passer le Yogāvacar sur l'« autre rive " où se dresse le Méru. Les textes mentionnent encore un vent dit de l'auguste Sūtr aux 8 livres (B8). Il ne s'agit pas là d'une lecture fautive pour le chiffre 5 . Ce nombre 8 est confirmé non seulement par différentes autres versions khmères mais aussi par les sources thaïes en caractères yuon ${ }^{5}$. En fait, ces 8 livres correspondent aux 8 nobles moines (B8) et sont les quatre chemins et les quatre fruits, c'est-à-dire les huit états supramondains.

Par la maitrise du vent du Vinay aux 5 livres qui met dans une situation semblable à celle de l'embryon dans la matrice, le candidat obtenait donc les quatre chemins (B5, 13). Ici, on dit que le Yogävacar est au terme de son parcours supramondain et qu'il arrive au pied de l'arbre du Dhamma dont il va déguster les fruits ${ }^{6}$. En faisant à nouveau circuler

(1) RBK. I, p. 86.

(2) RBK. I, p. 129.

(3) Voyage sur l'autre rive, en préparation.

(4) RBK. I, p. 74.

(5) TL 467/8 ja-A.

(6) RBK. I, p. 133 
son souffle dans les cinq sphères, le candidat contemplait en effet une lumière semblable, premièrement à celle de la luciole (B16), deuxièmement à celle de l'étoile du matin (B17), troisièmement à celle de la pleine lune (B18), quatrièmement à celle du soleil levant (B19). Il avait obtenu les quatre fruits de l'état d'Arahant (B19). Puis il sortait de l'extinction (B21) en parcourant le même chemin, mais cette fois à rebours, ce qui l'amenait à la contemplation d'une clarté de plus en plus forte : le soleil et la lune (B22), puis la lune et les étoiles (B23), puis le soleil, la lune et les étoiles (B24). Il saisissait enfin une lumière éclatante (B25) : le globe de cristal $^{1}$. Son souffle (B26) était alors dirigé vers la fontanelle, "la porte étroite du Nibbāna $\|^{2}$ (B27). "Les sept enceintes s'ouvraient pour laisser entrer la personne munie du globe précieux $»^{\mathbf{3}}$.

Nul doute, par conséquent, que le néophyte du Phnom Sampau fût comparé aux Enfants-esprits. La montagne figurait le mont Méru et la Grotte de la Naissance, le pays des Jambosiers ${ }^{4}$. Le Grū dont se souvient le Vénérable Dor Ghen, qui indiquait le chemin au postulant, était le dieu rencontré par les enfants sous l'arbre Usokbhoktar'5. A l'intérieur du ventre tellurique le postulant s'identifiait au figuier à cinq branches (C1-7). Il devait maitriser les oiseaux Indriy (ses propres facultés) et s'emparer du globe de cristal contenu dans les fleurs et les fruits du figuier (C8). Cela signifie qu'il devait, à l'image d'un $b r \bar{a} y^{6}$, s'intégrer dans les modalités physiques du fœtus en gestation, qu'il devait, si l'on préfère, élaborer son nouveau corps à l'aide des agents initiaux : les dix-sept livres du Tipițak $(C 9,11,12,13)$, trois mères $(C 14,16,17,18)$ associées aux trois MA A U (G10) et Brạ̣ Kèv (C15). Ainsi, le crâne, les orbites, les yeux, le nez, les oreilles, la bouche $(\mathrm{C} 11,14,15)$, les quatre globes de cristal (C15), les dix doigts $(\mathrm{C} 12,13)$, les rotules gauches et droites, les chevilles, les dix orteils $(17,18)$ et les quatre éléments (C23) étaient créés. Le néophyte du Phnom était donc façonné une nouvelle fois et selon un langage familier, puisqu'on retrouve dans cette genèse les mêmes conventions adoptées par l'äcäry pour figurer, par exemple, le nouveau corps du défunt dans la cendre funéraire.

Ce passage à l'élaboration d'un composé physique nouveau calqué sur le schéma des organes et des fonctions naturels, conduisait-il le candidat à l'initiation aux valeurs de l'homme idéal, de l'homme total ? Les renseignements font défaut pour dire si la Grotte de la Naissance était aussi le cadre de cette sublimation mystique du sujet. En fait, l'existence d'une arithmétique de la transcendance est bien connue du Yogāvacar, mais elle n'est divulguée réellement qu'à un degré déjà élevé d'initiation, à celui qui a dominé dans les étapes précédentes. L'élaboration des sept caractères de l'Abhidhamm doit être acquise, par la respiration, c'est-à-dire sur la base de la formule MA A U (D1, 2). Cinq
(1) RBK. I, p. 76.
(2) RBK. I, p. 95.
(3) RBK. I, p. 75.
(4) RBK. I, p. 119.
(5) RBK. I, p. 80, 81, etc.
(6) RBK. I, p. 114. 
de ces caractères donnent NA MO BU DDHA YA, les cinq agrégats (D3, 4), et les deux autres, les dix-neuf voyelles indépendantes (D5). Il s'agit là d'une récapitulation ontogénique, puisque ce sont les agents des formations corporelles ${ }^{1}$ que les trois souffles engendrent dans ce premier temps. A l'aide des mérites et des démérites (D8), les trente-trois consonnes (les douze parties liquides et les vingt et un organes) sont ensuite produites (D7, 8, 9). De même, à l'aide des dix moralités (D6), le candidat doit-il avoir développé en lui les " 8 directions" (les huit sīmā qui protègent le corps) et les " 8 nobles moines" (les huit états supra-mondains). C'est à ce stade de son apprentissage que l'initié peut poser l'équation de son identification avec la nature des Trois Joyaux, selon les combinaisons de nombres et de lettres enseignées. Par la création mentale, il engendre alors les 108 qualités du Dhamma, du Bouddha et du Sangha dont il totalise en son être la plénitude mystique (D11, 12,13,14,15). On dit de lui qu'il a pénétré le mystère de la formule MA A U. Au moment de l'expulsion, le fidèle récitait enfin les trois lettres extérieures A RA HAṂ (A37 et supra, p. 239).

Dans un manuscrit provenant du Vat Phnom Sampau, il est expliqué que la réincarnation a lieu par le biais des trois lettres A VI JA (avijjja, l'ignorance) qui produisent les caractères MA A U. Au moment de la renaissance, un vent souffle si fort que deux caractères se perdent et qu'il ne reste que la lettre $U^{2}$. De même en est-il de la formule A RA HAM dont seul HAM subsiste. C'est le cri nasal du nouveau-né à la naissance : ham! ham! ham! On a vu qu'une fois sorti de la matrice "on cherche en vain à se rappeler les trois augustes lettres intérieures"(A37). Ceci est la cause du désarroi de l'enfant et provoque ses pleurs.

L'odyssée intestine de l'initié puis son expulsion par l'utérus de la montagne exprimaient donc plus qu'une simple régénération. L'épreuve dissipait le composé physique du néophyte et faisait revenir celui-ci, ainsi dépouillé, à l'état initial de son individualité conditionnée : le nāmarūpa ${ }^{3}$. A l'image du voyage initiatique des Enfants-esprits, le candidat s'engageait sur le chemin du "noble emplacement qui est le lieu où l'on demeure l'esprit heureux, où s'éteint principalement la soif du désir des objets sensuels " (A22). Or ce noble emplacement, dont l'accès implique rituellement la mort, est le monde utérin qui renferme les états supramondains ${ }^{4}$, le vestibule, si l'on peut dire, du Nibbāna.

Le but ultime de cette quête abyssale consistait donc, non pas en une nouvelle naissance, non pas dans la libération utérine d'un corps rénové, mais proprement à acquérir, à travers le mystère d'une initiation supérieure, les dispositions nécessaires à l'accession au séjour de la Grande Félicité, à prendre possession, en d'autres termes, d'un corps nouveau

(1) RBK. I, p. 126.

(2) TL $3 / 2-B$.

(3) RBK. I, p. 112.

(4) RBK. I, p. 121 
pour passer d'une existence mortelle à une existence divine. Les rites d'initiation qui avaient lieu dans la Grotte de la Naissance étaient donc vécus par le Yogāvacar comme le moyen de rompre le cycle des existences, comme la préparation, l'entraînement, à un niveau donné, à la vraie renaissance qui succède à la mort du fidèle : cette naissance qui ne provoque pas les cris affolés du re-né. 


\section{Postface}

Dans le courant du mois de février 1973 , une équipe de carriers à la recherche d'un banc de calcite - cristaux qui se vendent de plus en plus cher pour être mélangés au ciment - s'est discrètement introduite dans la Grotte de la Naissance. Mais, aveuglés par l'accumulation de la poussière, étouffés par la suie des torches de résine, les violateurs ont dû abandonner les lieux avant même de pouvoir réduire en fragments les masses grenues déjà extraites pour les évacuer par l'unique goulet d'accès.

Or cinq mois plus tard, le 21 juillet, un groupe de pèlerins s'engageait pieusement dans les décombres de l'auguste matrice. Comme si rien n'était, il contournait les effondrements de parois, reconstituait mentalement le "cordon placentaire " et le "bassin amniotique " disparus et récitait les formules de l'expulsion après s'être agenouillé dans le noir de suie pour méditer. La date du pèlerinage suivant était ensuite fixée à la sortie, comme tous les ans...

L'attitude est déconcertante mais caractéristique. Une telle détermination inconditionnelle, un tel détachement des contingences étonnent. Mais cette foncière indifférence du Khmer devant l'événement, cette distance à l'égard des faits, se retrouvent en toute occasion, à tous les niveaux de la vie quotidienne, et entrent pour une grande part dans la composition de cette personnalité si particulière, si déroutante.

L'année suivante, le pèlerinage prévu eut lieu en effet, le 20 juillet 1974. Ce fut le dernier d'une tradition immémoriale. On sait pourquoi : un an plus tard, un nouveau type de société rayait les vieilles structures. La liquidation totale de l'ensemble des faits religieux s'imposait impérativement afin d'éliminer toutes les formes anciennes de cohésion sociale.

Or si cette rigueur implacable, si cette insensibilité totale a été possible, c'est en partie à cause précisément de cette faculté d'abstraction peu commune, celle-là même, paradoxalement, qui a permis aux Khmers d'isoler et de conserver depuis des siècles, mieux qu'aucun de leurs voisins semble-t-il, les archaïsmes d'une pensée en complète contradiction avec la société moderne dans laquelle ils se sont installés, non sans indifférence il est vrai, en vivant sur deux plans, en vivant sans noter le décalage entre le monde extérieur et celui de leurs propres conceptions.

La compréhension de l'âme d'une société ne peut être séparée de celle des structures fondamentales qui déterminent l'essence de tout phénomène religieux. On doit renvoyer ici à l'apport psychanalytique qui fait ressortir l'importance du latent, du caché, dans l'étude des faits religieux, ainsi qu'au structuralisme qui montre qu'il faut atteindre la structure 
inconsciente, sous-jacente à chaque contenu, pour obtenir un principe d'interprétation, et l'intérêt, dans ce cas, d'un comparatisme situé hors du temps, au niveau des modèles déterminant les actions des hommes. Une société ne crée rien d'absolu : elle opère un choix dans les structures de la pensée humaine et c'est cette combinaison qui forge son unité inconsciente spécifique. Arrêtons-nous un instant sur les données encore récentes de ce bouleversement social profond.

Face à la liquidation radicale de l'ancien régime, mais en même temps de toutes les idées, opinions, notions et conceptions précédemment admises, face à l'annulation du vieil habitat rural et urbain ainsi que de la toponymie traditionnelle, l'observateur non partisan reste perplexe. Il raisonne en termes d'idéologie, de morale, d'économie ou de politique. Or cet exorcisme national, cette expurgation démesurée, "pour désinfecter le pays et assainir les habitants ", a manifestement sa source ailleurs. Il trouve une explication - la seule peut-être - au niveau de l'inconscient de l'individu, là où intervient ce mécanisme fondamental qui pousse instinctivement ce dernier à faire table rase d'une situation détériorée. On se trouve bel et bien devant un retour typique au néant des origines, fondé sur la conviction intime qu'on ne peut modifier un état sans l'abolir au préalable. Ce retour au chaos, qui correspond à une mort, est inconsciemment ressenti comme une régression à une modalité latente, pleine de ses virtualités intactes, et l'image perçue est solidaire d'une gestation qui prépare la naissance à une vie nouvelle.

La question n'est pas de discuter ici l'authenticité d'une telle entreprise appliquée indistinctement à l'ensemble d'un pays, dès lors qu'elle ne s'adresse plus à des candidats motivés et préparés. Les institutions traditionnelles étaient en correspondance si étroite avec le génie du peuple khmer qu'elles étaient ressenties et vécues depuis des siècles comme une nécessité biologique. Leur transmutation autoritaire dont aucune analyse ne peut masquer l'aberration, devait donc inévitablement prendre la forme tragique d'une extermination. Or l'examen de ce phénomène moderne montre qu'on a ressuscité d'anciennes images typiques d'initiation, tout en rejetant par définition les motifs propres aux croyances antérieures. A des degrés différents ces motifs font partie du conditionnement psycho-sociologique de l'homme, de ses rêves, de sa vie imaginaire. C'est sans doute pourquoi il est possible de ranimer des schémas archaïques d'initiation à l'intérieur d'un grand nombre d'expériences humaines. Au Cambodge, le scénario est cependant frappant : aux reflets de l'inconscient collectif, car il n'y a de vie symbolique que collective, s'est ajoutée avec force l'empreinte des thèmes du passé. Regardons les faits tels qu'ils sont. De l'attribution d'un nouveau nom, des souffrances prescrites qui rappellent les macérations rituelles, jusqu'au son lénifiant et conjuratoire des formules de Radio-Phnom Penh qui annoncent l'avènement d'un peuple régénéré, né de la Révolution, c'est proprement à une mort initiatique que les nouveaux maitres du Cambodge soumettent la nation. Le comportement des instructeurs est caractérisé par la détermination inconditionnelle, mais en même temps dépourvue de haine, c'est-à-dire purement objective, comme si l'aspect humain de 
la question n'entrait pas en ligne de compte, d'accomplir jusqu'à l'extrême les directives impersonnelles et absolues de l'Añgkār. A la suite d'une séparation dramatique, le rite de passage s'appuie sur un nouvel enseignement (rien sütr), voire une nouvelle mythologie, communiqués à l'aide d'un vocabulaire remanié. L'adoption de l'Aṅgkār, en tant que famille véritable, doit être accompagnée du rejet éprouvé des parents. La population est divisée en "initiés " et "novices", prajäjan et anuprajājan ${ }^{1}$.

Prasat (Thaïlande), février 1976.

(1) prajājan (pāli : pajā, génération, et jana, personne) est le nouveau terme pour désigner le peuple véritable, c'est-à-dire la partie de la population considérée comme acquise au nouveau régime ; anupra jājan (anu, petit, sous-, futur) s'applique à la partie restante de la population constituée par ceux qui ne sont pas sortis de la période de preparation et d'apprentissage au terme de laquelle seulement ils seront admis dans le camp des prajājan et acquerront le statut supérieur de citoyen accompli. 


\section{Appendice}

\section{TRANSLITTERATION}

La translittération des extraits traduits, comme des mots dans le texte, est donnée selon le procédé habituel (Au Chrieng, Notice sur les caractères étrangers, Imprimerie Nationale, Paris 1948). Les majuscules correspondent aux caractères écrits en $m u \bar{l}$. Le tilde $(\sim)$ placé sur la consonne $g h$ remplace le trisabd (RBK. I, p. 49). Les notes reprennent les graphies erronées qui rendent la lecture du texte difficile mais ne signalent pas les particularités orthographiques que l'on peut dire de l'époque.

\section{Extrait de TL443 (p. 224)}

(TL443/1-A) / namottassa / patthamam pindhukam duttīyam diname ${ }^{1}$ tattīyam bhettakā catutham an̉kasama pañcamam sirisam / rūpakhandho veddanākhandho sañākhandho sakhārakhandho viñānakhandho kusalā akusalā pubittoey neh en hoey rūp khan kmeñ ${ }^{2}$ brah lakkhaña braḥ dhamma bhattakāal ${ }^{3}$ nā kāl bvamm dān koet tīy koet dik koet bhloen koet khsal akās kālnoḥ en bān jā hov jhmoḥ hov braḥ dhammavīnsumñ ait kālnoḥ grā noḥ sọ̣ sūn jhīn loh tal brạ kev dibv srot lok dran ñān nimit loen mak ambiy dis e koet mak pros tịy dik bhloen khsal ākās prakā tūcnoh pān jār is manuss phan dāṃn hlāy hov thā e koet 2 noḥ en hon pūbittoey ait kalnoḥ brah kèv dibv srot lok nimit jhān mak thit nūv kantāl cakravāl vīnsumn jaṃbuov dhvip neh hoey lok pañcañ nūv chabvānd ${ }^{4}$ rānsì rāksmiy dāmn் 8 hmoen ku nimitth jā pālāmnn ${ }^{5}$ bej kambuh 700 yoj doebv gun sammarthit ${ }^{6}$ loen loer pālāṃn tāmnn smādhiy jham brah bhat? dov dis e koet jā duor brah dharmm hoey koet kpāl brah dharmm (1-B) țaiy brah dharmm joen brah dharmm trajiek braḥ dharmm grupv dāṃn 8 duor brạ̣ dharmm e thpūn kpāl brah dharmm duor dāmnn 5 gĩ na mo bu ddhā ya e lec țaiy braḥ dharmm

(1) Les autres versions donnent également : diname (le jour?), ou dinape, opè, opeti. TL 40/ka-A donne dandhuvaca. Le Grū Suon Chun, à qui appartient ce document, lit dandam eva $c a$, parce que la seconde phase de la création consiste en l'allongement du bindu qui prend ainsi la forme d'un bâton, d'une hampe, et figure le premier trait du yantra primordial. Sur cette lecture, voir le ms. de la Bibliothèque Nationale no 290/B-1, provenant justement de la Collection Adh. Leclère (Au Chhieng, Catalogue du fonds khmer, Paris 1953, p. 239).

(2) (?) sauté dans les autres versions.
(3) bhaddakamm.
(4) chabvann.
(5) pallang.
(6) saṇthit.
(7) bhaktr. 
dāṃn 3 gīr ma a u e joeń joen̉ braḥ dharmm duor dāṃn 7 gīr ku sa lā a ku sa lā e koet duor braḥ dharmm tèr 1 isān bhnek stāmm brah̆ dharmm duor 2 gi a $\bar{a}$ agner bhnek chven brah dharmm duor 2 gi u $\overline{\bar{u}}$ bāyābv traciek chvien brah dharmm duor 2 gi e o nitīy traciek stām brah dharmm duor dāṃn 2 gi î i hoey brah kev lok git treḥ rị biccāraṇār knan் brah an lok thā dharmm e ṇār nin pros tĩy dik bhloen khsal akās neh bān doebv drañ dibvañān nūv braḥ dharmm tèl lok sanamat jhmoḥ hov brah bud gun doebv dür ${ }^{1}$ brah budd gun lok yak nūv dü ${ }^{1}$ thpū brah dharmm dāṃn 5 brạ̣ an doebv mak tāṃn smādhdhiy bicāraṇār koet loeñ pān jā tūc avijār dāmnn 5 braḥ an doebv lok tāṃn smādhiy duor brah dharmm 2 gi na ma ka mak biycārnār koet loen jā me tiy me dik doebv kic apijāa pphāt pamūl me tiy me dik tèr 1 jamdās ralās kracak kä dhvoer me tiy me dik loeñ pān jā mūy ray gūn (2-A) 1 bvān gun 1 hmoen gun 1 sèn gun nin gunnār trās ${ }^{3}$ rāp bvam bān loey hoey doebv brah budd gun lok tāmnn smārdhdhiy ${ }^{4}$ nūv dư braḥ dharmm dāmn் 3 gì bu ddhā ya ka koet loeñ jā mer bhloeñ me khsal me ākāss braḥ dharmm dāṃn 10 duor lok bicārraṇārr lam it ka koet jā k-èl brah̆ dharmm pān jā ang parass pruh mūy kä bvam ceh sratīy bvam ceh moel bvam ceh tin Ịar bvam mān viñān der mān tèr rūp hon / loḥ tèr brah bud gun lok tămñ smădhiy bhnek brah dharmm traciek braḥ dharmm dāmñ 8 dūr gi a $\bar{a}$ i $\bar{i}$ u u e o neh en bicārṇārr git loen pān jā ang braḥ sammârapād doebv rūp an nọ̣ en mān viñān bhnek ceh moel traciek ceh Ṭa taiy joen ceh kaṃroek pān rūp 1 noh mān terr sramol jā biy anak noh bvam tin khluon loey loh țal rūp noh en ceh soy phal nūv bvam dān cèh sratīy tal yūr pāntic rūp noh cẹ̣ soy laṃbun ākās nin pros parass satv damn் hloey jā e kroy viñ hợ

\section{Extrait de TL133 (p. 241) - A}

(TL133-I/koe-A) pabittoey ${ }^{5}$ nin saṃțèn ta dov diet ūy pān țin țammnoer brah dharmm dāmnn 4 pad noḥ hov jhmoh thā braḥ sūt 1 (koe-B) braḥ vinaiy 1 brah abbhidhamm 1 brah dhammasitthanisidann ${ }^{7} 1$ braḥ dhamm dāṃn 4 neḥ lok mak pan̉koet ja akkharā 4 neh gị / na ma ba da / neh en tè̀ nūv knun rūp kāy yoen neh lok ũy sgāl doebv beñ añg parapūr(ṇ) ${ }^{8}$ gị na dhātu dik / ma dhātu tì / ba dhātu bhloeñ / da dhātu khsal neḥ hov tām brạ̣ pandal ${ }^{9}$ dak mak ūy sgāl tuor dhātu dāṃn 4 noh tuor na neh dhātu khyal lok hov thā khyal dik / tuor ma dhātu dik lok hov thã dik tịy / tuor 1 dhātu tịy lok hov thā țîy bhloen / tuor da dhātu bhloen lok hov thā bhloen khyal lok thā kuṃ ūy chñal / thã poer chñal hoey neḥ vā chñāy sati nūv knử kāy bhāvanā ūy tịn braḥ dhamm tèl lok pañkoet tuor neh gị brah sūt 1 brạ̣ vinai 1 braḥ abbhidhamm 1 brah dhammasidanisidann 1 dāṃn 4 ang neh gị braḥ abbhidhamm / (kie-A) lok mak pańkoet tuor na brah vinai lok mak pankoet tuor ma brah sūt lok mak pankkoet tuor ba braḥ dhammasidanisidann

(1) tuo.

(6) țamṇoer.
(2) kicc avijjā. (7) dhammasitanisīdana.
(3) gụ̣ nātrā. (8) paripū(n).
(4) samādhi. (9) pandūl.
(5) pabitr oey. 
lok mak pankkoet tuor da neh hon / brah ang saṃtèn ${ }^{1}$ duk mak ūy pān țin toem / kummmoet ${ }^{2}$ manuss satv phà dāṃn hlāy ${ }^{3}$ kāl lok mak koet rūp kāy yoen neh gị braḥ sūt 1 brạ̣ vinaiy 1 brạ̣ abbhidhamm 1 braḥ dhammasidanisidann 1 dāmnn 4 ang neh / gị tuor na lok mak pankoet tuon jivit 1 khyal 1 viñān 1 citt 1 / tuor ma lok mak pankoet dik 1 jhām 1 khlāñ 1 khuor 1 sammpor 1 pamăt ${ }^{5} 1$ / tuor ba lok mak pankoet sec 1 ch-in 1 sasaiy 1 boḥ vien ddhamm 1 boh vien tuc 1 thloem 1 pèh tūn 1 / tuor da lok mak pankoet spèk 1 sak 1 rom 1 / e tuor da neh lok mak ghumm ūy jumm jạp an̉g dāṃn 3 (kie-B) neḥ hon e ańg dāṃn 3 neh gị brah abbhidhamm 1 brah vinaiy 1 braḥ sūt 1 noḥ mān khsèr can grup añg trai dāmñ 3 noh añsak gị jâ khsèr can abbhidhamm / vaḍhabandh ${ }^{6}$ drūn gị jā khsèr can brah vinay vaḍhabandh cankès gị jā khsèr can brah sūt e braḥ dhammasidanisidann noh lok jā me ghum trai dāmñ 3 neh lok tèn can trai cīvar noḥ doebv braḥ ang saṃtèn duk ūy tịn thā knuñ rūp kāy yoen neh mān khandh / noḥ 4 khandh neḥ lok pankoet jā khandh / knun rūp knuñ ang yoeñ neḥ gi brạ̣ dhammasidanisidann 1 brạ abbhidhamm khandh 1 braḥ vinaiy khandh 1 brah sūt khandh 1 nin samtèn knun khandh noh diet / brah dhammasidanasidann lok mak pankoet bī kpal țal dov kar neh hov thā khandh 1 brah abbhidhamm lok mak pańkoet bī kar dov țal toem drūn / (ke-A) noh hov thā khandh 1 brah vinaiy lok mak pankkoet bī toem drū no dov tal phcit neh hov thā khandh 1 brah süt lok mak pankoet bì phcit dov țal dhvār ddhamm nẹ̣ hov thā khandh 1 neh hov thā khandh dāṃn $\dot{4}$ / İlūvnèh nin samțèn duk țāk rapass ūy sgăl knuñ pacūvekkh patikūlp

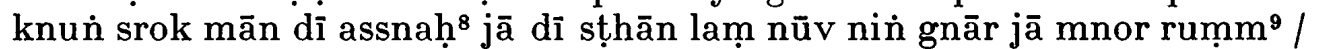
saṃrāk kāmmmmagun tạnhā jā mun noḥ pān jā braḥ ang saṃṭèn duk mak yak tè jā hètu pān tic 2 mak samțèn ūy pān țin kāl kic knun mūl braḥ jān duk mak noḥ gị kāl țoem țèl pān ruom dì samman ann kar ${ }^{10}$ nin gnār noḥ mān tuor sa neh pan̉koet jā tuor u neḥ doebv hov jā dik taṇhā ūy sgāl rūp bā $(r)^{11}$ saṃmpor riddhī dik noh e dik noḥ mūl pan khnàn sankkoec mān bā(r) tūic/(ke-B) bhnek knok sammpor noḥ sar țūc tpūn kèr sar sit ${ }^{12}$ nūv loer sloek jhūk mān kaṃläṃn riddhì noḥ p̈un kpāl ruy nūv krom carik mahā brahm țūc thā ${ }^{13}$ kra bat dĩ noḥ jā kāṃmmagun țèl pān ruom sammhan andhakar nin gnār hoey mān ang 3 lok mak pankkoet ūy sgāl tuor na neh lok mak pan̉koet toem kar jā toem / tuor ka neh lok mak pankoet toem drūin jā toem/tuor a lok mak pankkoet pañcasākhär dāmnn 5 duk nūv tèr knuñ an் / tuor na mūy neh doebv lok añg tuor na neḥ lok mak pankoet jā tuor ang 3 diet duk ūy nām satv phan் dāṃn hlāy mān tuor akkharāan thā / araham tuor dāmñ 3 neh lok duk ūy saparass ${ }^{14}$ prus srī manuss satv phan dāṃn hlāy parikāmmm bhāvanā dov kānd ${ }^{15}$ sțhān dīy brặ parammmasukkh ${ }^{16}$ pabit lok dāmń buońnoey kāl țèl niǹ nāmm / (kè-Ả) rūp mak noḥ mān ang akkhar̆à thā țūcnèh / na ka aṃn / nẹ̣ en țèl pān cūl mak jă sam-

(1) saṃṭèn.

(6) vatthabandh.

(10) smandha andhakara.

(15) kān'.

(16) paramasukh $\begin{array}{lll}\text { (2) toem kamṇoet. } & \text { (3) lāy. }\end{array}$

(7) pațikūlapaccavekkhana.

(11) barn. (12) kesar sit.

(4) sambor.

(8) āsana.

(13) than.
(5) pramāt'.

(9) manoramya.

(14) sappuras. 
maṇa ${ }^{1}$ raksā trai jîvar ūy țin ūy sgāl pacūvekkh paṭikūl jā dī ākrak jā dî l-ar hoey nin kānd dī āssna knun krov țūc gnār tẹl pān cūl mak raksā gun noḥ ùy țin rapass khān knun nin kānd īilyā path țūc jā brạ̣ ang mān / braḥ pandal desnār duk mak nẹ̣ khān krov nin khān knun țūc gnā dāṃn as poer nin daduol pacaiyy dān dāyuk ${ }^{2}$ noḥ ūy mān grup grān / parikkhār trai jīvar țūc jā nūv knuñ ūdar / braḥ mātā noh doebv trūv tām toy nūv ganlan̉ brah vinai noḥ hon / pabit lok dāṃn buoṅnoey / nin saṃtèn kāl nūv knun sṭhān kuttarà gị phdai mtāy 10 khèr nuḥ anguy nūv loer dan suk braḥ mātār ben pañjhar jangan kānd dan suk braḥ mātār hoey dhmec nettrār ${ }^{3}$ / (kè-B) māt bhāvanā braḥ akkhä̀ā tuor neḥ / na ka aṃn / kāl țèl nin prasūt ceñ mak neh sanlap vañven bhlec pāt smārtī nin rak an̉g brah akkhar̆ā dāmnn 3 noḥ ka bum pān ghoeñ viñ loey hoey pān jā brah ang desnā dunmān ${ }^{4}$ ūy pranīpatti ${ }^{5}$ bhāvanā rak ang / brạ̣ akkhar̈ā khān krov neḥ/ araham / nẹ̣ jā rapass khān krov ūy pranīpatti bhāvanā / tūc kāl nūv knun ūdar noḥ èn lok ūy ben ${ }^{6}$ joen țāk țai stāmm loer țai chven hoey ūy bhāvanār tuor brah / araham / neh họ / dọ pị nin் daduol pacūvekkh can hān ktĩ ũy dhvoer īiȳār țūc nūv knun ùdar noh en thā poer nin daduol atth parikkhār ${ }^{7}$ ūy mān trai grup grien assnah tūc nūv knun sthān kuttara phdai mtāy noḥ doebv trūv tām braḥ pandul desnār duk mak hơ kāl nūv knun sṭhān kuttara phdai mtāy noḥ (kai-A) mān grup grien mān bāri ${ }^{8}$ saṃmpor jhām noḥ kraham țūc kancan lākkh ${ }^{9}$ ka mān grup grien dāṃn as thā poer griè noḥ bự mān grup nūv knun sṭhān kuttars phdai mtāy noh ka rūp kāy yoeñ neḥ nin antarāy koet hloen bum pān loey / pabit lok dāmnn buonnnoey thà poer cūl mak dhvoer jā samaṇa raksār sil / sikkhār pad neḥ poer bụ̣ mān grien grup dāmnn 7 prakār noḥ anak raksār sil raksār gun noḥ sil guṇ noḥ nin antariày bum mān nūv loey îlūvnèh nin samtèn khāं kn nun ta dov viñ diet gị spà̀ vadhabandh cañkès 1 jïbar 1 vadhabandh drūn 1 samghațịio 1 an̉sak 1 braḥ krāp 1 neh grieñ dāṃn 7 prakār neh hon / ūy țin ūy sgāl jā rapass khāñ knun gi vaḍhabandh cańkès noḥ eñ jā dà phcit vaḍhabandh drūn noḥ jā kanduy lin ansāk neḥ jā dan suk / (kai-B) braḥ mātār braḥ krāp noḥ gị k-am dik bhloḥ koet jhām pantic saṃghatī noḥ jā srom sammmpuk khluon jībar noḥ ja srom dan suk span noḥ jā ghlā̀n $\operatorname{lmak}^{11}$ kăl khluon nūv knuñ ūdar braḥ va ${ }^{12}$ mātār e dik bhloḥ noḥ nūv loer kpāl tèn nin sroc sammrak / dov loer rūp kāy yoeñ neḥ hoǹ / thā poer bum mān dik srak sroc dov loer khluon yoeń neḥ ka yoen் bum mān jīvit ras loey hètu noḥ en hoey pān jā ūy țin dāṃn knun dāṃn krov nin pān kānd îriȳa pad ūy trūv tām kum națth ${ }^{13}$ knun krov țūc gnār e bāri saṃmpūr(ṇ) kraham țūc kancan jhām mān tèr bāri mūy neh en thā poer mān bāri e diet mak lāy bum țèl nin koet jā rūp pān loey e sil sikkhār sot thā poer raksār bum trim trūv nin ralāy tụuc rūp añg noḥ hon /

$\begin{array}{lllll}\text { (1) samaṇa. (2) paccayadān dāyak. (3) netrā. (4) dūnmān. } & \text { (5) pratipatti. }\end{array}$ $\begin{array}{lllll}\text { (6) bèn. (7) atțhaparikkhär. } & \text { (8) barṇ. } & \text { (9) kañcan̉ lakt. } & \text { (10) sanghāțī. }\end{array}$

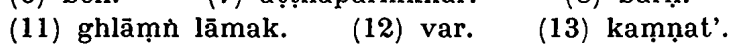


Extrait de TL235 (p. 247) - В

(TL 235/kka 34-A) / a ā i $\bar{i}$ u ù r ṛ l I e ai o au am ah / ūy bhāvanā nau aks dāṃn 16 neh jā kuṃrup 10 khèr hoey doebv braḥ mahā pațthān thā hèy anakkoey tal anak ceñ cāk nau ūdar mtāy hoey țal dhvā mas noḥ mān cau mār dāṃn 6 cāmmm nau dhvā mās mtāy noḥ ka ũy anak bhāvanā kum ūy bhlec nau braḥ gātthā dāṃn 16 duor noḥ loey / (kka 34-B) hoey anak kum bhit kuṃ khlāc loey rīy kūn noh bān stāp Ị cāṃm tauy nau brạ̣ gātthā țèl braḥ mahā patthān phtāmm prațau noh kūv cāmm srec hoey anak anguy phtut bhnen ben joen loek dāmnn tīy praṇammm bhāvanā loḥ țal 10 khèr doebv brah sūt kūn noḥ cāk ùdar mtāy mak hon / rīy e țanhoem kūn noḥ vā phut nau mūy rambej kālnoḥ hon neh hau brặ sūt dāmnn 5 kāmmbị hoñ rīy kāl nau knàn phdai mtāy kūn noh mān tảnhoem tè ambīy smoe phcīt (ka 35-A) dau țal knañ cramoh hon் neh hau brah vinaiy dāmnn 5 kāmmbịiy noḥ hon / passāsa neḥ hau khyal cūl knañ cramoḥ hon / assāsa neh hau khyal ciñ krov cramoh hon / nissāsa neḥ hau khyal brạ̣ abbhidhammi dāmnn 7 kāmmmbī gī khyal nìn nau knan் bun boḥ dim nau phcit noḥ hon / thā boer nin bhāvanā gātthā avī 2 noḥ ūy cùl nīrodh sam̄mā puggul noḥ hon doebv ūy nīmun nau braḥ arīyasağh dāmnn 8 brạ ang / (ka 35-B) gĩ assāsa braḥ satr dāmnn 8 kāmmmbīy gī khyal ceñ noḥ ūy srup khyal cūl mak knan cramoḥ doebv hau nìmun brah arīyasağh dāmn 8 brạ̣ ang hon riy khyal nai knan cramoh mak țal țoem ka noh hau khyal brạ̣ vinaiy dāmnn 5 kāmmmbì jhmoḥ brạ̣ srauttamagg hon / rīy khyal cuh mak bīy toem ka țal cun țanhoem gị braḥ sukkhidagamagg hờ / rīy khyal bìy cun tan்hoem mak tal phcit neh hau khyal brah añāgāmag hon / rīy khyal cuḥ bī phcit dau ța (ki36-A) l kanlās nin nau bụ ūy ceñ cūl gị khyal brạ arahattamag cūl nïrodh sammāmagi hon / uy tāmnn nau smātīy ūy l-it nin nau tūc kāl nau knañ phdai mtāy noḥ hờ / kum ūy khyal ceñ cūl bān loey boe dhvoer țūc nau pangāp' nẹ̣ hoey gị nīmunt brah arīyasag̃h dāṃn 8 braḥ ang gị cūl nīrodh sammā$\operatorname{mag}^{1}$ hon mān $^{2}$ knàn mag dāṃn $\dot{8}$ hon / rỉy khyal ambīy cramoḥ cuḥ mak țal toem ka bhāvanā l-it pān yal brah rāksmīy (ki36-B) țūc nau ambil ambèk neḥ hau bān phal luḥ țal srotār hon / rīy khyal cụ̣ mak ambiry țoem ka tau țal cun tan்hoem bhävanā l-it nau bān yal brạ̣ rāksmīy tuc phkāy brik noh hov bān phal luh sukkhīdagamag hon / rīy khyal bīy cun tan்oem cuḥ mak țal phcit bhāvanā l-it nau bān yal braḥ rāksmīy tūc nau braḥ cand beñ puramīy neḥ hov bān phal luḥ tal anāgāmag hon / rīy khyal bīy phcit cuh mak țal kanlās bhāvanā l-it dau bān yal (ki 37-A) braḥ rāksmī tūc nau braḥ adit ūdai hoey/neḥ hau bān phal luh țal arahattamag hon / neh cūl nïrodh sammāmag hon / rīy cit nīrodh sammāpatti noh țanhoem ceñ bīy kanläs mak țal phcit bhāvanā l-it nau bān yal braḥ rāksmì smoe sèn sūrīyā run roeñ tūc brạ̣ adit braḥ cand hon் rīy tan்hoem ceñ bīy phcit mak țal cuñ țan̉hoem
(1) samāpatti.
(2) bān? 
bhāvanā l-it nau bān yal braḥ candtariā ka noḥ hon / rīy tan̉hoem ceñ bīy cun ța (ki 37-B) ṅhoem mak țal țoem kar bhāvanā l-it nau bān yal braḥ rāksmī tūc sèn sūrīyā braḥ adit braḥ candțarā ka phan dāṃn hlāy koet bhloeh loè bron brāy chluḥ yal grup dhvā dāṃn 10 chluḥ yal tal bān nībān prakațțh run roeñ beg hon rīy țanhoem bīy toem ka mak talal tanhhoem ${ }^{1}$ kbāl noḥ bhāvanā l-it nau bān yal brah rāksmì boek nībān noh họ / hoey sammtèn noḥ cit ūy mūl sañrūm ūy l-a appamā pīy țūc nau pun sak anak (ku38-A) āmāragoyāni dhvīp noḥ hon / doebv cit noḥ bān rūc cūl nībān jā sṭhān parammmmsuk khsèm khsān prasoeț̣̂h begy hon /

\section{Extrait de TL12 (p. 249) - C}

(TL12/ga-B) e toem lvār gī khluon jā țoemm e mèk gī țaiy bīy joeñ bī jā mèk e slik gì traciek jā slik dāṃn bīy e phkār lvār gĩ dan suk jā phkār e phlèh giḥ kūn nau knun boh noḥ jā phlèr e ṛas gīh svāḥ dāṃn bīy jā ṛas kèv dāmnn bīy jă toem (gha-A) jā būj jā toem gī dik kèv dāṃn bī hūr cūl mak ka koet jā sṭhān kumbèn kèv dāṃn 7 jānd pit pāṃn rāṃn jit bam mān anak eṇā dau ghoeñ loey e țuon kèv gĩ bhnèk dāṃn bìy tuon brạ dhamm pramātth tuoñ kèv 1 peḥ țūn țūn ${ }^{2}$ kèv 1 kūn knun boh gĩ tuoñ kèv 1 noh gĩ tuoñ kèv dāmñ 4 / doebv brah kammațțhān mak phtāṃm nān citakumārīy nān citakumāịā dāṃn bĩ ūy mak rak tuon kèv knun phkā lvā phlèv lvār dāṃn 4 poe pān ghoeñ hoey nin poek ceñ bì dvā dāṃn 8 jānd' tejah anak tèl pān țuon kèv noh / ma a u / ma duor brạ̣ abbhỉdhamm dāṃn 7 kambī a braḥ sūtt dāṃn 5 kambì u braḥ vinaiy dāmñ 5 kambī / ma / mak pankoet jā kpāl e loeh jā nibvān / a / (gha-B) mak pañkoet jā kpāl cangañ stāmm / u / mak pańkoet jā kpāl cangaǹ chven் / e brạ̣ abbhidhamm dāṃn 7 gī bhnèk bì cramuḥ bī traciek bī mâtth' 1 / neḥ hau braḥ abbhidhamm dāmñ 7 e brah abbhidhamm gī mātth' jā brah abbhīdhamm e brah sūtt dāṃnn 5 gī mrām tai tāṃn 5 e braḥ vīnai dāṃn 5 gī mrām tai chven dāṃn 5 doebv mān mtay mak pańkoet ammpen mūy pandāh doebv mtāy mūy vĩñ diet yak ammmeñ mūy pandāḥ / doebv mān mtāy yak ammmpen mūy pandāh mak pān jā pī pandāh ūy mak phgammm ${ }^{3}$ gnā pān jā kpāl mūy / doebv brah kev mak vań bhnèk bĩ pandāḥ mak pańkoet jā prasrī ${ }^{4}$ kèv dāṃn 4 gì krahamm 1 khmau 1 sa 1 loeuñ 1 mān rākkhsmīy bhlīh ran' roen moel chluh (n்-A) dau suorg narakkh doebv mtāy dāṃn bīy anak mak jam gnār thā pān mak pan̉koet e loer hoey doebv mak pan̉koet e krom hau cangan stāmm / doebv mak pańkoet bhnèk go dāmnn 2 khān stāmnn mak pan̉koet ammrām dạ̣n 5 ūy rākkhsār khān் stām hau mtāy mūy / doebv mak pankoet kpāl cangan் khān chven mak pankoet ammrām joen dāṃn 5 mak pankoet bhnèk go dāṃn bīy ūy rākkhsār khān chveñ hau mtāy mūy mtāy dāṃn pìy neḥ mān gun dhñun hnās / doebv mak saṃmten e dhatu dāṃn 4 gĩ braḥ kèv mak pan̉koet dik hūr mak bī nībvān / doebv brạ̣ kèv mak
(1) pañhoey.
(2) țuon.
(3) phgum.
(4) braḥ srì. 
pańkoet jā tīy nau sṭhan kantāl/doebv brạ̣ kèv mak pan̉koet jā bhloen dāṃn 6 (na-B) doebv brah kèv suogi mak pankoet jā catu bhut dāmnn 4 ūy rākkhsā nagakāy dāṃn is

Extrait de TK176 (p. 251) - D

(TK176/B-17) MA pasvāt A asvāt U nisvāt / duor dāmnn 3 neh mak pankoet jā / SAM VI DDHĀ PU KA YA PA / SAM pan̉koet jā NA / VI pankkoet pañ jā MO / PU pańkoet jā BU / KA pańkoet pān jā DDHĀ / PA pańkoet jā YA / aksar dāṃn 5 nèh mak pañkoet pān jā / NA MO BU DDHĀ YA / jhmoḥ pañcakhan dāmnn 5 / sal aksar DDHĀ YA / nèh mak pańkoet pān jā / Si DDHAṂ A Ā I I U O R R L L E AI O AU AM ĀṂ AḤ / cèk pān dau sil 10 / dau dīy ${ }^{1}$ dāmñ 8 nau arīyasağh dāṃn 8 / doebv yak'/SAM VI DDHĀ PU KA YA PA/mak phsamm niñ / NA MO BU DDHĀ YA / pān jā 12 neh duk jā gun mtāy 12 / doebv yak kusal nin akusal mak phsamm nin SI DDHAṂ tal ccapp dau trūv jā 21 neh duk jā gun ābuk 21 / pūk gun mtāy nin ābuk jāmũy phan gnār trūv jā 33 nèh hauv ākār dāmnn 33 hon à āār dāṃn 33 mak pankoet jā manuss phan் (B-19) dāṃn hlāy noḥ doebv yak ākār dāmnn 33 mak phsaṃm niǹ rūppakānd dāmnn $4^{2}$ trūv jā gun brah dharmm 38 nèh gị ang brah dharmm en doebv yak/NA MO BU DDHĀ YA / nèh gun mtāy $12 \mathrm{MO}$ gun ābuk $21 \mathrm{BUT}^{3} 6$ gun sdec DDHĀ 7 gun ñāt YA 10 gun grūv āccār trūv pañcakhand dāṃn 5 hoey pampè jā gun brah but 56 / nèh gị ang brah but en yak PASV̈ĀT ASVĀT NISVĀT dāmn் 3 neh pancūl nin / SAṂ VI DDHĀ PU KA YA PA / nau ddhātu dāṃn 4 gị / NA MA A U / neḥ trūv jā gun braḥ sag̃h 14 / nèh gị añg brạ̣ sağh en் / puk dāṃn as' trüv jā 108 neḥ nau knun khluon yoen hon hèt tūcneh ūy is kulaput paggal jun phan dāṃn hlăy ūy bīcāraṇā ūy ghoeñ sgāl jāk prakațțh hơ /
(1) dis (TK $459 / \mathrm{B}-13)$
(2) 5 (TK 459/B-15).
(3) BU (TK 459/B-15). 


\section{ORIGINE DES MANUSCRITS UTILISÉS}

Pour éviter la confusion, les noms propres sont reproduits selon la transcription de l'époque du protectorat dont l'usage a été conservé par la suite.

\section{Cambodge :}

TL3 Vat Sampau, Phnom Sampau, Khèt Battambang.

TL12 Vat Tuol Tampong, Sanghat no 7, Khan Daun Penh, Reach Theani Phnom Penh.

TL14 Vat Chrouy Ampil Chas, Khum Kbal Kaoh, Srok Kien Svay, Khèt Kândal.

TK20 Grū Hin, Vat Prâthéat, Khum Rôluos, Srok Kândal Stung, Khèt Kândal.

TL40 Vat Kien Svay Krâo, Khum Dei Eth, Srok Kien Svay, Khèt Kândal.

TL53 Vat Stung Mean Ghey, Khum Dâng Kâo, Srok Phnom Penh, Khèt Kândal.

TL76 Phum Krâng Thnung, Khum Krâng Thnung, Srok Phnom Penh, Khèt Kândal.

TL90 Vat Khmuonh, Khum Khmuonh, Srok Phnom Penh, Khèt Kândal.

TL119 Phum Kaôh Prak, Khum Phum Thom, Srok Kien Svay, Khèt Kândal.

TL133 Vat Kdol, Khum Svay Paô, Srok Sangkê, Khèt Battambang.

TL168 Luk Tâ Gnem, Kilomètre $n^{\circ}$ 6, Reach Theani Phnom Penh.

TK176 Vat Krapoe Ha, Khum Ta Kmau, Srok Kandal Stung, Khèt Kândal.

TL191 Vat Kien Khleang, Sangkat no 19, Khan Chrouy Changvar, Reach Theani Phnom Penh.

TL210 Vat Svay Chrum, Khum Svay Chrum, Srok Khsach Kândal, Khèt Kândal.

TL222 Vat Prèk Samrong, Khum Ta Kmau, Srok Kândal Stung, Khèt Kândal.

TL235 Vat Prêk Thloeng, Khum Prêk Kâmpoes, Srok Kândal Stung, Khèt Kândal.

TL247 Vat Bô, Khum Siemreap, Srok Siemreap, Khèt Siemreap. 
TK257 Vat Ent Kossei, Khum Siemreap, Srok Siemreap, Khèt Siemreap.

TL272 Vat Ghak, Khum Siemreap, Srok Siemreap, Khèt Siemreap.

TC302 Ācāry Din, Phum Samraông Téav, Khum Krâng Thnung, Srok Phnom Penh, Khèt Kândal.

TL370 Vat Ta Phem, Khum Kambol, Srok Ang Snuol, Khèt Kândal.

TL413 Vat Châk, Khum Siemreap, Srok Siemreap, Khèt Siemreap.

TL422 Vat Prin, Khum Chreav, Srok Chreav, Khèt Siemreap.

TL437 Vat Tronum Chroeung, Khum Boeg Thom, Srok Ang Snuol, Khèt Kândal.

TL443 Vat Kompong Phlouk, Khum Kompong Phlouk, Srok Sot Nikum, Khèt Siemreap.

TL445 Vat Sangker, Khum Svay Pao, Srok Sangker, Khèt Battambang.

TK459 Lok tā Um Yok, Grand-devin du Palais Royal, Phom Penh.

TL461 Phum Kok Khsach, Khum Phloeung Chheh Roteh, Srok Phnom Penh, Khèt Kândal.

Thaïlande :

TL467 Vat Pao Samkha, Ampoeu Sam Kampheng, Changvat Chiang Mai. 


\section{INDEX}

A $\bar{A}, 225$.

Abhidhamm, 241, 241 n. 3, 242, 250, 255; vent de l'-, 247, 253, 254.

äcāry, 227, 233, 234, 235, 237, 238, 253, 255. agrégats : les cinq $-, 225,227$.

amnion, 246, 246 n. 6.

Ańgkār, 260.

anuprajājan, 260.

anus, $243,254$.

Aparagoyana, 249

A RA HAM, 238, 239, 240, 244, 245, 245 n. 3, 253.

Arahant, 227, 255.

arbre : - du Dhamma, 254 ; - Usokbhoktar, 255.

āsana, $243 \mathrm{n} .7,245 \mathrm{n} .1$.

assāsa, 247, 253, 254.

asvāt, voir assãsa.

bandit : les $6-, 247$; les $500-, 247$ n. 5 . base de la langue, $243 \mathrm{n}$. 3 .

bassin amniotique, 238, 240, 258.

Bareau, A., 242 n. 2.

bile, 242.

bouche, 250, 255 .

Bouddha, 227, 234, 235, 240, 256 ; parole

du -, 243 n. 9 ; les vertus du -, 252.

Bouddhaghosa, 249 n. 6.

bourse, 244.

Buddhagun, 225, 226.

BU DDHĀ YA, 226.

Brah Kèv, 225, 226, 227, 251, 255.

branche, 250 ; les cinq -, 244.

bras, 225, 226, 250.

brāy, 255.

caillot de sang, 224 .

calcite, 238, 253.

canon pāli, 224.

ceinture : - de poitrine, 243,246 ; - - de taille, 243, 246.

cendre funéraire, 255.

cent huit, 252, 256.

centres vitaux : les quatre -, 243 n. 3.

chair, 242.

Chao, Vén., 231, 232.

chemin : - de gauche, 234 ; - de droite, 234 ; - de la naissance, 244 ; les quatre $-, 248,254$. cerveau, 242.

cheveux, 242, 249.

chevilles, 251, 255.

citadelle du corps, 251.

Cittakumārā Cittakumārī, 227, 228, 250.

coccyx, 243 n. $3,248,254$.

cœur, 242, 250.

conscience, 242 .

cordon (attache) : les trois - , 242, 243.

cordon ombilical, 246, 246 n. 1, 250.

cordon placentaire, 235, 238, 240, 245, 246,

246 n. 3, 253, 258.

cou, 240, 243, 244, 248, 254.

cou-poitrine, 243.

cou-sternum, 248.

couleur, 242 ; - des vêtements, 247,247 n. 3 .

crâne, $250,255$.

création, $224,227$.

création mentale, 247.

DDHA YA, 252.

dent : - du fœtus, 246 n. 2.

Dhamma, 225, 226, 227, 228 ; -- personniflé, 224,226 ; les vertus du -, 252.

Dhammajhān, 224, 226 n. 8, 243 n. 8, 243 n. 9.

Dhammasit, 241, 241 n. 3, 242, 243, 242 n. 1.

Dhammatrāy, 241 n. 2.

Dhammaviñsun, 224, 226, 243 n. 8.

directions : les huit -, 252, 256.

doigts de la main, 250, 255.

Dor Ghen, 231, 232, 234, 255.

Duong Set, 231 .

eau , 225, 226, 242, 251 ; les --(amniotiques), 246,253 ; voir semence.

écharpe, 243, 246.

élément : les cinq —, 225, 226 ; les quatre $241,242,251,253,255$.

Éliade, M., 228, 228 n. 3, 233 n. 1.

embryon, 227, 238, 241, 250, 253.

emplacement : le noble -, 243, 244, 245,

253,256 ; 一 intérieur, 245 n. 1.

enceinte : les sept -, 228, 250, 255.

enfant (l') dans le ventre, 254; - = fruit du figuier, 250.

Enfants-esprits, 250, 255, 256.

E O, 225.

épiglotte, 240 .

esprit, 228, 242. 
éther, 225, 226.

étoile, 249, 255 ; - du matin, 248, 255.

étole, 246 ; couleur de l',$- 246 \mathrm{n}$. 5 .

Etre primordial, 224, 226, 228.

Éveil, 227.

extinction, 248, 249.

faculté : les six -, 247 n. 5.

feuilles du figuier, 250 .

feux, 225, 226 ; les six - 251 .

figuier : - cosmique, 228 ; - à cinq branches, $250,254,255$.

fleurs du figuier, $250,255$.

fotus, 227, $237 \mathrm{n} .2,246$ n., 255 ; sept stades de formation du -, 254 .

foie, 242 .

fontanelle, 243 n. $3,249,254,255$.

fruit : les $4-, 248,249,254,255$; $-\mathrm{du}$ figuier, $250,255$.

gambir, 254.

globe de cristal, 228, 249 n. 5, 250, 254, 255.

globe vital, 242

gomme-gutte, 245,247 n. 1.

graisse, 242.

HAM, 256.

ignorance, 225,226 .

I I, 225.

intérieur $=$ extérieur, 244, 246, 253.

intestin, 242.

Jacques, C., 234 n. 1, 238 n. 1.

jambe, 225, 226, 250.

Jambosier : pays des —, 225, 226, 228, 250, 255.

jhān, 240.

Joyaux : les Trois - 256.

jupe, 246.

kammajavāt, 234.

Kammațthān, 250.

kammațthān: mūl-, 234, 249.

kāyasiddh, 244 n. 3.

kesarasit, 244.

Kev Chuon, 231.

KU SA LA A KU SA LA, 225, 226 n. 3.

Laporte, R., 230 n. 1.

Leclère, A., 224.

Lemoine, J., 238 n. 2.

lettre : les - intérieures et extérieures, 245 ; les trente-trois $\longrightarrow, 252,256$

livre : les trois -, 242 n. 3 ; les cinq -, 254 ; les sept —, 254; les huit --, 254; les dix-sept -, 255.

loge suspendue, $237,240$.

lokuttara, 245 n. 2.

lotus : feuille du,- 244.

luciole, 248, 255. lumière : les six - 225,227 ; les quatre-vingt mille - 225.

lune, 249, 255.

MA A U, 225, 226, 226 n. 3, 250, 251, 255, 256. mahānikāy, 227, 241, 243, 252 n. 3, 254.

Mahā Pațțhān, 234, 247, 253.

Mahāsānghika, 242 n. 2.

manteau, 246.

matrice, 232, 234, 237, 238, 241, 245, 246, 247.

méditant $=$ embryon, 253.

méditation embryonnaire, 226.

médium, 229, $235,236$.

mère, 222, 252.

mérites et démérites, 225, 225 n. 9, 256.

Méru, 254, 255.

mythe, 224, 227, 250.

moines : les huit nobles - , 248, 252, 254, 256.

monde utérin, 245 n. 2,256 ; portail du 240.

moralité : les dix -, 252 ?, 256.

mort initiatique, $222,259$.

Mouhot, H., 233, 233 n. 2.

nagarakäy, 243 n. 6.

NA KA AM, 244, 245, 253.

NA MA, 226.

NA MA BA DA $=$ quatre éléments, 241 , $242,253$.

nāmarūpa, 256.

NA MO BU DDHA YA, 225, 226, 251, 252, 256 ; couleur des lettres -, 240.

narines, 250.

nez, 240, 248, 254, 255; intérieur du -, 247.

nez-cou, 248.

nisìdana, 241 n. 3, 243 n. 1, 253.

nissäsa, 247, 251, 253, 254.

nisvāt, voir nissāsa.

nombril, 240, 243, 243 n. 3, 247, 248, 254.

nombril-anus, 243.

nombril-coccyx, 248 .

Nouvel An, 233.

océan, 240.

œil, 225, 226, 250, 255 ; - du paon, 244.

offrandes, 245.

oiseaux Indriy, 228, 255.

ombilic, 246 n. 1.

ombre, 226.

orbite, $251,255$.

oreilles, 225, 226, 250, 255.

orteils, 251, 255 .

os, 242.

passāsa, 247, 251, 253.

pasvāt, voir passāsa.

pāysī, 245 n. 1 .

peau, 242,243 n. 1 .

Pec Gniou, 234.

père : les vertus du -, 252. 
Phnom Sampau, 230, 231, 232, 235, 236, Sütr, 241, 241 n. 3, 242, 250 ; vent du 一, $255,256$.

piti 240.

placenta, 246, $246 \mathrm{n}$.

poche à méconium, 246.

poils, 242.

poitrine, 243, 244.

poitrine-nombril, 243.

Porée-Maspéro, E., 230 n. 1.

porte : - d'or, 237, 237 n. $3,239,247$; -

à huit degrés, 250 ; - du Nibbāna, 255.

portion corporelle : les quatre $-, 243,248$,

253.

possession, 235, 236.

poumons, 242.

prajājan, 260,260 n. 1.

prasūt $=$ brah Sütr, 254.

Prohm : le Grand -, 244.

punaise : le dos d'une -, 244.

queue cousue, 246,246 n. 2.

régression utérine, $222,227,233,235,238$, 240.

répugnance : contemplation de la,- 243 , $244,253$.

respiration embryonnaire, 234, 247.

Révolution, 259.

robe, 246.

rotule droite et gauche, $250,251,255$.

$\mathrm{SA}, 244$.

SAṂ VI DDHĀ PU KA YA PA, 251, 252.

SAM VI PU KA PA, 251.

sang, 242; couleur du -, 245, 247.

Sangha, 252 n. 3, 256 ; les vertus du -, 252.

sébile, 240,245 n. 4.

séjour utérin, 245.

semence, $227 ;-=$ eau du désir, $244 ;-$ = eau du Nibbāna, 251.

sexe viril, 250 .

sexuel : union --, 234, 244, 244 n. 1, 250.

sìmā, les huit -, 256.

slā dhamm, 245.

soleil, $249,255$.

souffle : les trois -, 256 ; voir vent.

Sovann Muni, 240, 254.

sternum, 240, 248, 254.

sternum-nombril, 248.

sthan kuttara, 245 n. 2

234, 247, 253.

terre, 225, 226, 251.

tête, 243,250 ; - de mouche, 244.

tête-cou, 243.

Theravāda, 224.

Tipitaka, 241 n. 3, 242 n. 3, 255.

tronc, 250.

trône de l'Illumination, 225, 227, 240.

U, 244, 256.

Uttarakuru, 249 n. 6.

$\mathrm{U} \mathbf{0}, 225$.

Vat Unalom, 233.

veine, 242.

vent, 225, 226, 251,253; - au niveau du nombril, 248, 254; - du Sûtr aux huit livres, 248, 254 ; - sans sortir ni entrer, 248, 254 ; - du Sütr, de l'Abhidhamm et du Vinay, voir Sütr, Abhidhamm et Vinay.

ventre maternel, 226, 245, 253.

vertèbre $d u$ tronc maternel, 238.

vertu : les six - du roi, 252 ; les sept de la famille, 252; les dix - du Grū, 252 ; les douze — de la mère, 252 ; les quatorze - du Sangha, 252; les vingt et une - du père, 252 ; les trente-huit - du Dhamma, 252 ; les cinquante-six du Bouddha, 252 .

vésicule biliaire, 250 .

vêtements monastiques, 240,241 n. 3,242 n. $3,242,253$; attaches du,- 243 ; pièces du —, 245, 245 n. 4, 246.

vidage stercoraire, 254 .

ville Nibbăna, 228.

Vinay, 241,241 n. $3,242,245,250$; vent du $-, 247,248,253,254$.

Vipassanākammațțhān, 241 .

voyelles : les huit,- 226 ; les seize,- 247 , 253 ; les dix-neuf $-, 252,256$.

yantra, 235.

yeux, voir œil.

Yeak, Vén., 232, 237, 240.

Yogāvacar, 222, 224, 227, 228, 253, 254, $255,257$.

yojana, 225 n. 5.

yuon, 254. 


\section{GROTTE DE LA NAISSANCE}

( RAĀî́ PRASŨt)

PHNOM SAMPAU

\section{BATTAMBANG}

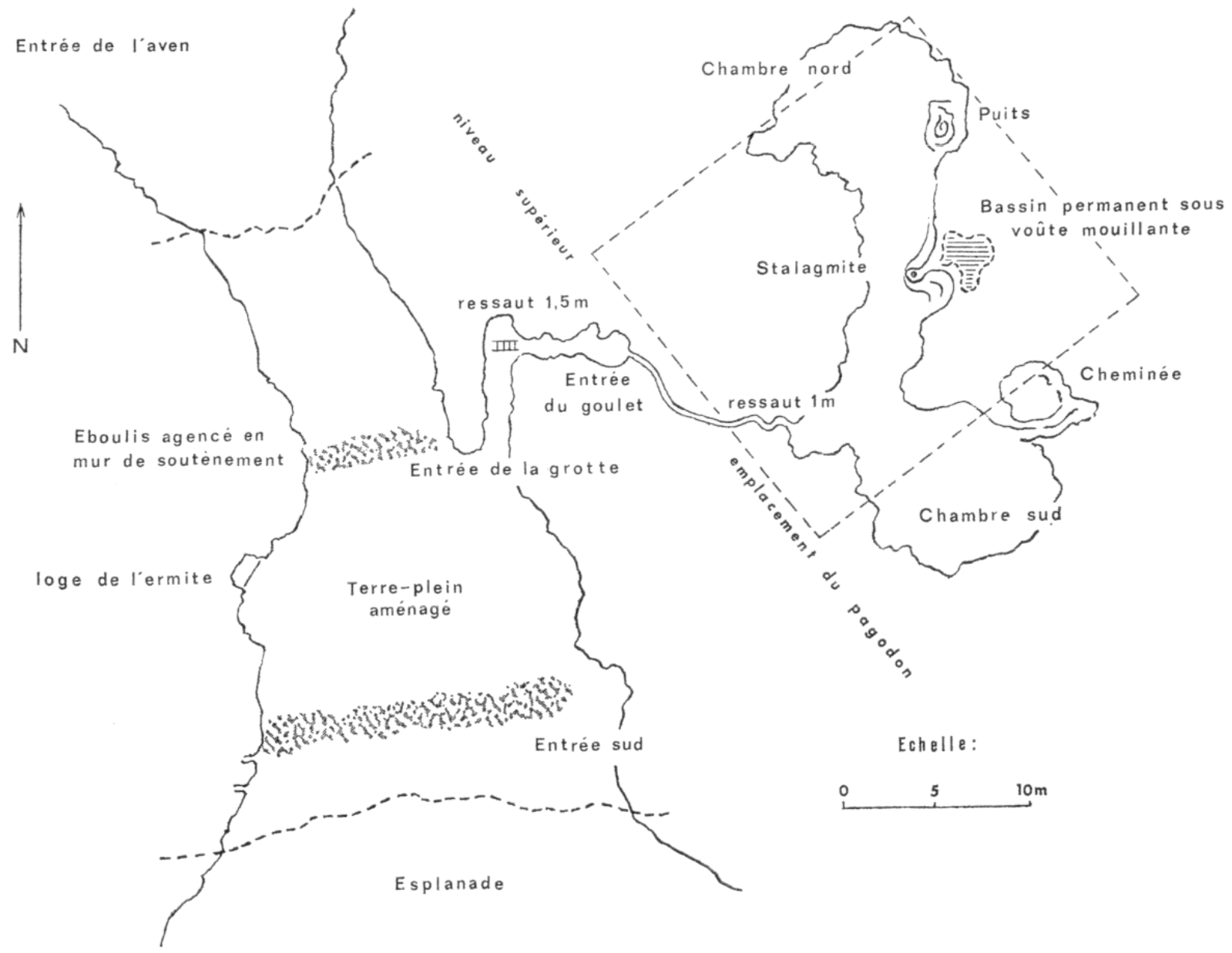




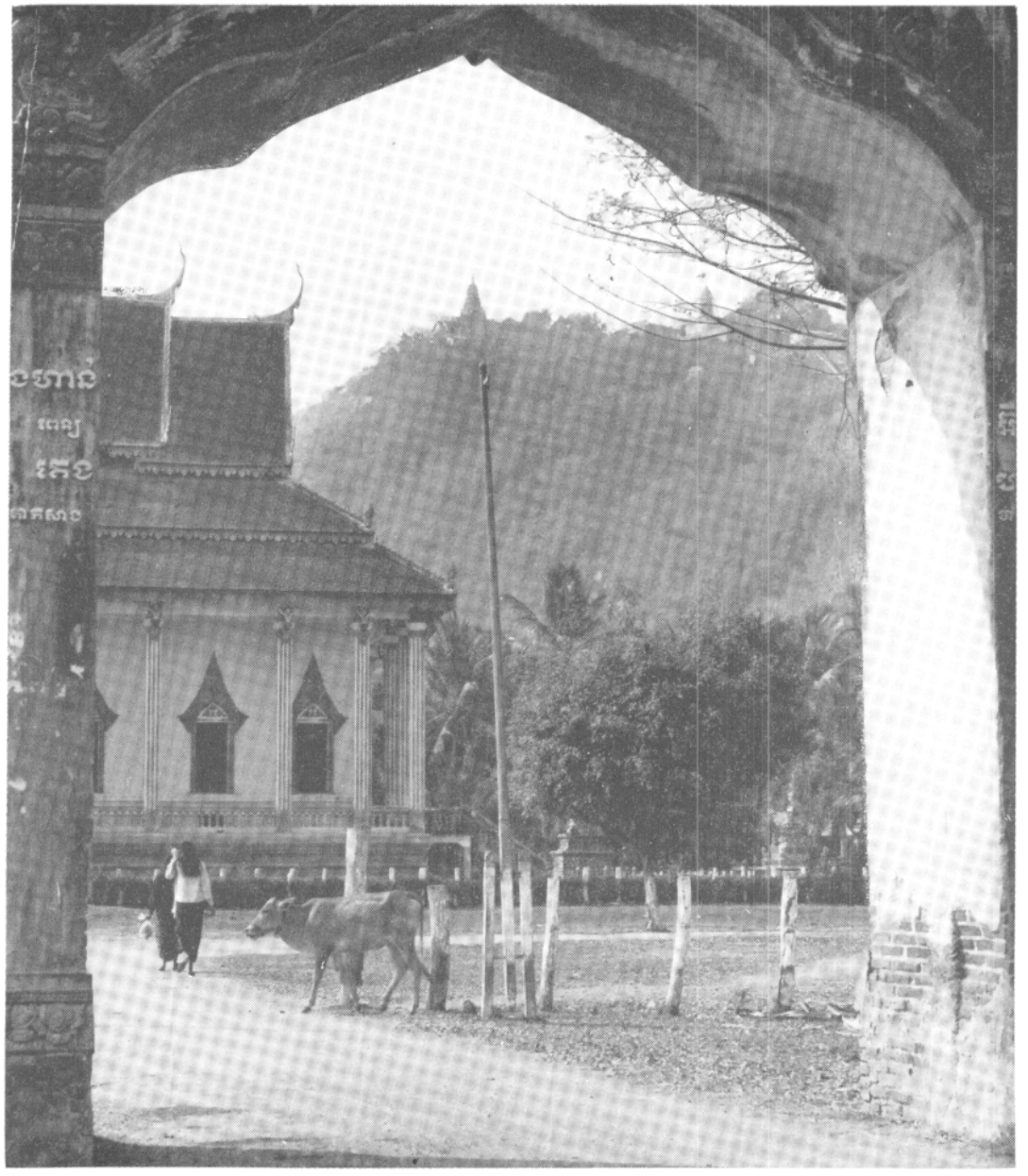

Photo no 1. .... L'ermitage du Phnom Sampau se profile sous le porche du monastire.

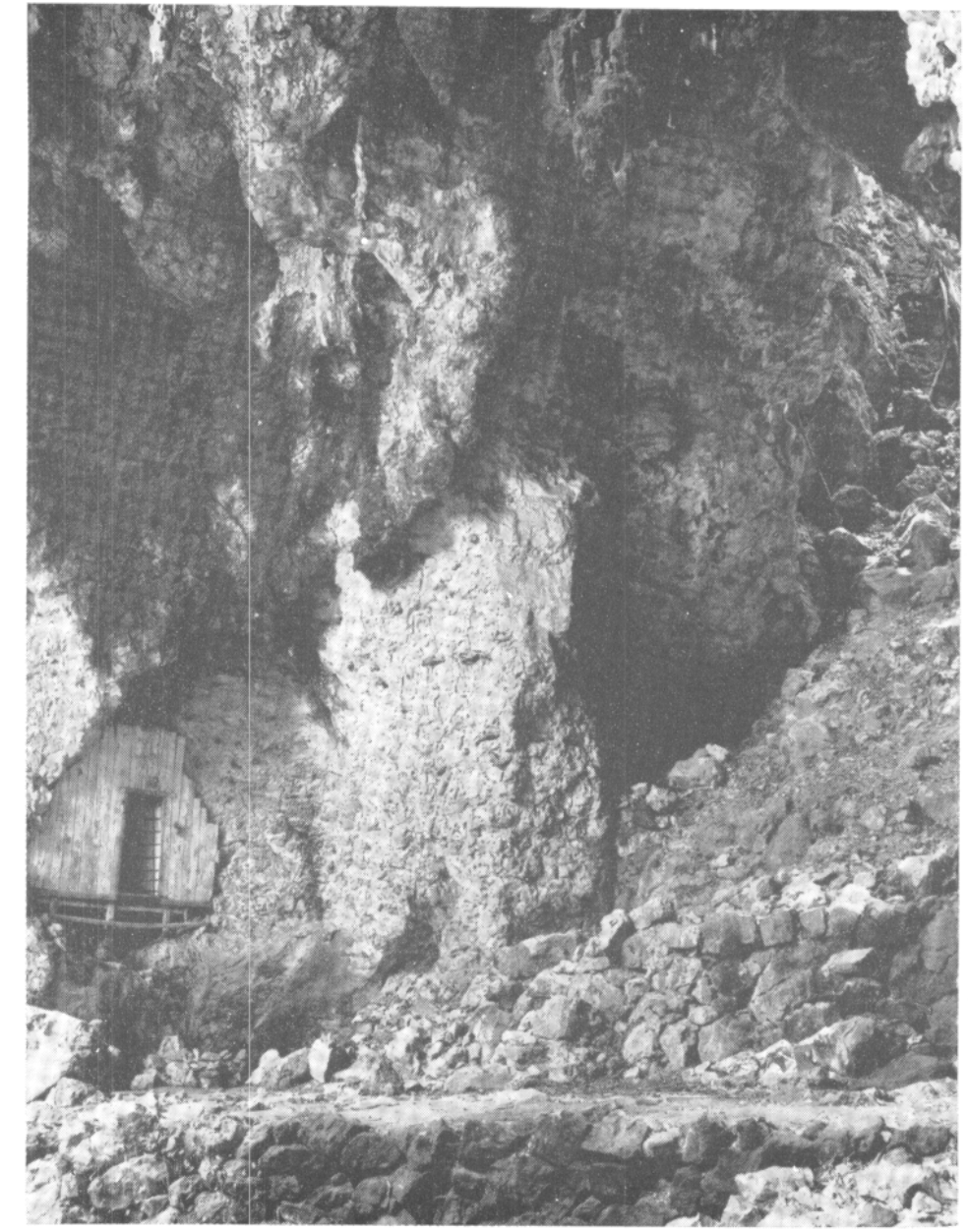

Pholo $n^{\circ} 2 .-A$ l'Ouest du terre-plein a gauche sur la photoi, la loge suspendue de l'ermite. 
Planche XiI

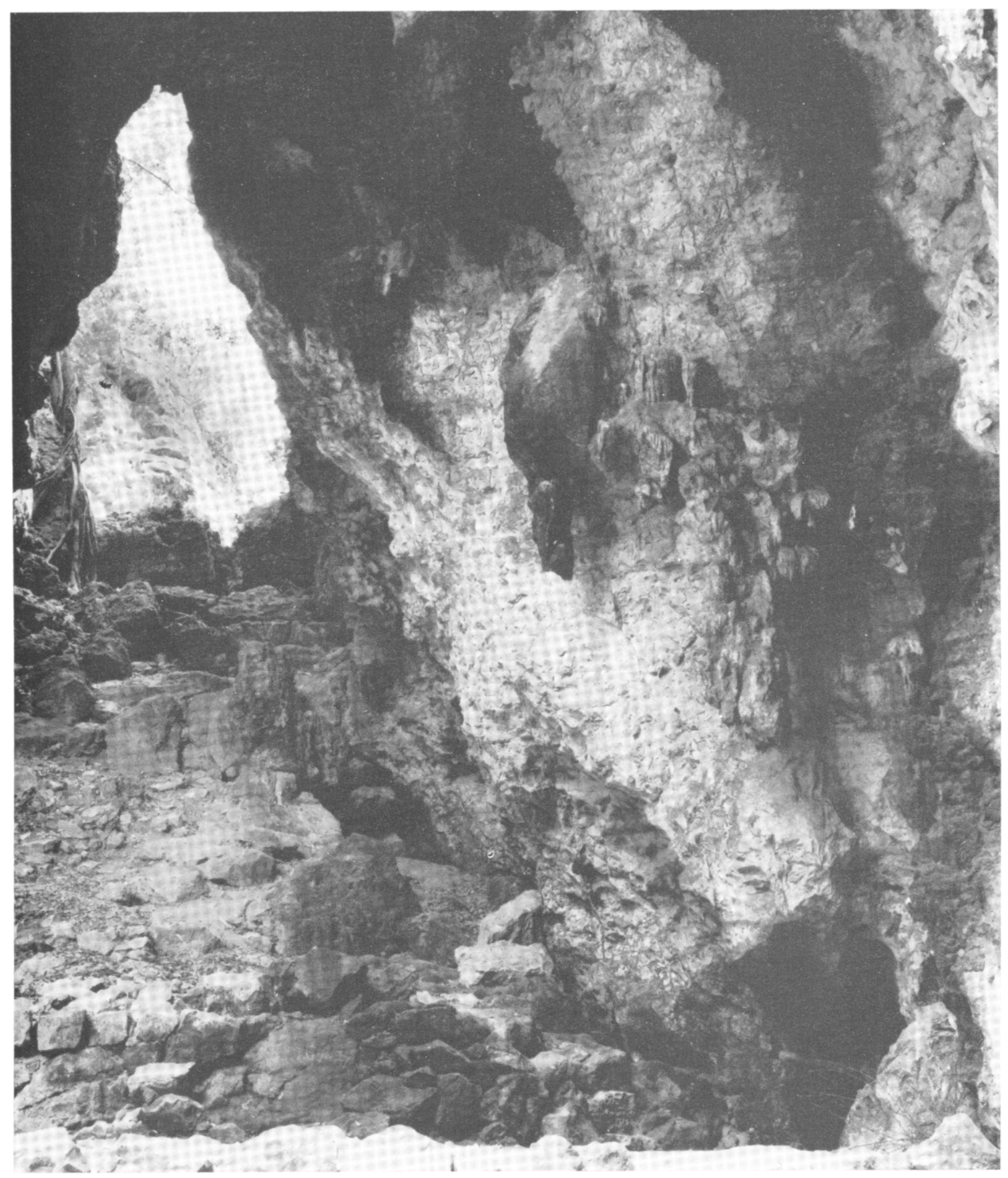

Pholo $n^{\circ} 3 . \quad$ - Al'Est à droite sur la photo', l'entrée du souterrain. 


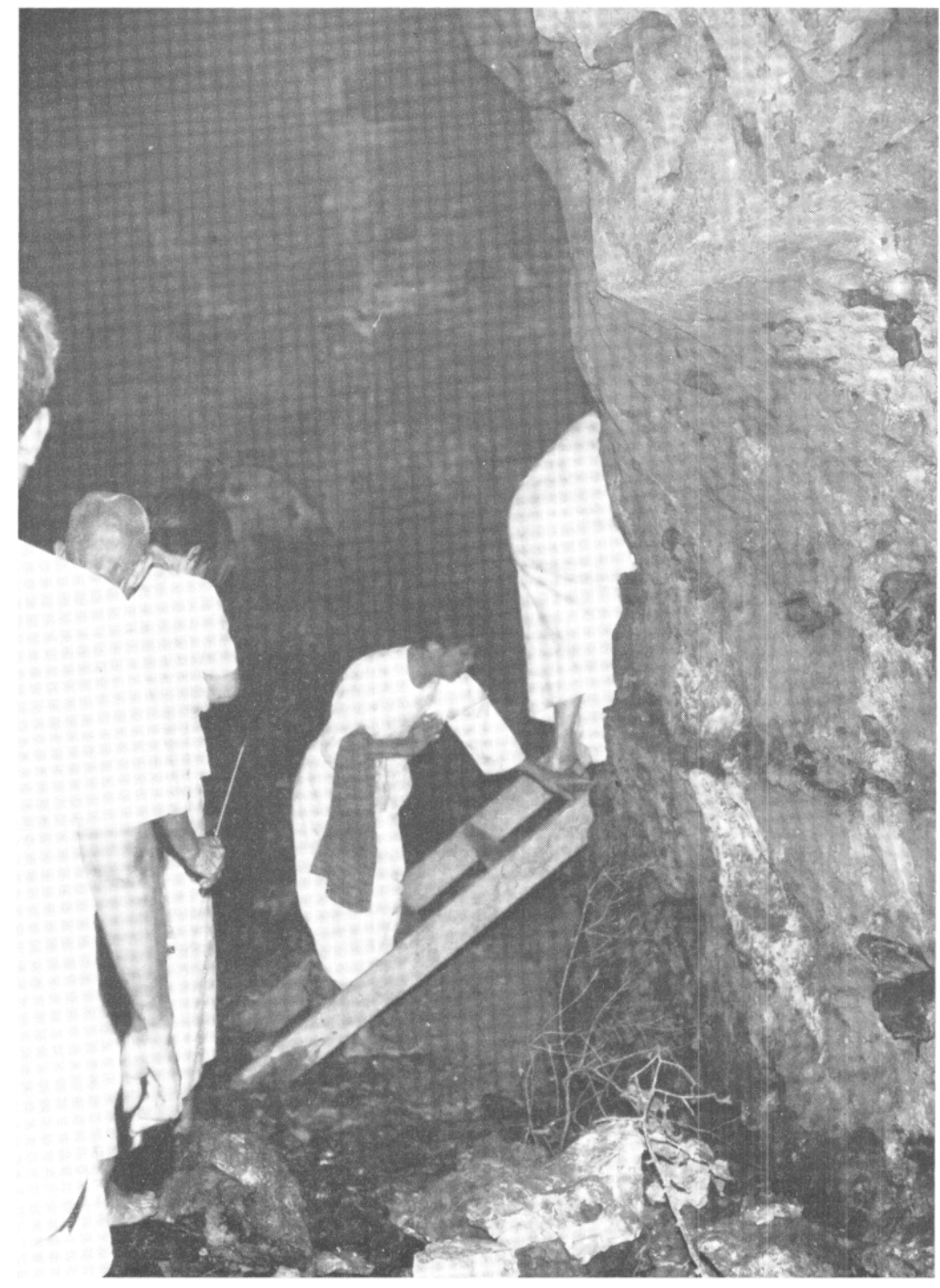

Pholo $n^{\circ} 4$. - le parcours : premier ressiut.

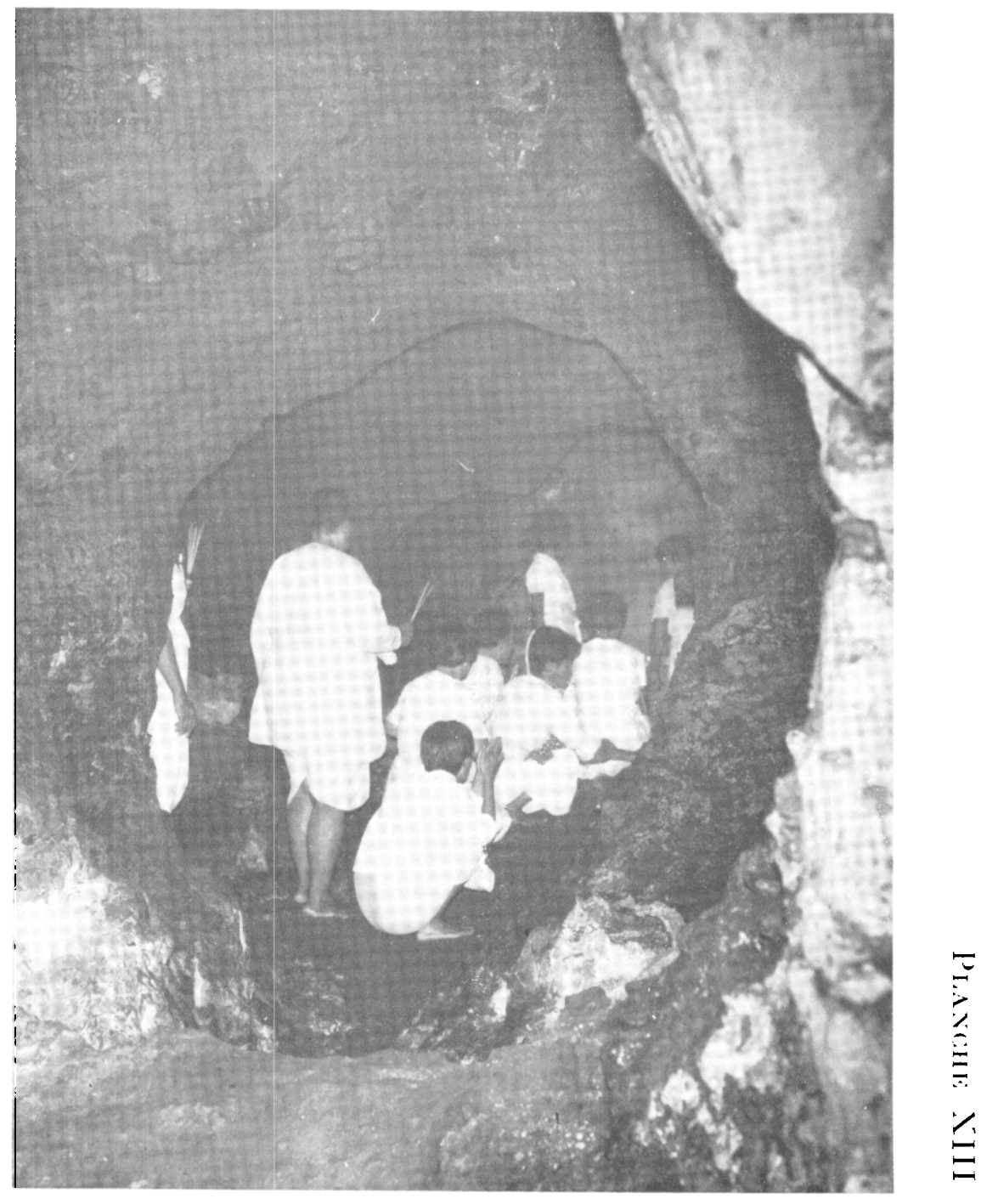

Photo no r. Ie vestibule d'accès. 


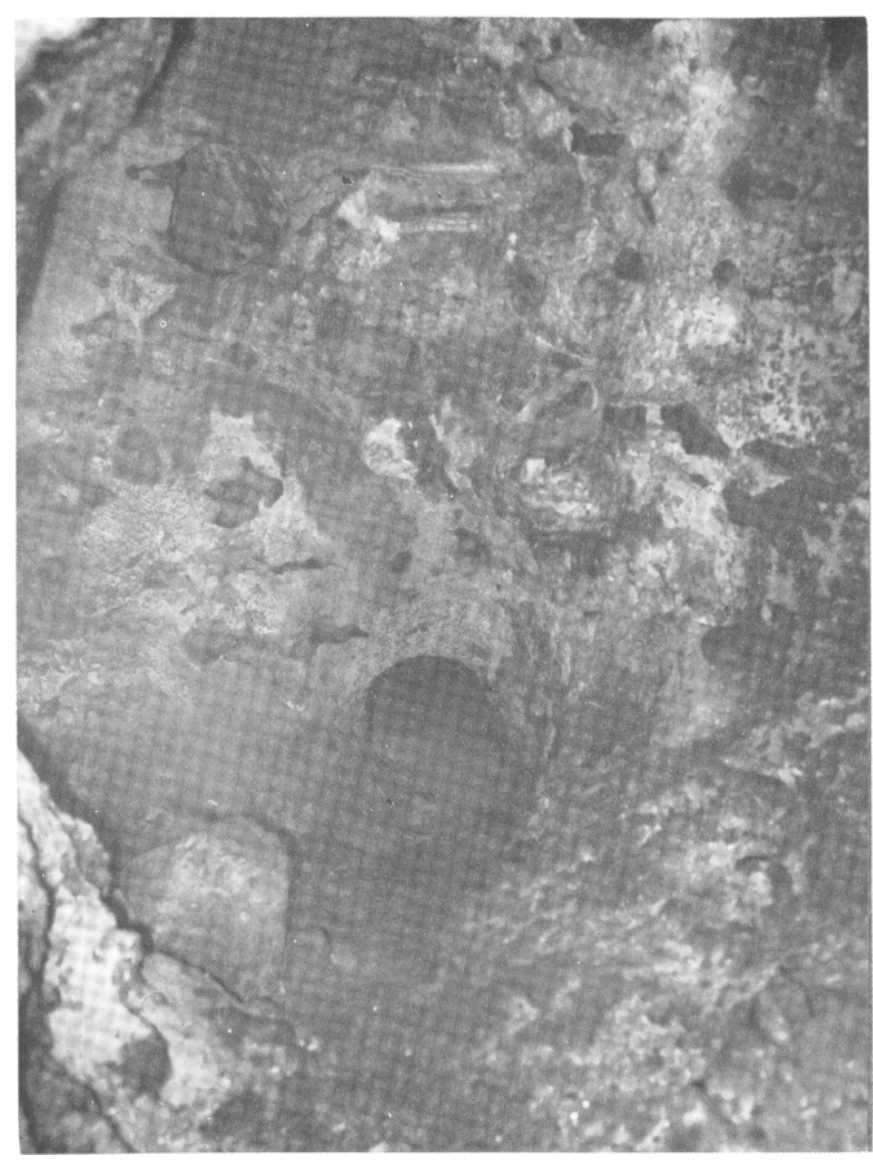

Photo no 6. Lal Porte d'or.

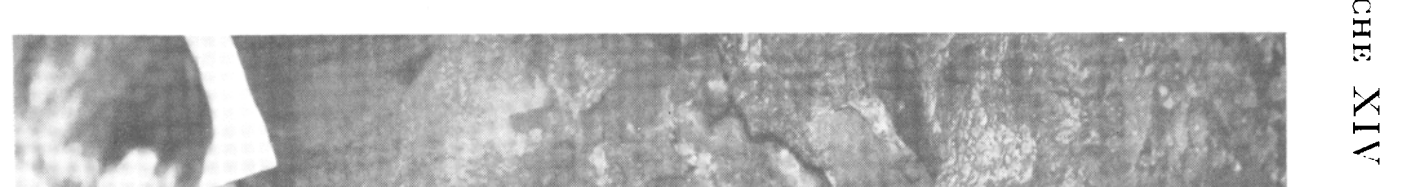

5
3
0 
Planche $\mathrm{XV}$

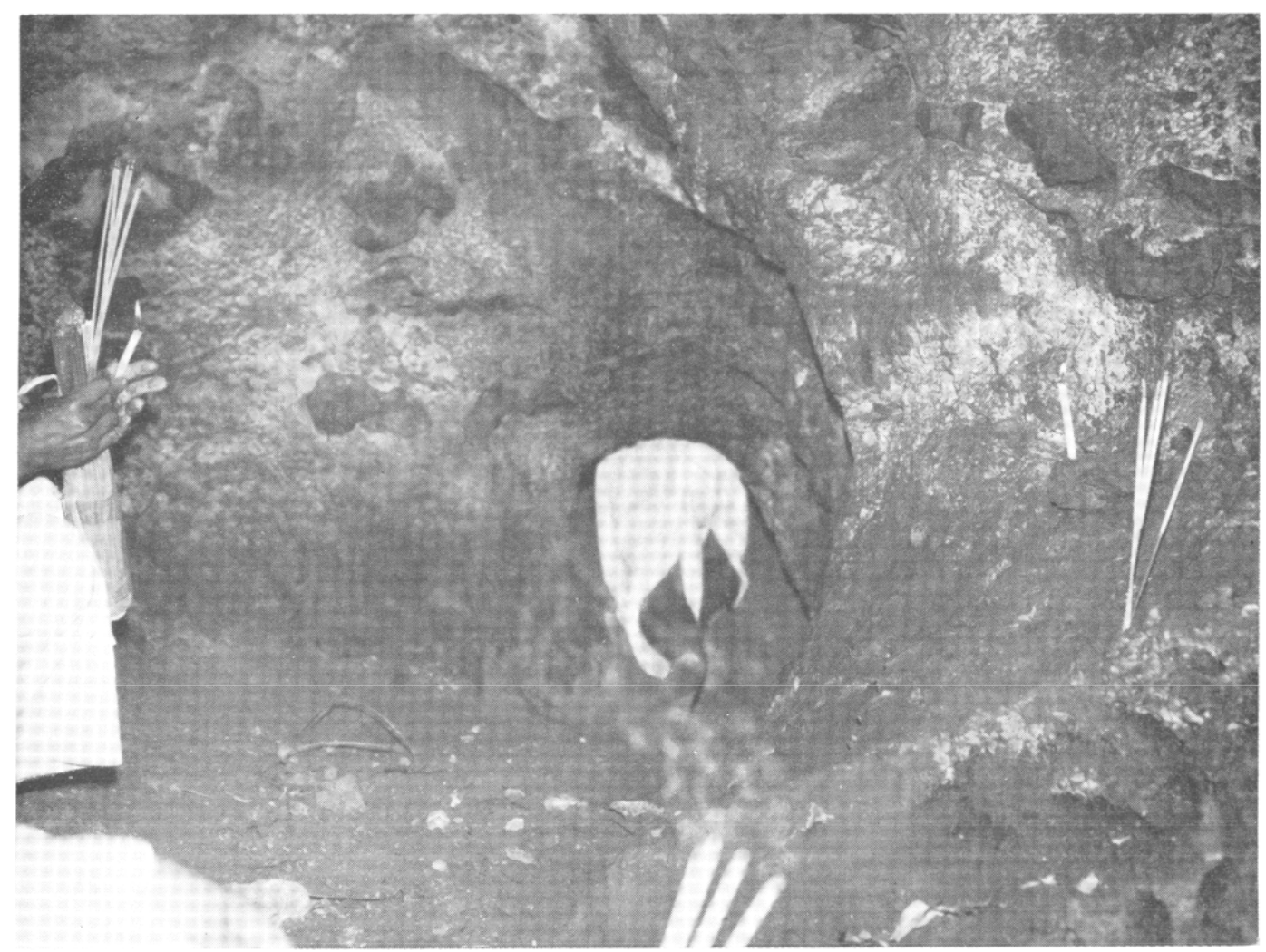

Photo no 8 . . La pénétralion dans le goulet.

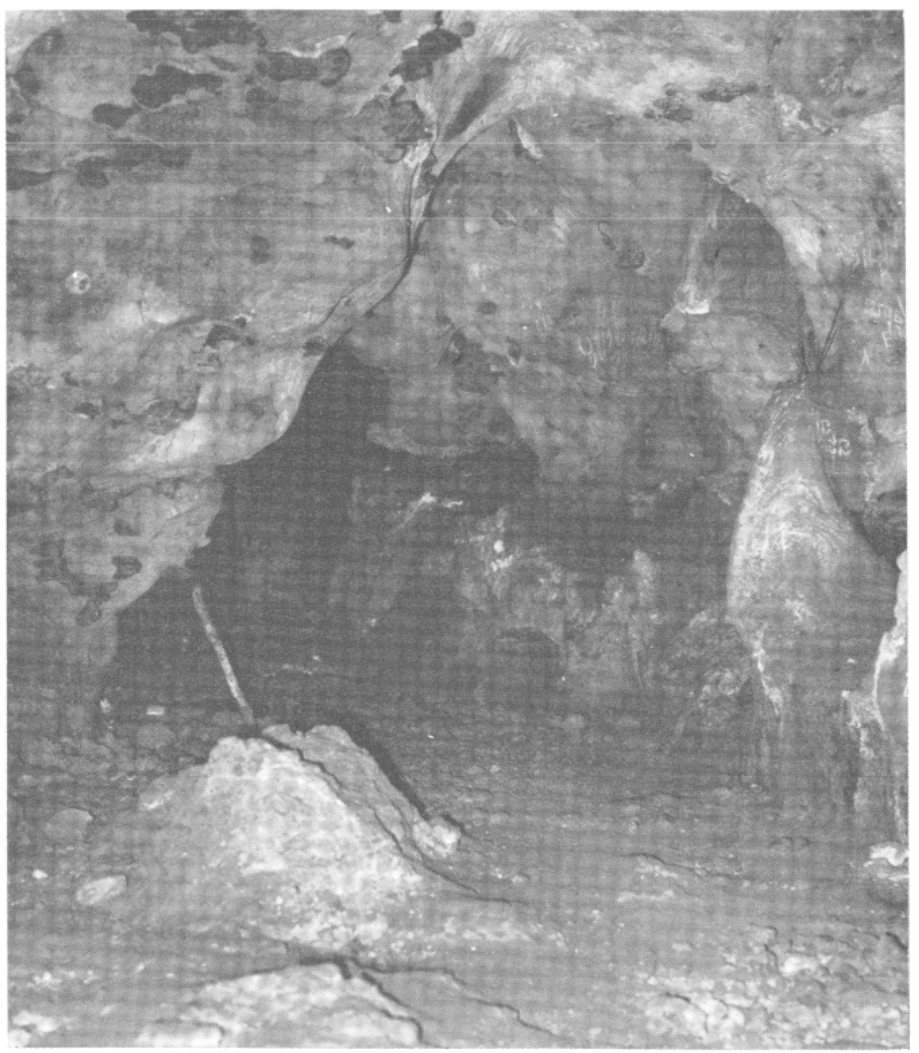

Photo $n^{\circ}$ 9. - L'emplacement central. 


\section{Planche XVl}

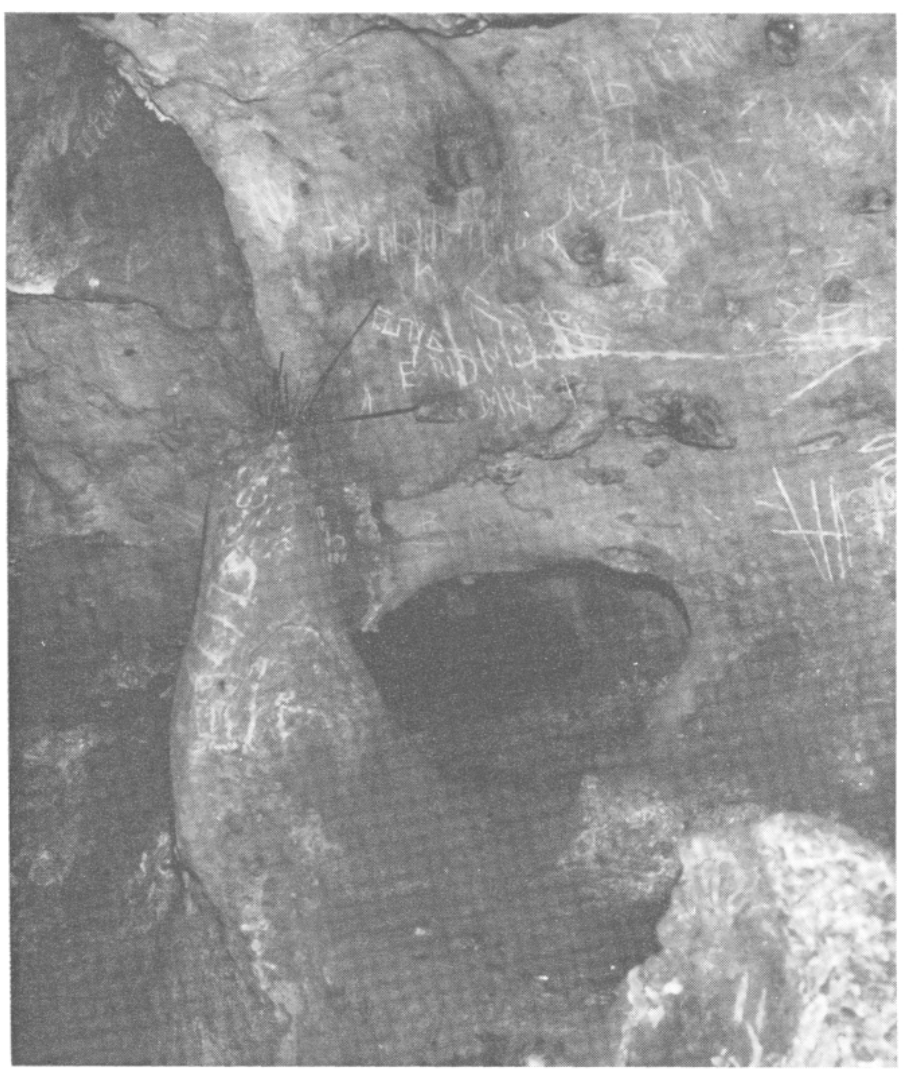

Photo no 10. …- Le "cordon placentaire".

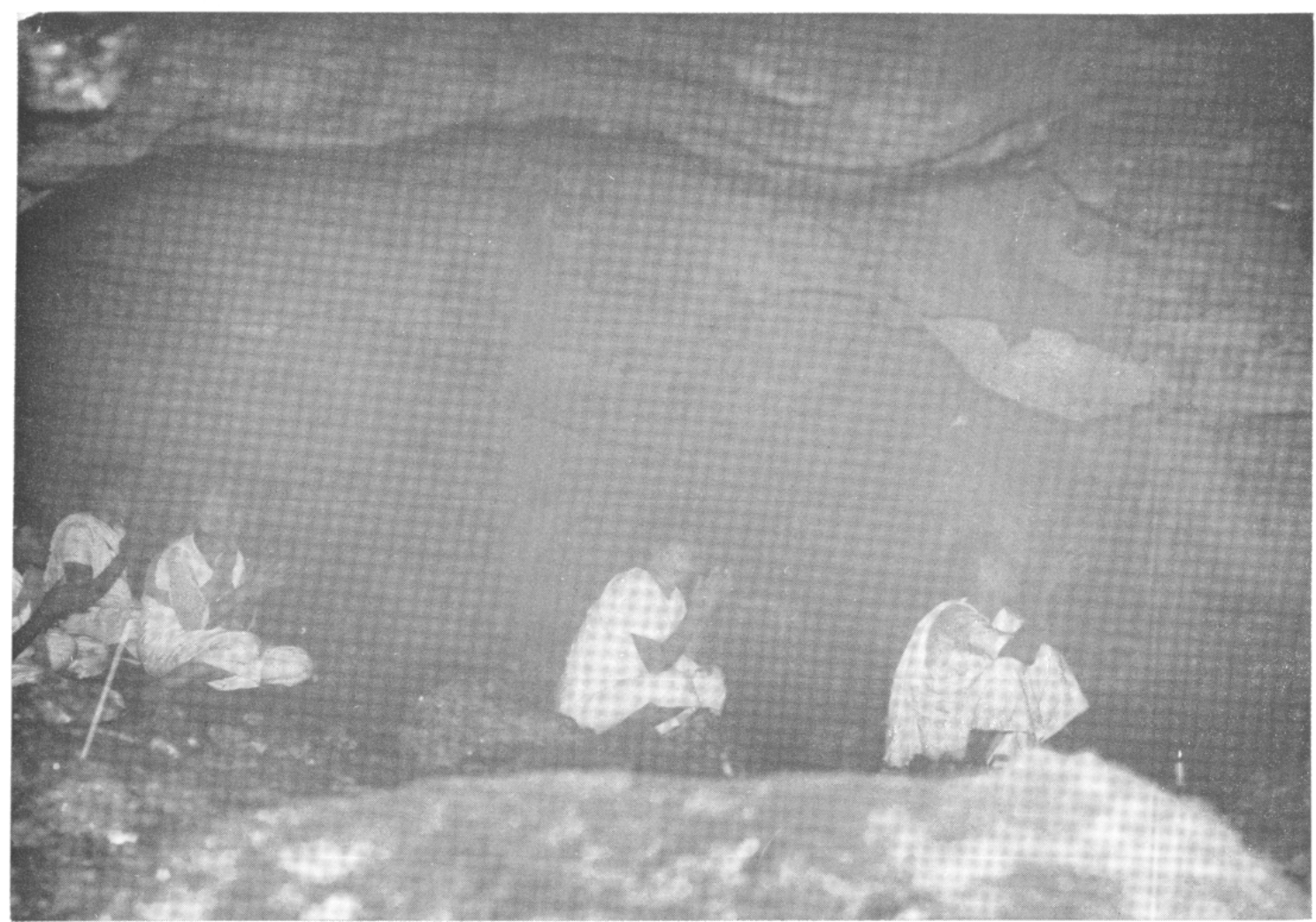

Photo $n^{\circ}$ 11. - Méditation intra-utérine dans la chambre Nord. 


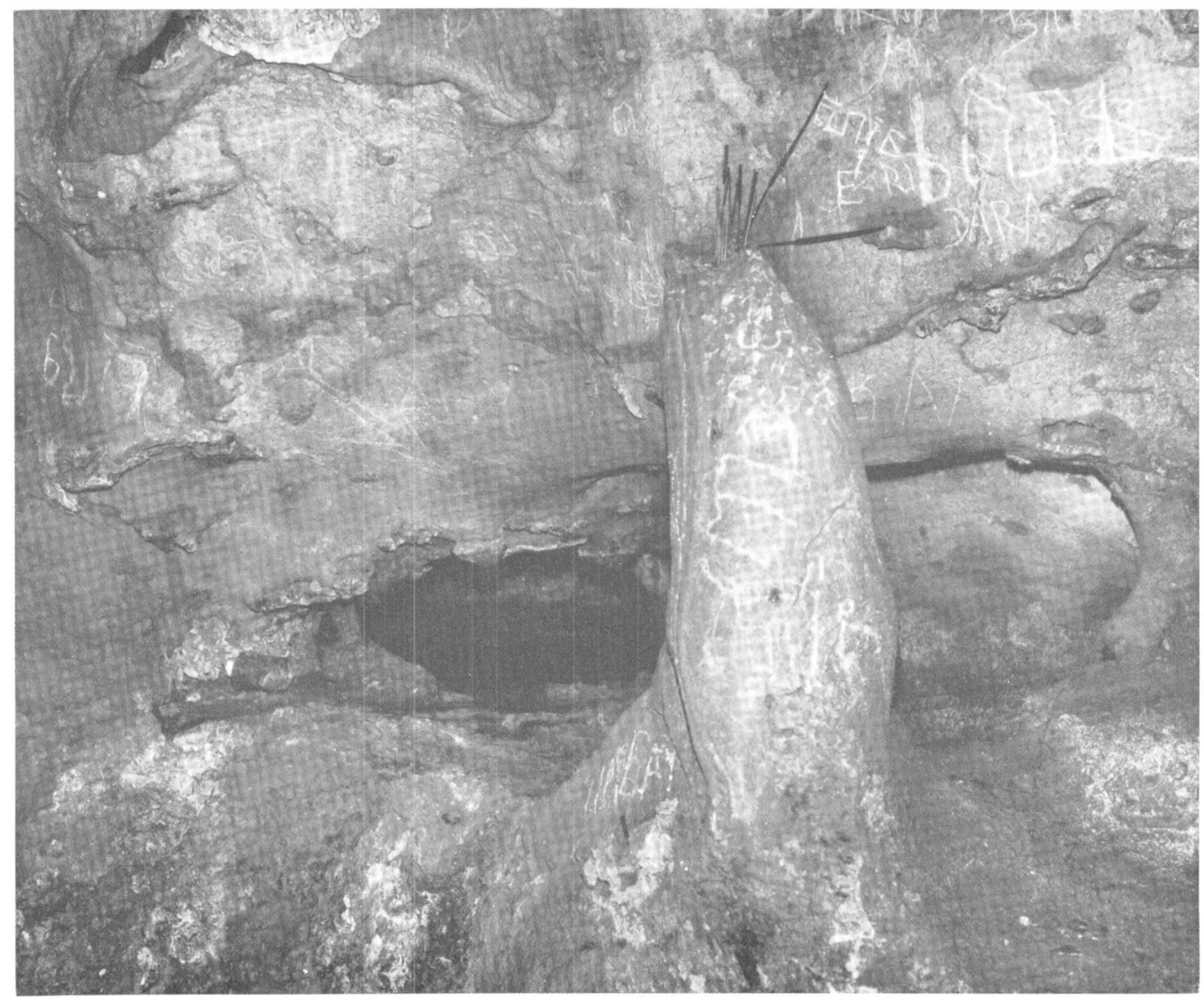

Photo no 12. ... Derrière le "cordon placentaire ", la voùte du "bassin amniotique ". 
Planche XVIII

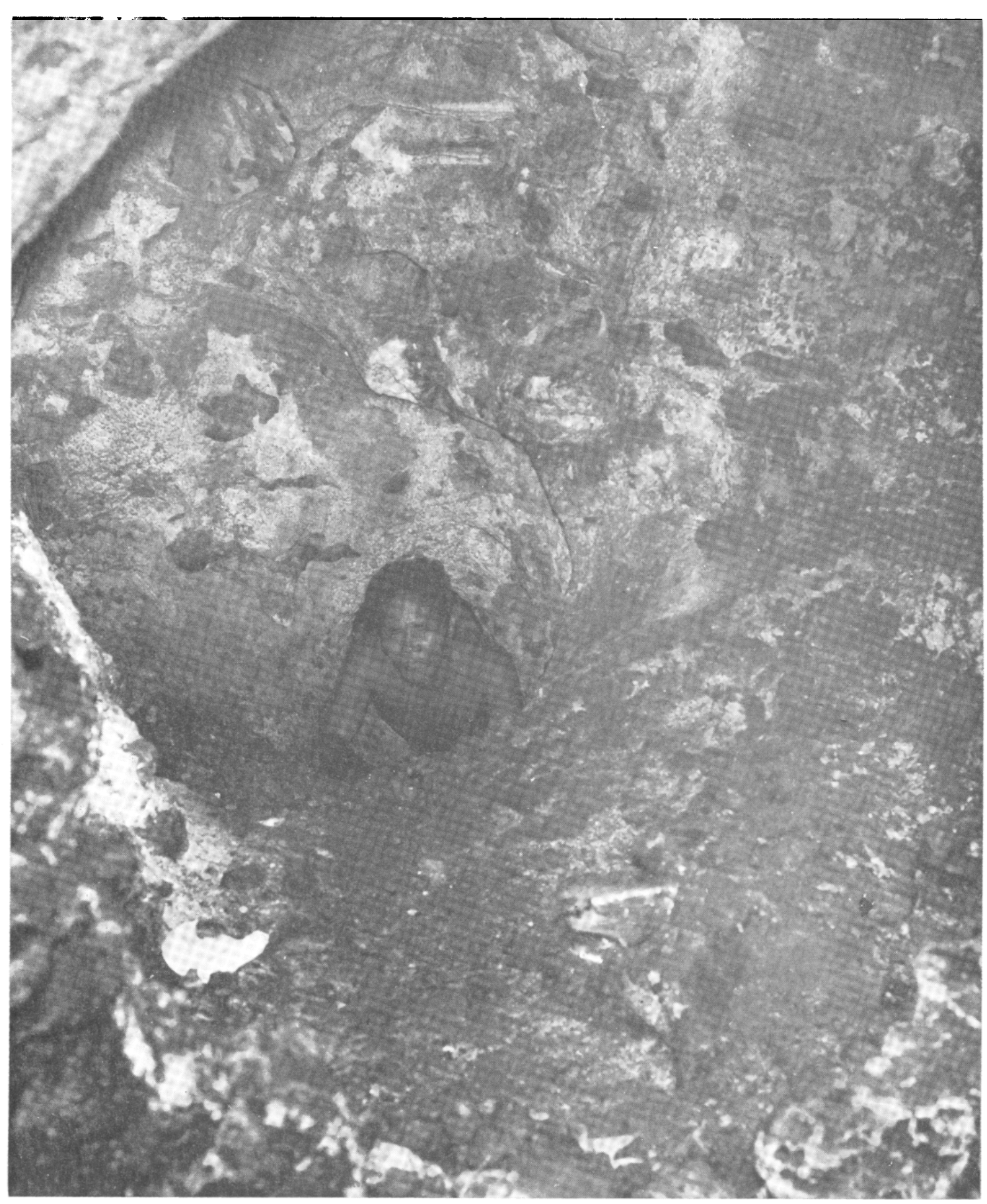

Pholo n" 13. L- L'expulsion. 